\title{
Amorphous and crystalline aerosol particles interacting with water vapor: conceptual framework and experimental evidence for restructuring, phase transitions and kinetic limitations
}

\author{
E. Mikhailov ${ }^{1,2}$, S. Vlasenko ${ }^{2}$, S. T. Martin $^{3}$, T. Koop ${ }^{4}$, and U. Pöschl ${ }^{1}$ \\ ${ }^{1}$ Max Planck Institute for Chemistry, Biogeochemistry Department, 55128 Mainz, Germany \\ ${ }^{2}$ St. Petersburg State University, Atmospheric Physics Department, Institute of Physics, 198904 St. Petersburg, Russia \\ ${ }^{3}$ Harvard University, School of Engineering and Applied Sciences \& Department of Earth and Planetary Sciences, \\ Cambridge, MA 02138, USA \\ ${ }^{4}$ Bielefeld University, Department of Chemistry, 33615 Bielefeld, Germany
}

Received: 6 March 2009 - Published in Atmos. Chem. Phys. Discuss.: 20 March 2009

Revised: 28 November 2009 - Accepted: 7 December 2009 - Published: 16 December 2009

\begin{abstract}
Interactions with water are crucial for the properties, transformation and climate effects of atmospheric aerosols. Here we present a conceptual framework for the interaction of amorphous aerosol particles with water vapor, outlining characteristic features and differences in comparison to crystalline particles. We used a hygroscopicity tandem differential mobility analyzer (H-TDMA) to characterize the hydration and dehydration of crystalline ammonium sulfate, amorphous oxalic acid and amorphous levoglucosan particles (diameter $\sim 100 \mathrm{~nm}$, relative humidity $5-95 \%$ at $298 \mathrm{~K}$ ). The experimental data and accompanying Köhler model calculations provide new insights into particle microstructure, surface adsorption, bulk absorption, phase transitions and hygroscopic growth. The results of these and related investigations lead to the following conclusions:
\end{abstract}

(1) Many organic substances, including carboxylic acids, carbohydrates and proteins, tend to form amorphous rather than crystalline phases upon drying of aqueous solution droplets. Depending on viscosity and microstructure, the amorphous phases can be classified as glasses, rubbers, gels or viscous liquids.

(2) Amorphous organic substances tend to absorb water vapor and undergo gradual deliquescence and hygroscopic growth at lower relative humidity than their crystalline counterparts.

(3) In the course of hydration and dehydration, certain organic substances can form rubber- or gel-like structures

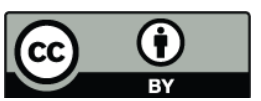

Correspondence to: U. Pöschl (u.poschl@mpic.de) (supramolecular networks) and undergo transitions between swollen and collapsed network structures.

(4) Organic gels or (semi-)solid amorphous shells (glassy, rubbery, ultra-viscous) with low molecular diffusivity can kinetically limit the uptake and release of water and may influence the hygroscopic growth and activation of aerosol particles as cloud condensation nuclei (CCN) and ice nuclei (IN). Moreover, (semi-)solid amorphous phases may influence the uptake of gaseous photo-oxidants and the chemical transformation and aging of atmospheric aerosols.

(5) The shape and porosity of amorphous and crystalline particles formed upon dehydration of aqueous solution droplets depend on chemical composition and drying conditions. The apparent volume void fractions of particles with highly porous structures can range up to $\sim 50 \%$ or more (xerogels, aerogels).

(6) For efficient description of water uptake and phase transitions of aerosol particles, we propose not to limit the terms deliquescence and efflorescence to equilibrium phase transitions of crystalline substances. Instead we propose generalized definitions according to which amorphous and crystalline components can undergo gradual or prompt, partial or full deliquescence or efflorescence.

We suggest that (semi-)solid amorphous phases may be important not only in the upper atmosphere as suggested in recent studies of glass formation at low temperatures. Depending on relative humidity, (semi-)solid phases and moisture-induced glass transitions may also play a role in gas-particle interactions at ambient temperatures in the lower atmosphere.

Published by Copernicus Publications on behalf of the European Geosciences Union. 


\section{Introduction}

The interaction of aerosol particles with water vapor is a central issue of research in atmospheric and climate science (Martin, 2000; Kanakidou et al., 2005; Lohmann and Feichter, 2005; Pöschl, 2005; McFiggans et al., 2006; Fuzzi et al., 2006; Andreae and Rosenfeld, 2008; Rosenfeld et al., 2008; Wang et al., 2008a, b; Heintzenberg and Charlson, 2009; and references therein). Numerous studies have investigated the hygroscopicity of aerosol particles, i.e. their ability to absorb water vapor, as a function of chemical composition and relative humidity (RH), and many researchers have noted that the hygroscopic properties of aerosol particles can substantially differ from those of the corresponding bulk material.

For example, aerosol particles composed of certain watersoluble inorganic salts can reversibly take up water vapor without the prompt deliquescence and efflorescence phase transitions and hysteresis effects typically observed for the corresponding crystalline bulk material: $\mathrm{CaCl}_{2}$ and $\mathrm{MnSO}_{4}$ (Cohen at al., 1987); $\mathrm{NH}_{4} \mathrm{NO}_{3}$ (Tang, 1980; Dougle et al., 1998; Cziczo and Abbatt, 2000; Lee and Hsu, 2000; Mikhailov et al., 2004; Schlenker et al., 2004; Schlenker and Martin, 2005; Svenningson et al., 2006), $\mathrm{NH}_{4} \mathrm{HSO}_{4}$ (Tang and Munkelwitz, 1994; Cziczo et al., 1997; Cziczo and Abbatt, 2000; Lee and Hsu, 2000; Martin et al., 2003; Colberg et al., 2003, 2004; Schlenker et al., 2004; Schlenker and Martin, 2005), $\mathrm{NaNO}_{3}$ (McInnes et al., 1996; Lee and Hsu, 2000, Gysel et al., 2002; Hoffmann et al., 2004), $\mathrm{Ca}\left(\mathrm{NO}_{3}\right)_{2}$ (Liu et al., 2008), and sea salt (Tang et al., 1997).

Similar behaviour has been observed for certain organic compounds such as carbohydrates, dicarboxylic acids and multifunctional compounds: levoglucosan (Mochida and Kawamura, 2004; Chan et al., 2005; Svenningsson et al., 2006), mannosan and galactosan (Chan et al., 2005), maleic and malonic acid (Peng et al., 2001; Choi and Chan, 2002a; Brooks et al., 2003; Wise et al., 2003), malic and citric acid (Peng et al., 2001; Choi and Chan, 2002a), fulvic acids and humic-like substances (HULIS, Gysel et al., 2004; Dinar at al., 2007), and protein macromolecules (Mikhailov et al., 2004).

Depending on the nature and proportion of substances involved, the internal mixing of organic and inorganic aerosol components usually leads to a decrease of deliquescence and efflorescence RH (Brooks et al., 2002, 2003; Choi and Chan, 2002b; Marcolli et al., 2004; Mikhailov et al., 2004; Parson et al., 2004; Moore and Raymond, 2008; Zardini et al., 2008) or to gradual reversible water uptake starting at very low RH (Dick et al., 2000; Peng and Chan, 2001; Choi and Chan, 2002b; Brooks et al., 2003; Prenni et al., 2003; Svenningsson et al., 2006; Zardini et al., 2008).

Mechanistically, the ability for continuous and reversible water uptake has been attributed to the presence of residual water in non-effloresced, (quasi-)liquid particles (Peng et al., 2001; Prenni et al., 2003; Mochida and Kawamura,
2004; Moore and Raymond, 2008; Zardini et al., 2008) or to the morphology or amorphous state of (quasi-)solid particles (Cohen et al., 1987; Onasch et al., 2000; Peng and Chan, 2001; Marcolli et al., 2004; Liu et al., 2008).

Based on electron microscopy and infrared spectroscopy, Hoffman et al. (2004) concluded that the drying of aqueous $\mathrm{NaNO}_{3}$ droplets yields solid amorphous particles that remain metastable at very low relative humidity as well as under vacuum conditions and undergo continuous hygroscopic growth. Using Raman spectroscopy, Tang and Fung (1997) found that the drying of levitated aqueous droplets of $\mathrm{Ca}\left(\mathrm{NO}_{3}\right)_{2}$ and $\mathrm{Sr}\left(\mathrm{NO}_{3}\right)_{2}$ yields solid amorphous microparticles that deliquesce at lower RH than their crystalline counterparts. Krueger et al. (2003) found similar deliquescence behavior of $\mathrm{Ca}\left(\mathrm{NO}_{3}\right)_{2}$ formed by heterogeneous reaction of $\mathrm{CaCO}_{3}$ particles with gaseous nitric acid. By Raman-microscopy Liu et al. (2008) observed that pure and mixed $\mathrm{Ca}\left(\mathrm{NO}_{3}\right)_{2}$ and $\mathrm{Ca}\left(\mathrm{NO}_{3}\right)_{2} / \mathrm{CaCO}_{3}$ microparticles exhibit reversible water uptake and form amorphous hydrates below 7\% RH. Rosenoern et al. (2008) suggested that the hygroscopic properties of nanocrystalline aerosol particles may also deviate from those of crystalline bulk material, and several studies pointed out that the drying conditions have a strong influence on the morphology of solid aerosol particles (e.g., Mikhailov et al., 2004; Biskos et al., 2006; Rose et al., 2008; Rosenoern et al., 2008).

The formation of amorphous solid particles upon spraydrying of aqueous solutions of organic substances is a wellknown standard process in the food and pharmaceutical industries. It applies to organic compounds with a wide range of molecular masses (e.g., mono-, di- and polysaccharides), and the amorphous state of spray-dried organic materials was confirmed by X-ray diffraction, differential scanning calorimetry and dynamic vapor sorption methods (Corrigan, 1984; Bhandari and Howes, 1999; Roberts and Debenedetti, 2002; Price and Young, 2003; Burnett et al., 2004; Langrish and Wang, 2006; and references therein).

Recently, Murray (2008) and Zobrist et al. (2008) have shown that emulsified and bulk samples of atmospherically relevant aqueous organic and multi-component solutions can form glasses at low temperatures and may influence the interaction of aerosol particles with water in the upper troposphere, in particular the nucleation and growth of ice crystals. To our knowledge, however, the formation of solid amorphous aerosol particles upon drying of aqueous organic solution droplets of atmospheric relevance has not yet been positively identified, and the relations between the deliquescence/efflorescence and the microstructure of amorphous organic particles have not been characterized in earlier studies investigating the hygroscopic properties of atmospheric aerosols.

In this study we present a conceptual framework for the interaction of amorphous aerosol particles with water vapor, and we outline characteristic features and differences in comparison to crystalline particles (Sect. 2). We have employed 


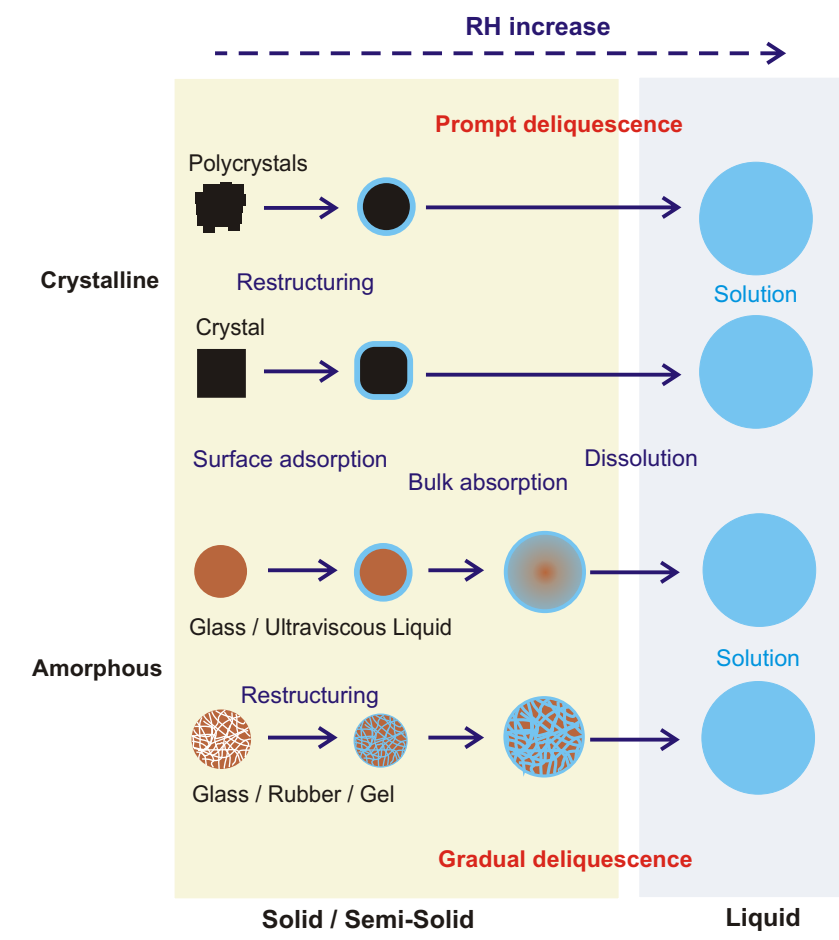

Fig. 1. Water uptake by aerosol particles consisting of crystalline or amorphous (semi-)solid substances: characteristic structures, phases and processes.

a hygroscopicity tandem differential mobility analyzer $(\mathrm{H}-$ TDMA, Sect. 3) and various Köhler models (Appendix A) to investigate the water uptake and phase transitions of amorphous and crystalline aerosol particles in the size range of the atmospheric aerosol accumulation mode (dry particle diameter $\sim 100 \mathrm{~nm}$, relative humidity $<5 \%$ to $95 \%$ at $298 \mathrm{~K}$ ). Here we present measurement and model results for pure levoglucosan, oxalic acid, and ammonium sulfate (Sects. 4.1-4.3, Appendix B).

\section{Conceptual framework}

\subsection{Water uptake by crystalline substances}

Figure 1 outlines some basic processes and differences in the uptake of water vapor by aerosol particles consisting of crystalline or amorphous substances. The envelope shape of solid crystalline particles is often not spherical, and polycrystalline materials and agglomerates may also be porous. The porosity of crystalline sub-micron aerosol particles generated by spray drying, however, is usually not very high (apparent void fractions <20\%; Krämer et al., 2000; DeCarlo et al., 2004; Mikhailov et al., 2004). Upon hydration (increase of relative humidity), crystalline substances typically adsorb only a small amount of water at the surface, which may lead to microstructural rearrangements and compaction of the particle (change of shape or porosity and decrease of mobility equivalent diameter) due to capillary effects or partial dissolution and recrystallization (Krämer et al., 2000; Mikhailov et al., 2004; Biskos et al., 2006; Zardini et al., 2008). Bulk absorption of water into the crystalline material may occur in case of hydrate formation (uptake of crystal water), but this appears not relevant for the inorganic salts that are most abundant in the atmosphere and it does normally not lead to a major increase of particle diameter.

At a substance-specific threshold relative humidity, pure substances (particles) that are crystalline and water-soluble undergo prompt deliquescence transitions, i.e., first-order phase transitions in which the solid substances (particles) are transformed into saturated aqueous solutions (liquid droplets). Note, however, that crystalline multi-component mixtures can exhibit a stepwise onset of deliquescence (eutonic point) followed by further gradual water uptake until complete dissolution. Upon dehydration (decrease of RH), the evaporation of water and crystallization of the solute (efflorescence transition) typically occurs at a lower relative humidity than the deliquescence transition (hysteresis effect), which is due to the persistence of metastable aqueous solution droplets that are supersaturated with respect to the corresponding crystalline phases. For most watersoluble crystalline substances of atmospheric relevance the deliquescence relative humidity is higher than 50\% (Martin, 2000). Ammonium sulfate is a typical example for such substances, and the surface adsorption of water, microstructural rearrangements and phase transitions of ammonium sulfate aerosol particles will be illustrated below (Sect. 4.1).

\subsection{Water uptake by amorphous substances}

Water uptake by amorphous substances typically proceeds in a gradual way, and their transition from solid to liquid state may involve intermediate semi-solid stages. Amorphous substances have no long-range atomic order and are classified as solid glasses when their viscosity exceeds $10^{12} \mathrm{~Pa}$ s (Angell, 1995; Debenedetti and Stillinger, 2001). Semi-solid amorphous substances like rubbers and gels have lower viscosities but still tend to retain their envelope shape (Roberts and Debenedetti, 2002).

The rubbery state usually occurs in polymeric substances, in which the individual macromolecules are entangled or cross-linked by covalent or hydrogen bonds, van der Waals forces, or other types of interaction (Erman and Mark, 1997; Cowie and Arrighi, 2007; Sperling, 2006). In food science and pharmaceutical research, however, the term rubber is also used for semi-solid amorphous substances with low molecular mass such as monosaccharides (Roos and Karel, 1991, 1992; Roos et al., 1999; Hancock and Zografi, 1997; Bhandari and Howes, 1999; Burnett et al., 2004).

Gels are two-phase mixtures of liquids dispersed in (semi-)solid amorphous matrices (supramolecular networks; Flory, 1974; Keller, 1995; Abdallah and Wise, 2000; Sangeetha and Maitra, 2005; He et al., 2007), and the uptake 
of water into a gel can involve gradual swelling as well as stepwise volume increases related to thermodynamically well-defined phase transitions (Dusek and Patterson, 1968; Tanaka, 1978; Erman and Mark, 1997). Upon drying, gels can form highly porous structures (xerogels/aerogels; Kistler et al., 1935; McNaught and Wilkinson, 1997).

Ultra-viscous or highly viscous liquids exhibit viscosities that are close to the viscosity of glasses $\left(>10^{10} \mathrm{Pas}\right)$ or at least several orders of magnitude higher than the viscosity of water at ambient conditions $\left(>10^{4} \mathrm{~Pa}\right.$ s vs. $\sim 10^{-3} \mathrm{Pas}$; Hecksher et al., 2008). Such liquids can also be regarded as semi-solids when they behave in a non-ergodic manner, i.e., when the relaxation times of relevant properties are comparable to or longer than the time scales of imposed changes and observations, respectively (Lubchenko and Wolynes, 2007). For example, highly viscous liquids may exhibit fluid behavior such as viscous flow over long times scales. On short time scales, however, they may not be able to respond to mechanical forces or changes of ambient conditions (temperature, humidity) and thus appear (semi-)solid rather than liquid (non-ergodic behavior due to kinetic limitations).

The transition from the glassy state to a semi-solid state (rubbery, gel-like or ultra-viscous liquid) is called glass transition and characterized by the glass transition temperature, $T_{\mathrm{g}}$ (Angell, 1995; Debenedetti and Stillinger, 2001; Roberts and Debenedetti, 2002; Zobrist et al., 2008). At the glass transition, discontinuous changes can be observed in thermodynamic properties such as molar volume, enthalpy or entropy, but dynamic properties such as viscosity and diffusivity change only gradually. Thus, glass transitions are different from classical first-order phase transitions (crystalto-liquid: melting or prompt deliquescence; liquid-to-crystal: freezing or prompt efflorescence) or second-order phase transitions (solid-to-solid: crystal lattice transformation). This is most evident by the fact that the glass transition temperature depends on the history of the glass formation process: large cooling rates usually result in higher $T_{\mathrm{g}}$ values than small cooling rates (Debenedetti and Stillinger, 2001; Zobrist et al., 2008).

Due to the very low molecular diffusivity of glasses, the uptake of water vapor by glassy aerosol particles may often be limited to surface adsorption - at least on the time scales that are most relevant for the processing of particles suspended in the atmosphere or in laboratory experiments (seconds to hours; Parker and Ring, 1995; Burnett et al., 2004; He et al., 2006). In contrast, amorphous particles in a rubbery, gel-like or viscous liquid state $\left(T>T_{\mathrm{g}}\right)$ can efficiently absorb water into the particle bulk (Slade and Levine, 1991; Hancock, 1993; Mackin et al., 2002; Price and Young, 2003; Burnett, 2004; Dawson et al., 2009). Moreover water can act as a plasticizer and reduce the glass transition temperature of amorphous solids (Slade and Levine, 1991; Roos and Karel, 1991; Hancock and Zografi, 1997; Lourdin at al., 1997; Zobrist et al., 2008).
For example, the glass transition temperature of spraydried lactose particles decreases with increasing relative humidity from $373 \mathrm{~K}$ under dry conditions to $298 \mathrm{~K}$ at $30 \% \mathrm{RH}$ (Burnett et al., 2004). Accordingly, the increase of relative humidity over glassy lactose at $298 \mathrm{~K}$ leads to a phase transition ("moisture-induced glass transition") that occurs at a "glass transition relative humidity" of $\mathrm{RH}_{\mathrm{g}} \approx 30 \%$. At $\mathrm{RH}_{\mathrm{g}}$ the solid glass is transformed into a semi-solid state (rubbery, gel-like, ultra-viscous) that can absorb water and swell accordingly. Continued absorption converts the (semi-)solid particles into concentrated aqueous solution droplets that may be metastable (supersaturated/supercooled) with regard to crystalline phases but are in equilibrium with the relative humidity of the surrounding gas.

Overall, the transformation of (semi-)solid amorphous particles (glassy, rubbery, gel-like, or ultra-viscous) into liquid aqueous solution droplets by uptake of water vapor (combined humidification and liquefaction) can be regarded as a deliquescence transition ("amorphous deliquescence"). Similar to the glass transition ("amorphous melting"), the amorphous deliquescence can be a non-equilibrium phase transition when the particles are not in thermodynamic equilibrium with the surrounding water partial pressure. Alternatively the amorphous deliquescence can also be an equilibrium process when it is due to the transition between collapsed and swollen gel-like structures (Dusek and Petterson, 1968; Tanaka, 1978; Erman and Mark, 1997), as detailed below in Sect. 4.2.2.

Due to the high viscosities and low molecular diffusivities of (semi-)solid amorphous substances, their deliquescence is likely to be kinetically limited (non-ergodic) on short time scales $(\leq$ minutes/hours for sub-micron and micronsized particles). In analogy to the dependence of $T_{\mathrm{g}}$ on the rate of temperature change, $\mathrm{RH}_{\mathrm{g}}$ is expected to depend on the rate of humidity change, whereby higher rates of $\mathrm{RH}$ increase should lead to higher $\mathrm{RH}_{\mathrm{g}}$ values. For example, Burnett et al. (2004) observed an increase of $\mathrm{RH}_{\mathrm{g}} \approx 30 \%$ at $d \mathrm{RH} / d t=2 \% \mathrm{~h}^{-1}$ to $\mathrm{RH}_{\mathrm{g}} \approx 40 \%$ at $d \mathrm{RH} / d t=10 \% \mathrm{~h}^{-1}$ for spray-dried lactose at $298 \mathrm{~K}$.

The absorption of water vapor or other gas molecules into the bulk of particles and droplets can be kinetically limited by surface processes (mass accommodation or surface accommodation and surface-bulk transfer, respectively) or by diffusion in the particle bulk (Seinfeld and Pandis, 2006; Taraniuk at al., 2007; Pöschl et al., 2007). In case of highly viscous substances, the uptake of water is likely to be limited by bulk diffusion, leading to kinetically limited, gradual deliquescence transitions. The uptake of water into particles consisting of molecules with higher molecular mass will generally lead to a decrease of viscosity and increase of diffusivity. Thus, the process should be self-accelerating and may lead to temporary formation of core-shell structures with higher diffusivity in the outer shell, because water uptake begins at the surface (Zobrist et al., 2008). 
Structural defects such as veins and pores in the particle bulk can accelerate the water uptake and reduce or abrogate diffusion-related kinetic limitations of deliquescence (Sjorgen et al., 2007; Zardini et al., 2008). On the other hand, some organic substances ("gelators", including carbohydrates and proteins) are able to form gel-like structures (supramolecular networks) that may inhibit molecular diffusion in the particle bulk and reinforce kinetic

limitations of deliquescence (Farhat et al., 1997; Abdallah and Weiss, 2000; Estroff and Hamilton, 2004; He et al., 2007). Moreover, the filling or formation of aqueous pockets in gel-like structures can lead to stepwise swelling in the course of hydration and gradual deliquescence of amorphous aerosol particles (see results reported below and by Mikhailov et al., 2004).

While multicomponent mixtures may be thermodynamically stable in an amorphous state (Marcolli et al., 2004; Cappa et al., 2008), amorphous (semi-)solids consisting of pure compounds or mixtures of a small number of components are usually metastable (supercooled/supersaturated) with regard to corresponding crystalline phases. The rates at which amorphous and dissolved organic substances crystallize are generally low and depend strongly on the presence of seed materials for crystal nucleation (e.g., Hilfiker, 2006). At room temperature and relative humidities of 50$70 \%$ the crystallization of spray-dried lactose and other sugars was found to proceed on time scales of hours (Burnett et al., 2004; Wang and Langrish, 2007), and no crystallisation was observed for micron-sized lactose particles of high purity (Price and Young, 2003). Accordingly, crystallization of organic compounds is not likely to occur in nanometer-sized aerosol particles unless they contain suitable seeds.

Upon dehydration of deliquesced organic particles (aqueous droplets) on time scales of seconds to minutes, continuous desorption of water vapor is expected to gradually convert the aqueous solution droplets into (semi-)solid amorphous particles ("amorphous efflorescence"). The desorption of water and gradual efflorescence transition can be kinetically limited by the formation of gel-like structures or core-shell structures with low diffusivity in the outer shell (glassy, rubbery, ultra-viscous) where equilibration with the gas phase begins (Zobrist et al., 2008). Limitations of mass transport and charge effects may also lead to the formation of porous structures and irregular envelope shape, which can be particularly pronounced in case of organic substances mixed with inorganic salts (Mikhailov et al., 2004).

\subsection{Generalized definitions of deliquescence and efflo- rescence}

For efficient description of water uptake and phase transitions of amorphous and crystalline organic and inorganic aerosol particles and particle components, we propose not to limit the terms deliquescence and efflorescence to equilibrium phase transitions of crystalline substances (salts) interacting with water vapor. Instead we propose the following generalized definitions:

1. Deliquescence is the transformation of a (semi-)solid substance into a liquid aqueous solution, whereby water is absorbed from the gas phase ("liquefaction/liquescence upon humidification/hydration”).

2. Efflorescence is the transformation of a substance from a liquid aqueous solution into a (semi-)solid phase, whereby water is evaporated ("solidification upon drying/dehydration").

According to these definitions, individual components as well as entire aerosol particles can undergo gradual or prompt, partial or full deliquescence or efflorescence, which is indeed the case not only for amorphous organic substances but also for mixtures of crystalline inorganic substances. If required, the attributes gradual/prompt, partial/full and amorphous/crystalline should enable a clear and unambiguous distinction between the various types of deliquescence and efflorescence transitions that may occur upon humidification or drying of aerosol particles.

When dealing with crystalline substances - as assumed in most earlier atmospheric studies - deliquescence can be regarded as a classical equilibrium phase transition with a well-defined deliquescence point. When dealing with amorphous solids (glasses) or other (semi-)solid substances (gels, rubbers, etc.), deliquescence can be regarded as a nonequilibrium phase transition like the glass transition. Studies explicitly discriminating different forms of deliquescence can simply add appropriate adjectives or nouns: crystal(line) deliquescence, amorphous deliquescence, glass(y) deliquescence, rubber(y) deliquescence, gel deliquescence; etc.

Thus, we consider the broad definitions proposed above more useful and suitable for aerosol and atmospheric research than alternative approaches that might restrict the terms deliquescence and efflorescence exclusively to prompt dissolution or formation of crystalline substances, respectively. Note that earlier studies have already used the term deliquescence in ways that go beyond classical equilibrium phase transitions and deliquescence points - see discussions of pre-deliquescence and non-prompt, nucleated or other pathways of deliquescence (e.g., Cantrell et al., 2002; Biskos et al., 2006; Zardini et al., 2008; McGraw and Lewis, 2009, and references therein).

The broad definitions of deliquescence and efflorescence proposed above are also consistent with the definition proposed by IUPAC (http://goldbook.iupac.org/D01582.html) and the various definitions used throughout chemistry, biology and medicine, which are usually not restricted to crystalline substances (e.g.: http://www.merriam-webster.com/dictionary/deliquescence, http://www.biology-online.org/dictionary/Deliquescence, http://medical.merriam-webster.com/medical/deliquesce, 
http://chemistry.about.com/od/chemistryglossary/a/

deliquescencedf.htm, etc.).

Note that the proposed general definition of deliquescence does not include gradual hygroscopic growth and water uptake (dilution) of liquid aqueous solution droplets, because the latter does not involve the liquefaction of (semi-)solid phases. As shown below and in earlier studies, the hygroscopic growth of liquid aqueous droplets (fully deliquesced particles) usually leads to a smooth continuous change of particle size with relative humidity. In contrast, the onset, transformation of intermediate stages (semi-solid gel or shell structures) and completion of the deliquescence and efflorescence transitions of (semi-)solid amorphous substances are usually related to discontinuities in the variation of aerosol particle size with relative humidity (distinct changes in the slope and curvature of $D_{\mathrm{b}}, g_{\mathrm{b}}, \sigma_{\mathrm{b}}$, and $N_{\mathrm{ML}}$ plotted against $\mathrm{RH}$; see below). In this regard and in general, the above definitions are also consistent with the definitions given by Martin (2000) in a review of phase transitions in atmospheric aerosols, including the deliquescence and efflorescence of (crystalline) salt particles.

In the following we present experimental investigations and model calculations on the uptake and release of water by crystalline and amorphous aerosol particles. In particular, we relate the size changes observed in H-TDMA experiments to structural rearrangements and phase changes according to the conceptual framework outlined above.

\section{Experimental methods}

\subsection{Substances and deliquescence relative humidity of bulk samples}

The following substances were used to prepare the investigated aerosols and bulk samples (provider, purity, molar mass and density at $298 \mathrm{~K}$ ): crystalline ammonium sulfate $\left((\mathrm{NH} 4)_{2} \mathrm{SO}_{4}\right.$, Fluka, $>99.5 \%$, $\left.132.16 \mathrm{~g} \mathrm{~mol}^{-1}, \quad 1769 \mathrm{~kg} \mathrm{~m}^{-3}\right)$, crystalline oxalic acid dihydrate $\left((\mathrm{COOH})_{2} \cdot 2 \mathrm{H}_{2} \mathrm{O}\right.$, Fluka, $>96 \%, 126.07 \mathrm{~g} \mathrm{~mol}^{-1}$, $\left.1653 \mathrm{~kg} \mathrm{~m}^{-3}\right)$, crystalline levoglucosan (1,6-anhydro- $\beta$-Dglucopyranose, $\mathrm{C}_{5} \mathrm{H}_{10} \mathrm{O}_{5}$, Fluka, $>98 \%, 162.14 \mathrm{~g} \mathrm{~mol}^{-1}$, $\left.1600 \mathrm{~kg} \mathrm{~m}^{-3}\right)$, crystalline glutaric acid $\left(\mathrm{COOH}-\left(\mathrm{CH}_{2}\right)_{3}\right.$ $\mathrm{COOH}$, Fluka, $>96 \%, 132.12 \mathrm{~g} \mathrm{~mol}^{-1}, 1429 \mathrm{~kg} \mathrm{~m}^{-3}$ ), and deionised water (Millipore - Milli Q plus $185,18.2 \mathrm{M} \Omega \mathrm{cm}$, $\left.18.02 \mathrm{~g} \mathrm{~mol}^{-1}, 997.1 \mathrm{~kg} \mathrm{~mol}^{-1}\right)$.

To determine the deliquescence relative humidity of bulk samples, $7-8 \mathrm{~g}$ of the crystalline substances were placed in a plastic bottle (polyethylene, $3.5 \mathrm{~cm}$ i.d., $8.5 \mathrm{~cm}$ height), and liquid water was added to prepare a thoroughly mixed aqueous slurry with a thin liquid solution layer $(\sim 2 \mathrm{~mm})$ covering the solid sample substance (Wexler and Brombacher, 1951). A capacitive humidity sensor (Ahlborn A646, precision $\pm 0.5 \% \mathrm{RH}$, accuracy $\pm 2 \% \mathrm{RH}$ and $\pm 0.1 \mathrm{~K}$ ) was positioned in the center of the bottle over the liquid surface.
Then the bottle was closed with a plastic lid, dipped into a water bath kept at $(298.2 \pm 0.2) \mathrm{K}$, and equilibrated over several hours to days (until the measured RH was constant over several hours). The constant saturation RH measured over the bulk samples $\left(\mathrm{RH}_{\mathrm{s}, \mathrm{b}}\right)$ was taken as the bulk deliquescence $\mathrm{RH}$ of the investigated crystalline substances $\left(\mathrm{RH}_{\mathrm{d}, \mathrm{b}}\right)$.

The humidity sensors used in the bulk sample and aerosol experiments (H-TDMA) were calibrated over the range of $11-94 \%$ RH using saturated aqueous solutions/slurries of $\mathrm{LiCl}(11.3 \pm 0.3 \%), \quad \mathrm{CH}_{3} \mathrm{COOK}$ $(22.0 \pm 0.3 \%), \mathrm{MgCl}_{2}(32.8 \pm 0.2 \%), \mathrm{K}_{2} \mathrm{CO}_{3}(43.2 \pm 0.3 \%)$, $\mathrm{Mg}\left(\mathrm{NO}_{3}\right)_{2}(52.9 \pm 0.2 \%), \mathrm{NaCl}(75.3 \pm 0.1 \%),\left(\mathrm{NH}_{4}\right)_{2} \mathrm{SO}_{4}$ $(81.0 \pm 0.3 \%), \quad \mathrm{KNO}_{3} \quad(93.6 \pm 0.6 \%) \quad$ as standards (Greenspan, 1977) in the same setup as for the determination of $\mathrm{RH}_{\mathrm{s}, \mathrm{b}}$. The uncertainty of the calibration was of the order of $\sim 1 \% \mathrm{RH}$ (standard deviation of linear regressions).

\subsection{H-TDMA setup and modes of operation}

The hygroscopicity tandem differential mobility analyzer $(\mathrm{H}-$ TDMA) system and experimental procedures were essentially the same as described by Mikhailov et al. (2004), except for a few modifications aimed at minimizing experimental uncertainties (Fig. 2). Aerosols were generated by nebulization of aqueous solutions of the investigated substances in deionised water (solute mass fraction $0.1 \%$ ). The solution droplets generated by nebulisation were dried using a couple of silica gel diffusion dryers (SDD) with an overall aerosol residence time of $\sim 30 \mathrm{~s}$; the residual relative humidity was $<5 \%$ throughout all experiments (RH1, Fig. 2). All $\mathrm{H}$-TDMA experiments were performed at ambient temperature and pressure $(298 \pm 2 \mathrm{~K}, \sim 960 \mathrm{hPa})$.

The dry polydisperse aerosol was passed through a neutralizer $\left({ }^{85} \mathrm{Kr}\right.$, TSI, $2 \mathrm{mCi}$, Model 3077), and a monodisperse aerosol with the desired initial dry particle diameter was selected by the first differential mobility analyzer (DMA1). The size-selected particles were then passed through a conditioner (Nafion, Ansyco) with a residence time of $13 \mathrm{~s}$ (conditioner and subsequent lines leading to DMA2). The size distribution of the conditioned particles was measured with a scanning mobility particle sizer (SMPS) consisting of DMA2 (TSI Model 3071), a condensation particle counter (CPC, TSI 3025), and a computer (TSI AIM 4.3 software).

The mass flow meters used to control the sheath and excess flows of DMA 2 (TSI Model 2011B) were calibrated using a film flow meter (Gilian Gilibrator 2, standard flow cell, accuracy $0.2 \%$ ). At the beginning, middle and end of every experiment the film calibrator was used to check the sheath and aerosol flow rates, which were generally very stable (variations $<0.5 \%$ ). The relative humidity and the temperature of aerosol and sheath inflow and exhaust outflow of DMA2 were measured with capacitive humidity sensors (Ahlborn A646) calibrated as described above. A fan was used to ventilate air through the housing of DMA2 to 


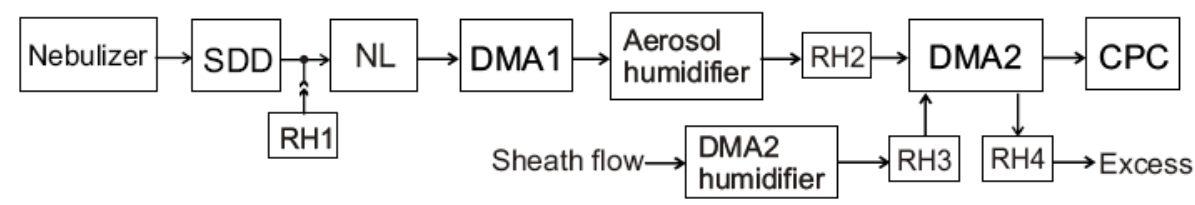

Fig. 2. Experimental setup of the hygroscopicity tandem differential mobility analyzer (H-TDMA) system: RH - relative humidity sensor, SDD - silica gel diffusion dryer, NL - aerosol neutralizer, DMA - differential mobility analyzer, CPC - condensation particle counter.

Table 1. Sequence of relative humidities ("RH history") experienced by the investigated aerosol particles in the key elements of the HTDMA system (DMA1, conditioner, DMA2) during different types of H-TDMA experiments (modes of operation, Sect. 2.2). For each type of experiment, $X$ represents the independent variable, i.e., the RH value taken for plotting and further analysis of the measurement results.

\begin{tabular}{lcccc}
\hline $\begin{array}{l}\text { H-TDMA experiment } \\
\text { (operation mode) }\end{array}$ & $\begin{array}{c}\text { DMA 1 } \\
\text { (size selection) }\end{array}$ & $\begin{array}{c}\text { Conditioner } \\
\text { (humidification) }\end{array}$ & \multicolumn{2}{c}{$\begin{array}{c}\text { DMA 2 } \\
\text { (size measurement) }\end{array}$} \\
\hline RH1 (\%) & $\mathrm{RH} 2(\%)$ & $\mathrm{RH} 3(\%)$ & $\mathrm{RH} 4(\%)$ \\
\hline hydration (1) & $<5$ & $X$ & $X$ & $X$ \\
dehydration (2) & $<5$ & $\mathrm{RH}_{\mathrm{s}, \mathrm{b}^{+}} 5^{\mathrm{a}}$ & $<5$ & $X$ \\
hydration\&dehydration (h\&d, 3) & $<5$ & $X$ & $<5$ & $\leq 10^{\mathrm{b}}$ \\
\hline
\end{tabular}

a In dehydration experiments (mode 2) RH2 was kept 5\% higher than the relevant crystalline bulk deliquescence relative humidity $\mathrm{RH}_{\mathrm{s}, \mathrm{b}}$ (Table 2). For oxalic acid particles, RH2 was kept at $95 \%$.

${ }^{\mathrm{b}}$ In h\&d experiments (mode 3 ) the increase of RH2 from $<5 \%$ to $95 \%$ led to an increase of RH4 from $<5 \%$ to $\sim 0.1 \times \mathrm{RH} 2$.

equilibrate the temperature and relative humidity of sheath flow and excess flow (agreement of RH3 and RH4 generally better than $\pm 2 \% \mathrm{RH})$. Note that the uncertainties of humidity control in the H-TDMA system (up to $\pm 2 \% \mathrm{RH}$ ) was generally larger than the uncertainty of measuring diameter changes and growth factors, respectively $(<0.4 \%)$.

Based on Mikhailov et al. (2004), the H-TDMA system was used in three different modes of operation. These correspond to different sequences of humidification and drying ("RH histories") of the aerosol particles as outlined in Table 1 and enable efficient investigation of different phenomena.

1. H-TDMA mode 1 ("hydration") provides information about structural rearrangements and deliquescence phase transitions of dry particles and the hygroscopic growth of deliquesced particles (aqueous solution droplets) as a function of relative humidity upon particle sizing and conditioning (variable $X \approx \mathrm{RH} 2 \approx \mathrm{RH} 3 \approx \mathrm{RH} 4)$.

2. H-TDMA mode 2 ("dehydration") provides information about the efflorescence transition of deliquesced particles and the hysteresis loop between deliquescence and efflorescence transitions as a function of relative humidity upon particle sizing after conditioning and deliquescence at high $\mathrm{RH}$ (variable $X \approx \mathrm{RH} 4$; $\mathrm{RH} 2 \approx \mathrm{RH}_{\mathrm{s}, \mathrm{b}}+5 \% ; \max .95 \%$ ). In this mode as well as in mode 3, DMA2 serves not only for particle sizing but also for particle drying (residence time $\sim 7.5 \mathrm{~s}$; Mikhailov et al., 2004).
3. H-TDMA mode 3 ("hydration \& dehydration", "h\&d") provides information about structural changes and/or partial evaporation of particles as a function of the maximum relative humidity experienced during a cycle of humidification and drying (variable $X \approx \mathrm{RH} 2$; RH3 $<5 \% ; 5 \%<$ RH4 $<12 \%$ ). The minimum mobility diameter observed in mode 3 can be used to approximate the actual mass equivalent diameter of dry particles, which is a prerequisite for accurate Köhler model calculations, and differences between the mobility diameters observed in modes 1 and 3 (hydration and h\&d experiments) can provide information about the surface adsorption of water on dry aerosol particles, as discussed below and in Mikhailov et al. (2004).

Note that in most other H-TDMA studies a pre-dryer has been applied before DMA2 when performing dehydration or h\&d experiments. For the experiments presented in this manuscript, however, we have intentionally not used a predryer before DMA2 in order to obtain information about kinetic limitations of dehydration processes. In our dehydration and h\&d experiments with dry sheath air $(\mathrm{RH} 3<5 \%)$, the average relative humidity in DMA2 obtained by equilibration of aerosol and sheath flow through diffusion of water vapor was in the range of $<5 \%$ to $\sim 10 \%(\approx 0.1 \times \mathrm{RH} 2)$. Model calculations solving the convective-diffusion equation with a finite element software package (FEMLAB \& Matlab) for the applied DMA and operating conditions (TSI Model 3071; aerosol flow 0.31/min; sheath flow 31/min) show that the maximum radial deviations from the average 

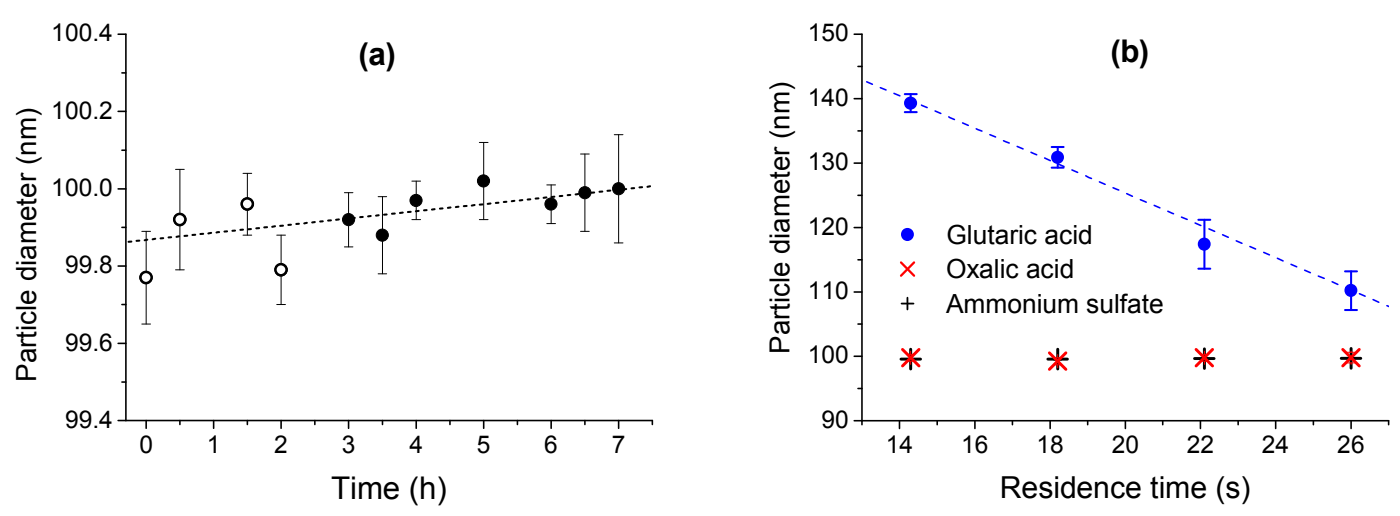

Fig. 3. Measurement precision and dry particle stability characterized by test measurements of particle mobility diameter $\left(D_{\mathrm{b}}\right)$ over time: (a) Initial mobility diameter $\left(D_{\mathrm{b}, \mathrm{i}}\right)$ as selected with DMA1 and measured with DMA2 for ammonium sulfate particles over the full duration of an H-TDMA experiment $(\sim 7 \mathrm{~h})$. Symbols and error bars represent the arithmetic mean \pm standard deviation of five repeated measurements; open symbols indicate warm-up time. The slope of the linear fit indicates a drift of $0.018 \mathrm{nmh}^{-1}(<0.2 \%)$. (b) Mobility diameter of oxalic acid, glutaric acid, and ammonium sulfate particles under dry conditions plotted against residence time between DMA1 and DMA2 (conditioner and tubing). The slope of the linear fit indicates an evaporation rate of $(2.5 \pm 0.2) \mathrm{nm} \mathrm{s}^{-1}$ for glutaric acid particles, whereas no significant evaporation was observed for oxalic acid and ammonium sulfate $\left(<0.03 \mathrm{~nm} \mathrm{~s}^{-1}\right)$.

relative humidity in DMA2 were reduced to $\leq 30 \%$ after $0.1 \mathrm{~s}$ $(<5 \%$ after $0.5 \mathrm{~s})$ and should have negligible influence on the experimental results. Only at high RH in the h\&d experiments, the enhanced RH of the aerosol flow (up to $\sim 30 \%$ for $\sim 0.1 \mathrm{~s}$ ) may have had a significant influence on the measured mobility diameter, causing deviations up to $\sim 1 \%$ or $\sim 1 \mathrm{~nm}$, respectively, according to the DMA model calculations described below.

To characterize the effects of combined drying and sizing of aerosol particles in DMA2, i.e., the influence of dehydration-related particle mobility changes inside DMA2, we performed DMA model calculations for aerosol particles undergoing size changes in the range of $200 \mathrm{~nm}$ to $100 \mathrm{~nm}$ (Wang and Flagan, 1990; Endo et al., 1997). The model results have the following implications: (1) If the dehydration processes (efflorescence, restructuring, or desorption) inside DMA2 are completed within $\sim 0.1 \mathrm{~s}$, then the resulting changes in particle mobility diameter should be fully captured with deviations $<1 \%$. (2) Kinetically limited dehydration processes that lead to progressive changes of particle mobility on a time scale of $\sim 0.1-10$ s should significantly influence the particle sizing (deviations $>1 \%$ ) and lead to a broadening of the measured size distributions (increase of geometric standard deviation, $\sigma_{\mathrm{g}}$ ). (3) Dehydration processes progressing on time scales $>10 \mathrm{~s}$ should have no effect on particle sizing (no change of mobility diameter and no broadening of size distribution).

\subsection{H-TDMA measurement data analysis and precision}

The particle size distributions measured with the SMPS system (DMA2) were fitted with a log-normal distribution function (CPC raw counts on a linear scale vs. mobility equivalent diameter on a logarithmic scale with 64 channels per decade; TSI AIM 3.4 and Origin 7.5 software), and the modal diameter $\left(D_{\mathrm{b}}\right)$ and geometric standard deviation $\left(\sigma_{\mathrm{g}}\right)$ of the fit function were used for further data analysis and plotting. The initial dry particle diameter $\left(D_{\mathrm{b} . \mathrm{i}}\right)$, i.e. the modal diameter of unconditioned monodisperse aerosol size-selected with DMA1, was generally kept at $(99.5 \pm 0.2) \mathrm{nm}$. Mobilityequivalent particle growth factors, $g_{\mathrm{b}}$, were calculated relative to the minimum mobility diameter observed in H-TDMA operation mode $3(\mathrm{~h} \& \mathrm{~d}): g_{\mathrm{b}}=D_{\mathrm{b}} / D_{\mathrm{b}, \mathrm{h} \& \mathrm{~d} \text {,min }}$.

The precision of repeated mobility diameter measurements was generally about $\pm 0.1 \%$ (relative standard deviation of five repeated measurements), the variability over the $\sim 4 \mathrm{~h}$ needed to perform a complete experiment in one of the H-TDMA operation modes (preceded by $\sim 3 \mathrm{~h}$ warm-up time) was generally less than $\pm 0.2 \%$, and the drift was less than $0.2 \%$ (Fig. 3a). $D_{\text {b.i }}$ was checked at the beginning, middle and end of every experiment. The measurement data were not corrected for drifts of $D_{\mathrm{b} . \mathrm{i}}$, but the experiment was discarded and repeated if the drift exceeded $0.2 \%$.

Accordingly, the uncertainty of relative changes in $D_{\mathrm{b}}$ and the uncertainty of $g_{\mathrm{b}}$ were less than $0.4 \%$. The statistical uncertainty of $\sigma_{\mathrm{g}}$ was around $0.3 \%$ (relative standard deviation of five repeated measurements). Potential effects of RH changes on particle mobility sizing with the SMPS, i.e., effects of changes in mean free path and viscosity on electrical mobility, were estimated using the empirical formulas reported by Weingartner et al. (1997). Overall these effects should influence the observed growth factors by less than $\sim 0.3 \%$. As this is within the specified uncertainties, we have chosen not to correct the measurement data.

High precision and accuracy of the measured and calculated values of $D_{\mathrm{b}}$ and $g_{\mathrm{b}}$, respectively, were confirmed by good agreement of the measurement results for pure 
ammonium sulfate particles with a reference Köhler model (mean relative deviation $<1 \%$; Sect. B1).

Figure $3 \mathrm{~b}$ shows the results of test experiments in which the residence time of the aerosol between the two DMAs up to $30 \mathrm{~s}$ under dry conditions, to check if investigated organic aerosol components evaporated on the time scale of the reported experiments. No evaporative losses were detected for levoglucosan and oxalic acid, whereas glutaric acid particles evaporated rapidly at a rate of $2.5 \mathrm{~nm} \mathrm{~s}^{-1}$ (slope of linear fit).

\section{Experimental results and discussion}

In Sect. 4.1 we present results from high precision H-TDMA experiments with crystalline ammonium sulfate particles, which are the basis for a systematic comparison of amorphous and crystalline particle behavior and comprise a new approach of measuring surface adsorption of water vapor. However, readers interested only in amorphous particle behavior might want to skip Sect. 4.1 and proceed to Sects. 4.2 and 4.3 (amorphous oxalic acid and levoglucosan particles).

\subsection{Ammonium sulfate}

\subsubsection{Phase transitions and hygroscopic growth}

Figure $4 \mathrm{a}$ shows the mobility equivalent growth factors observed for pure ammonium sulfate (AS) particles as a function of relative humidity $(\mathrm{RH})$ in the H-TDMA operation modes of hydration and dehydration, respectively (Table 1 , Sect. 3.2). It illustrates the typical behavior of crystalline inorganic salt aerosol particles interacting with water vapor (Martin, 2000).

Upon hydration, a steep increase of particle diameter due to a prompt deliquescence transition was observed at $\sim 80 \%$ $\mathrm{RH}$ in good agreement with bulk measurements and literature data of $\mathrm{RH}_{\mathrm{d}}$ for crystalline AS (Table 2). The hysteresis loop observed upon dehydration is characteristic for crystalline salt particles; it is due to the persistence of metastable aqueous solution droplets which are supersaturated with respect to crystalline AS (Martin, 2000). The efflorescence transition resulting in the formation of salt crystals and the evaporation of liquid water was observed at $\sim 30 \% \mathrm{RH}$ in good agreement with literature data of $\mathrm{RH}_{\mathrm{e}}$ for submicron ammonium sulfate particles (Table 2). Both the deliquescence and efflorescence transitions are also reflected by a broadening of the measured particle size distributions (increase of geometric standard deviation, Fig. 4b) which can be attributed to non-uniformity of the size-selected particles and experimental conditions (Weingartner et al., 2002; Mikhailov et al., 2004; Biskos et al., 2006). For Köhler model calculations of the hygroscopic growth see Appendix B (Sect. B1).

\subsubsection{Microstructure and surface adsorption}

Upon hydration from $\sim 20 \%$ to $\sim 50 \% \mathrm{RH}$, the mobility equivalent diameter of the investigated ammonium sulfate aerosol particles decreased by $\sim 3 \%$, which can be attributed to the transformation of porous or irregularly shaped particles into compact near-spherical particles (Krämer et al., 2000; Gysel et al., 2004; Brooks et al., 2004; Mikhailov et al., 2004). The difference between the mobility diameters of dry AS particles $(\mathrm{RH}<20 \%)$ observed in the hydration and in the dehydration experiments, respectively, can be explained by differences in the drying process before and after size selection in the H-TDMA system (Mikhailov et al., 2004; Biskos et al., 2006). Most likely the AS particles generated by nebulization carried excess electric charges and formed slightly porous or irregularly shaped structures upon drying (apparent volume void fraction $\sim 4 \%$, Table 2; Weis and Ewing, 1999). As pointed out before (Mikhailov et al., 2004; Biskos et al., 2006; Rose et al., 2008), not only the charge state but also the exact conditions and rate of drying are important for the microstructure of aerosol particles generated by nebulization of aqueous solutions. In test experiments with increased residual relative humidity in the diffusion dryer (less dry silica gel), the mobility diameter reduction upon hydration decreased to $\sim 2 \%$ at $\mathrm{RH} 1=9 \%$ and to $\sim 1 \%$ at $\mathrm{RH} 1=15 \%$, respectively. Similarly, Gysel et al. (2002) and Biskos et al. (2006) had reported mobility diameter reductions of 1$2 \%$ upon hydration of AS particles.

On the other hand, the AS particles formed upon dehydration and efflorescence of size selected particles (mostly carrying only a single elementary charge) appear to have been compact and spherical. The mobility diameter of dry particles in the dehydration experiment $\left(D_{\mathrm{b}, \mathrm{h}, \mathrm{min}}\right)$ was nearly the same as the minimum mobility diameter observed in the hydration\&dehydration (h\&d) experiment $\left(D_{\mathrm{b}, \mathrm{h}, \min } \approx\right.$ $D_{\mathrm{b}, \mathrm{h} \& \mathrm{~d}, \min }$, Table 2), and Köhler model calculations based on $D_{\mathrm{b}, \mathrm{h} \& \mathrm{~d}, \mathrm{~min}}$ as the mass equivalent dry particle diameter $\left(D_{\mathrm{m}, \mathrm{s}}\right)$ are in excellent agreement with the observed hygroscopic growth curve. These findings confirm the compactness and spherical shape of dry particles with $D_{\mathrm{b}} \approx$ $D_{\mathrm{b}, \mathrm{h}, \min } \approx D_{\mathrm{b}, \mathrm{h} \& \mathrm{~d} \text {,min }}$ (Sect. B1).

The higher geometric standard deviation of the particles observed at $\mathrm{RH}<50 \%$ in the dehydration experiment $\left(\sigma_{\mathrm{g}} \approx\right.$ $1.08)$ compared to the hydration experiment $\left(\sigma_{\mathrm{g}} \sim 1.06\right.$, Fig. $4 \mathrm{~b}$ ) can be explained by the size selection of particles with the same mobility but different porosity or shape in the first mobility analyzer of the H-TDMA (DMA1). Upon conditioning and deliquescence/efflorescence in the H-TDMA the particles become more compact/spherical, and the original differences in porosity/shape are converted into differences in size (mass conservation). Particles that were more porous/irregular prior to conditioning are expected to exhibit smaller mobility diameters after conditioning, leading to a spread of the size distribution measured with the second mobility analyzer (DMA2). 
Table 2. Parameters characterizing the microstructural rearrangement and phase transitions of the investigated aerosol particles/substances:

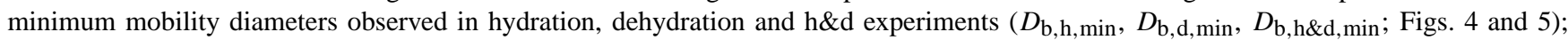
apparent volume void fraction of particles upon initial size-selection $\left(f_{\mathrm{v}, \mathrm{i}}=D_{\mathrm{b}, \mathrm{i}}^{3} / D_{\mathrm{b}, \mathrm{h} \& \mathrm{~d}, \min }^{3}-1, D_{\mathrm{b}, \mathrm{i}}=99.5 \mathrm{~nm}\right)$; relative humidities of deliquescence and efflorescence as observed in the H-TDMA experiments of this study $\left(\mathrm{RH}_{\mathrm{d}}, \mathrm{RH}_{\mathrm{e}}\right)$; relative humidity measured over saturated aqueous bulk samples in this study $\left(\mathrm{RH}_{\mathrm{s}, \mathrm{b}}=\mathrm{RH}_{\mathrm{d}, \mathrm{b}}\right)$; deliquescence relative humidities reported in earlier studies $\left(\mathrm{RH}_{\mathrm{d}, \text { lit }}\right)$.

\begin{tabular}{|c|c|c|c|c|c|c|c|c|}
\hline Substance & $\begin{array}{l}D_{\mathrm{b}, \mathrm{h}, \min } \\
(\mathrm{nm})\end{array}$ & $\begin{array}{l}D_{\mathrm{b}, \mathrm{d}, \min } \\
\quad(\mathrm{nm})\end{array}$ & $\begin{array}{c}D_{\mathrm{b}, \mathrm{h} \& \mathrm{~d}, \min } \\
(\mathrm{nm})\end{array}$ & $\begin{array}{l}f_{\mathrm{v}, \mathrm{i}} \\
(\%)\end{array}$ & $\begin{array}{l}\mathrm{RH}_{\mathrm{d}} \\
(\%)\end{array}$ & $\begin{array}{l}\mathrm{RH}_{\mathrm{e}} \\
(\%)\end{array}$ & $\begin{array}{c}\mathrm{RH}_{\mathrm{d}, \mathrm{b}} \\
(\%)\end{array}$ & $\begin{array}{c}\mathrm{RH}_{\mathrm{d}, \mathrm{lit}} \\
(\%)\end{array}$ \\
\hline Ammonium sulfate (AS) & 96.5 & 95.7 & 95.7 & 4 & 80 & 30 & 79.4 & $\begin{array}{r}79.9^{\mathrm{a}}, 80.2^{\mathrm{b}}, 80^{\mathrm{c}} \\
80^{\mathrm{d}}, 79.9^{\mathrm{e}}, 79^{\mathrm{f}}\end{array}$ \\
\hline Oxalic acid (OA, dihydrate) & 92.3 & 89.0 & 89.0 & 40 & $45-80$ & $20-80$ & 96.7 & $\begin{array}{c}97.8^{\mathrm{b}}, 93.0^{\mathrm{g}}, \\
97.3^{\mathrm{h}}, 99^{\mathrm{i}}\end{array}$ \\
\hline Levoglucosan (LG) & 99.5 & 103.8 & 99.5 & 0 & $30-60$ & $<14$ & 81.9 & $80.0^{\mathrm{j}}, 81.5^{\mathrm{k}}$ \\
\hline
\end{tabular}

${ }^{a}$ Robinson and Stokes (1970), bulk solution measurements; ${ }^{b}$ Marcolli et al. (2004), bulk solution measurements; ${ }^{\mathrm{c}}$ Gysel et al. (2002), HTDMA measurements; ${ }^{d}$ Tang and Munkelwitz (1993), electrodynamic balance measurements; ${ }^{2}$ Onasch et al. (1999), FTIR spectroscopy measurements; ${ }^{\mathrm{f}}$ Biskos et al. (2006), HTDMA measurements; $\mathrm{g}$ Brooks et al. (2002), bulk solution measurements, $24^{\circ} \mathrm{C}$; ${ }^{\mathrm{h}}$ Peng et al. (2001), bulk solution measurements, $25^{\circ} \mathrm{C}$; ${ }^{i}$ Prenni et al. (2001), thermodynamic model; ${ }^{\mathrm{j}}$ Mochida and Kawamura (2004), bulk solution measurements at $20^{\circ} \mathrm{C} ;{ }^{\mathrm{k}}$ Parson (2006), optical microscope coupled to a flow cell.

As illustrated in Fig. 5a and b, the difference between the mobility diameters observed in the hydration experiments and in the h\&d experiments provide information about the amount of water adsorbed on the surface of crystalline aerosol particles prior to deliquescence. Upon hydration, DMA2 is operated under humidified conditions and measures mobility diameter of particles with adsorbed water $\left(D_{\mathrm{b}, \mathrm{h}}\right)$, whereas the h\&d mode enables the measurement of dry particle size $\left(D_{\mathrm{b}, \mathrm{h} \& \mathrm{~d}}\right)$ at $\mathrm{RH}<5 \%$ to $12 \%$. At $\mathrm{RH} \leq 45 \%$ the differences between the hydration and h\&d operation modes can be attributed to differences in the kinetically limited microstructural rearrangement process (Mikhailov et al., 2004), which appears to be more efficient when the particles are not only humidified (hydration) but also re-dried ( $\mathrm{h} \& \mathrm{~d}$ ).

At $\mathrm{RH} \approx 50-70 \%$ the mobility diameter observed in the $\mathrm{h} \& \mathrm{~d}$ mode was practically independent of $\mathrm{RH}\left(D_{\mathrm{b}, \mathrm{h} \& \mathrm{~d}} \approx\right.$ $\left.D_{\mathrm{b}, \mathrm{h} \& \mathrm{~d}, \mathrm{~min}}\right)$, indicating that the restructuring and compaction of the particles were completed. The increase of $D_{\mathrm{b}, \mathrm{h} \& \mathrm{~d}}$ at $\mathrm{RH}>80 \%$ may be due to changes of particle microstructure resulting from the cycle of deliquescence and efflorescence that occurs in the course of h\&d experiments at $\mathrm{RH}>\mathrm{RH}_{\mathrm{d}}$ or to the influence of particle drying on particle sizing in DMA2 (Sect. 3.2).

Assuming that the compacted particles at $\mathrm{RH} \approx 50-70 \%$ were spherical and that the thickness of a monomolecular layer (ML) of water adsorbed on the surface is $\sim 0.2 \mathrm{~nm}$ (Romakkaniemi et al., 2001), we have converted the difference between the mobility diameters observed in hydration and $\mathrm{h} \& \mathrm{~d}$ experiments into an equivalent number of water ML: $N_{\mathrm{ML}}=\left(D_{\mathrm{b}, \mathrm{h}}-D_{\mathrm{b}, \mathrm{h} \& \mathrm{~d}}\right) /(0.4 \mathrm{~nm})$ with the particle diameters given in units of $\mathrm{nm}$. As detailed in the experimental section, the H-TDMA measurement precision was generally better than $\sim 0.2 \mathrm{~nm}$; thus the uncertainty of $N_{\mathrm{ML}}$ is assumed to be less than \pm 1 ML. As illustrated in Fig. 5b, we obtained a near constant surface coverage by $\sim 2 \mathrm{ML}$ of water for the RH range of 50-70\% and an apparent increase up to $\sim 10 \mathrm{ML}$ over the range of $70-77 \% \mathrm{RH}$.

The findings are consistent with earlier H-TDMA studies of water adsorption on AS particles. Romakkaniemi et al. (2001) found 0.5-1.5 ML of water on AS particles with $15 \mathrm{~nm}$ diameter in fair agreement with theoretical calculations considering the Kelvin effects and various types of adsorption isotherms. The adsorption of $\sim 2-3 \mathrm{ML}$ of water on the surface of ammonium sulfate at $50-70 \% \mathrm{RH}$ is in good agreement with the BET (Brunauer, Emmett, Teller) isotherm calculations presented by Romakkaniemi et al. (2001) and with free energy model calculations of Russell and Ming (2002). Biskos et al. (2006) also observed a gradual increase of the mobility diameter of AS particles in the range of 50-80\% RH and attributed it to water adsorption. For particles in the size range of $40-60 \mathrm{~nm}$ they reported a diameter increase of $2-3 \%$ at $\sim 79 \% \mathrm{RH}$, corresponding to $\sim 3 \mathrm{ML}$ of water adsorbed on the surface. Moreover, Biskos et al. (2006) demonstrated that stronger increases of mobility diameter prior to deliquescence observed in earlier H-TDMA experiments (apparent non-prompt deliquescence) can be explained by measurement artifacts (deviations of RH in aerosol and sheath flow).

Accordingly, we attribute the apparent mobility diameter increase observed in our experiments at $\mathrm{RH}>70 \%$ (equivalent to up to $\sim 10 \mathrm{ML}$ of adsorbed water) to deviations between aerosol and sheath flow RH in DMA2. The adsorption of $\sim 10$ and more ML of water on the surface crystalline aerosol particles prior to deliquescence appears unlikely, because this would essentially correspond to bulk condensation rather than surface adsorption of liquid water. In contrast to 

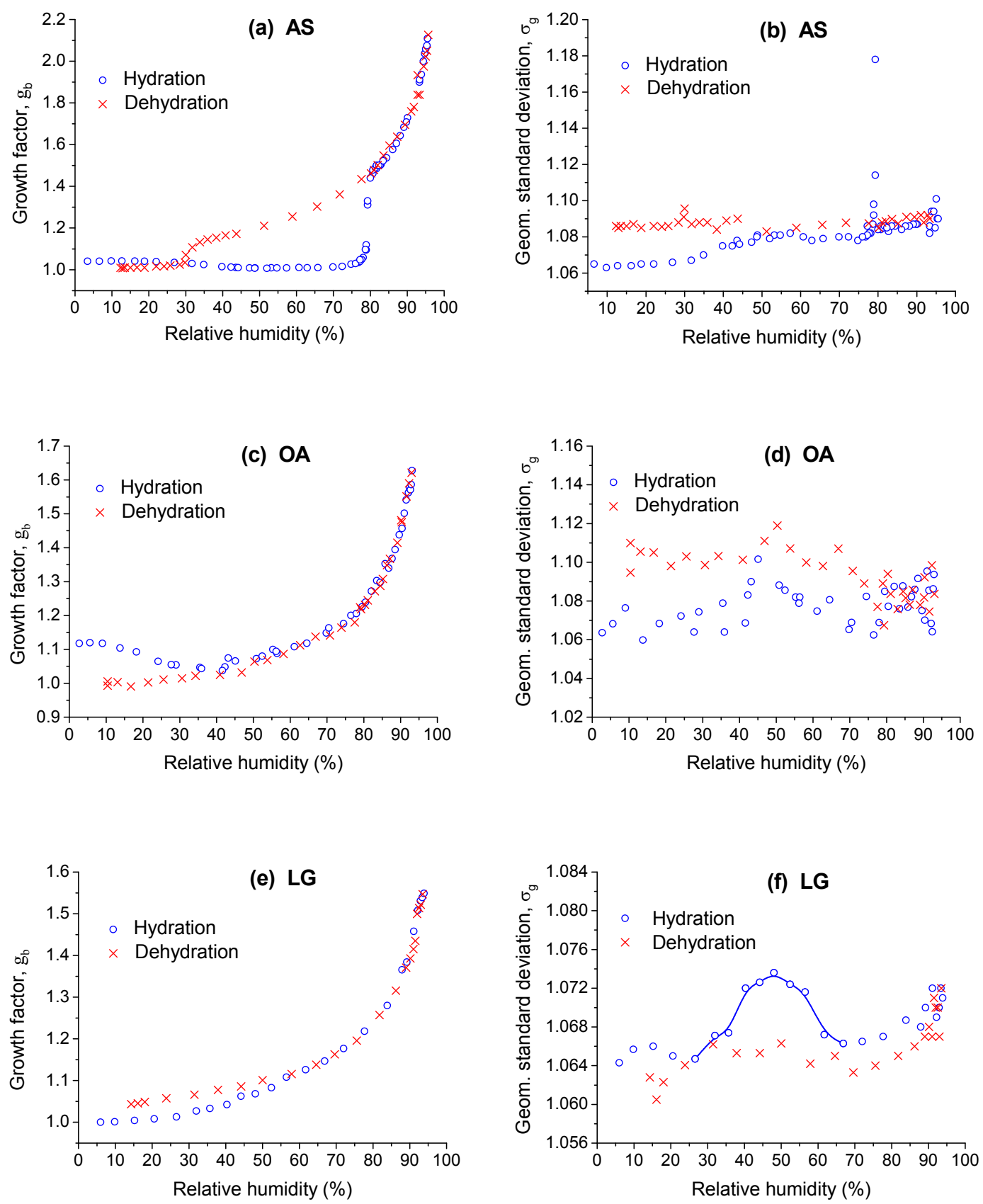

Fig. 4. Mobility equivalent growth factors $\left(g_{\mathrm{b}}\right.$, panels $\left.\mathbf{a}, \mathbf{c}, \mathbf{e}\right)$ and geometric standard deviations $\left(\sigma_{\mathrm{g}}\right.$, panels $\left.\mathbf{b}, \mathbf{d}, \mathbf{f}\right)$ observed in hydration experiments and dehydration experiments with aerosol particles composed of ammonium sulfate (AS), oxalic acid (OA), or levoglucosan (LG). The growth factors refer to the minimum mobility particle diameters observed in h\&d experiments (Fig. 5, Table 2). The line in panel (f) is a spline fit to guide the eye.

the gradual absorption of water into the bulk of amorphous substances, a swelling of crystalline salt particles due to bulk absorption of water appears not plausible.

In any case, the results of this and earlier studies show that care needs to be taken to avoid artifacts in the measurement and interpretation of H-TDMA and other experimental data with regard to surface adsorption or bulk absorption of water vapor by aerosol particles. In particular, the potential influence of particle microstructure (shape and porosity) should not be neglected in aerosol experiments. As illustrated in Fig. 5a and b, restructuring induced by hydration can have stronger effects on particle mobility diameter than the adsorption or absorption of water at low RH. 

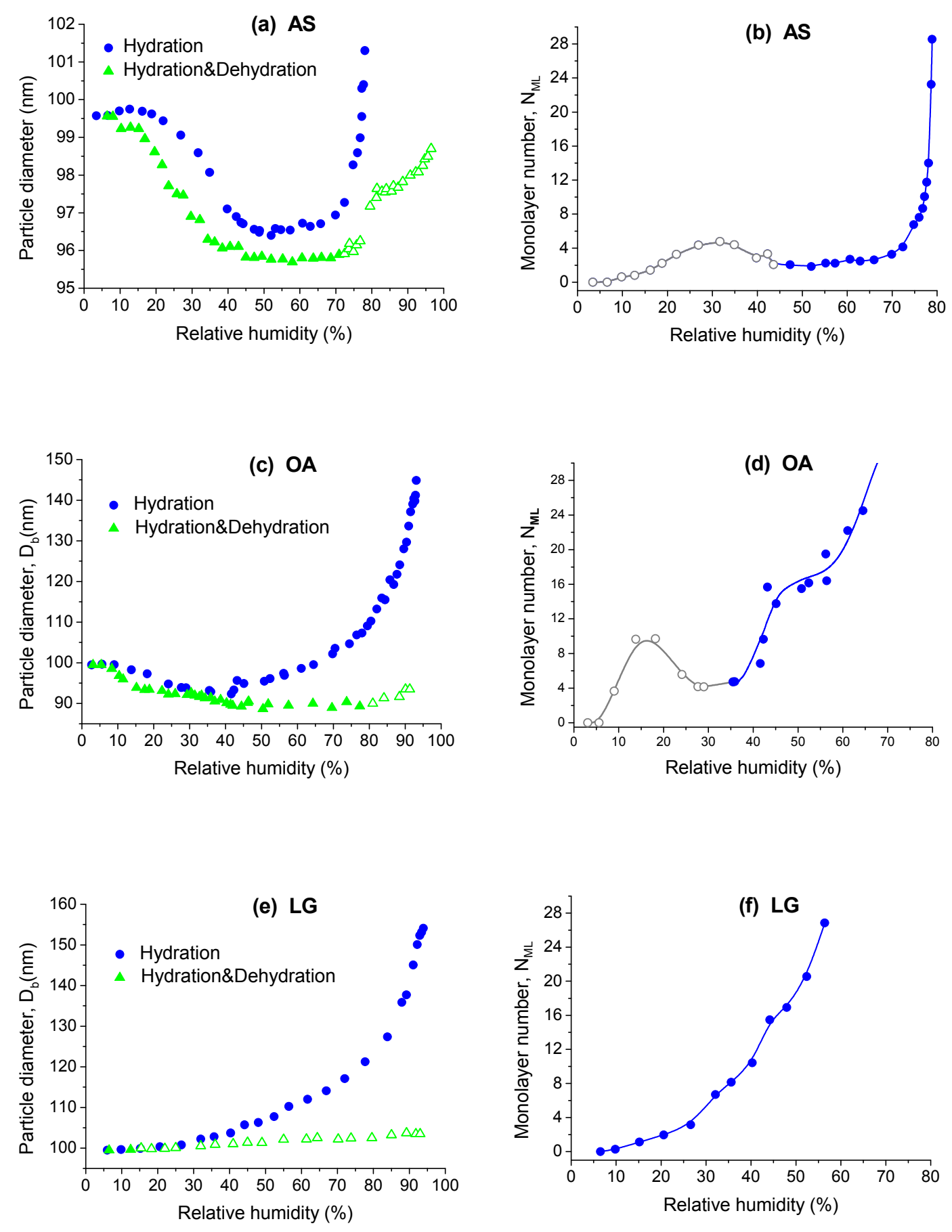

Fig. 5. Mobility equivalent diameters observed in hydration experiments and in hydration \& dehydration (h\&d) experiments $\left(D_{\mathrm{b}}\right.$, panels a, $\mathbf{c}, \mathbf{e})$ and equivalent numbers monomolecular layers of water corresponding to the diameter difference ( $N_{\mathrm{ML}}$, panels $\left.\mathbf{b}, \mathbf{d}, \mathbf{f}\right)$ for aerosol particles composed of ammonium sulfate (AS), oxalic acid (OA) or levoglucosan (LG). Where $D_{\mathrm{b}, \mathrm{h} \& \mathrm{~d}}$ increased rather than decreased with RH (open green triangles), $N_{\mathrm{ML}}$ was calculated from the difference between $D_{\mathrm{b}, \mathrm{h}}$ and $D_{\mathrm{b}, \mathrm{h} \& \mathrm{~d} \text {, min }}$. Open grey circles indicate RH range where the difference between $D_{\mathrm{b}, \mathrm{h}}$ and $D_{\mathrm{b}, \mathrm{h} \& \mathrm{~d}}$ appears dominated by restructuring rather than water uptake. Lines are spline fits to guide the eye. 


\subsection{Oxalic acid}

\subsubsection{Particle composition and stability}

Several studies have shown that dicarboxylic acids can evaporate on time scales of seconds and lead to artefacts in $\mathrm{H}$ TDMA experiments (Cruz and Pandis, 2000; Prenni et al., 2001, 2003; Pradeep Kumar et al., 2003; Bilde et al., 2003). As demonstrated by test experiments with increasing particle residence time under dry conditions in our H-TDMA setup (Fig. 3b), the oxalic acid particles (OA) generated and investigated in our study did not evaporate on the time scale of our experiments (up to $\sim 30 \mathrm{~s}$, relative change of $D_{\mathrm{b}}<0.4 \%$ and $\left|d D_{\mathrm{b}} / d t\right|=<0.03 \mathrm{~nm} \mathrm{~s}^{-1}$, respectively). In contrast, we could observe rapid evaporation of glutaric acid particles under the same conditions $\left(d D_{b} / d t=-2.5 \mathrm{~nm} \mathrm{~s}^{-1}\right)$, although the equilibrium vapor pressure of glutaric acid $\left(132 \mathrm{~g} \mathrm{~mol}^{-1}\right)$ is an order of magnitude lower than that of anhydrous oxalic acid $\left(90 \mathrm{~g} \mathrm{~mol}^{-1}\right)$ at $298 \mathrm{~K}: 7.8 \times 10^{-6}$ Torr vs. $8.3 \times 10^{-5}$ Torr (Saxena and Hildemann, 1996).

The most plausible explanation for the high stability (effective non-volatility) of the investigated OA particles is that they were not anhydrous but composed of oxalic acid hydrates. Indeed also the Köhler model calculations presented in Appendix B (Sect. B2) suggest that the particles observed under dry conditions consisted of oxalic acid dihydrate or non-stoichiometric hydrates containing about two water molecules per oxalic acid molecule. This is consistent with earlier studies suggesting that the tendency of aqueous acids to form glasses is most pronounced at compositions that correspond to stable hydrates (e.g., amorphous sulfuric acid monohydrate; Kanno and Itoi, 1984; Das et al., 1997; Tomikawa and Kanno, 1998; Koop, 2004). Besides hydration also dimer formation and surface kinetic effects could possibly play a role in making OA particles less volatile than glutaric acid particles (surface vs. bulk accommodation, adsorption \& desorption rate coefficients, etc.; Pöschl et al., 2007). In any case, our results are consistent with those of earlier H-TDMA experiments by Prenni et al. (2001), who also observed evaporative losses for glutaric acid but not for oxalic acid and could describe the hygroscopic growth of OA particles under the assumption that the "dry" particles consisted of oxalic acid dihydrate (Sect. 4.2.4).

\subsubsection{Phase transitions and hygroscopic growth}

Figure $4 \mathrm{c}$ shows the mobility equivalent growth factor observed upon hydration and dehydration of OA aerosol particles. Upon hydration up to $\sim 40 \% \mathrm{RH}$, the mobility diameter of the OA particles decreased by $\sim 7 \%$. As discussed below, this can be explained by microstructural rearrangements and indicates that the investigated OA particles obtained by nebulisation and diffusion drying of aqueous solution droplets were not liquid-like but (semi-)solid and highly porous. At $\sim 43 \%$ RH the particles exhibited a small but significant step- wise increase of mobility diameter by $\sim 3 \%$, which is accompanied by a pronounced broadening of the measured particle size distribution (peak of $\sigma_{\mathrm{g}}$, Fig. $4 \mathrm{~d}$ ). These observations indicate a deliquescence transition, which is the transformation of (semi-)solid amorphous OA particles into aqueous droplets that starts at much lower RH than for crystalline OA $\left(\mathrm{RH}_{\mathrm{b}, \mathrm{s}}=96.7 \%\right.$, Table 2).

The continuous hygroscopic growth and the approximate coincidence of hydration and dehydration curves above $\sim 50 \%$ RH confirm that the particles were at least partially deliquesced aqueous droplets (Fig. 4c). However, the multiple wiggles in the growth curves and the large offset in the geometric standard deviations observed upon hydration and dehydration over the range of $\sim 50-80 \%$ RH (Figs. 4c, d) are untypical and not plausible for fully deliquesced particles. With regard to the growth curves, the observed deviations are at the edge of experimental precision, which is limited primarily with regard to $\mathrm{RH}$, but for $\sigma_{\mathrm{g}}$ they are clearly larger. Only above $\sim 80 \% \mathrm{RH}$ did the growth factors and geometric standard deviations agree within experimental uncertainty, indicating that the particles were fully deliquesced liquid aqueous solution droplets.

The most plausible explanation for these observations is a gradual deliquescence transition that involves the formation and swelling of gel-like structures in the highly concentrated aqueous OA droplets, which is consistent with the tendency of OA to form hydrogen bonds and hydrates (Hermida-Ramon et al., 2004; Chitra et al., 2004; Wenger and Bernstein, 2007). The formation and collapse of gel-like structures and related kinetic limitations of a gradual efflorescence transition are also the most plausible explanation for the stepwise $\sim 3 \%$ diameter decrease and the concurrent peak of $\sigma_{\mathrm{g}}$ observed at $\sim 50 \% \mathrm{RH}$ in the dehydration experiment (Fig. 4c, d). Apparently, the oxalic acid and water molecules form a hydrogen-bonded network that breaks down when the volume fraction of water exceeds $\sim 50 \%$ (corresponding to $g_{\mathrm{b}} \geq 1.2$ at $\mathrm{RH} \geq 80 \%$ ). Similar deliquescence and efflorescence transitions of amorphous organic aerosol particles and the formation of gel-like droplets have already been reported for aerosol particles composed of protein macromolecules (bovine serum albumin, BSA, $67 \mathrm{~kg} \mathrm{~mol}^{-1}$; Mikhailov et al., 2004): stepwise $3 \%$ change of mobility diameter at $\sim 40 \%$ $\mathrm{RH}$, wiggly growth curves, kinetic limitations of water uptake and release.

Most likely the stepwise diameter increase at $\sim 40 \% \mathrm{RH}$ is related to a phase transition between collapsed and swollen gel structures (Dusek and Patterson, 1968; Tanaka, 1978; Erman and Mark, 1997), which might be triggered by a moisture-induced glass transition (Brownsey et al., 2003; Farahnaky et al., 2005; Zobrist et al., 2008). Whether or not the onset of deliquescence was triggered by a glass transition, further swelling and stepwise transformation of gellike network structures appear to be the most plausible explanation for the wiggly particle growth curve and the size distribution broadening that persisted upon hydration up to 
$\sim 80 \%$ RH. On the other hand, a collapse of gel-like structures most plausibly explains the stepwise diameter decrease that occurred upon dehydration at higher relative humidity than the stepwise diameter increase observed upon hydration ( $\sim 50 \%$ vs. $\sim 43 \%$, Fig. 4 c).

The results of our H-TDMA experiments with oxalic acid and their interpretation have recently been confirmed by the results of first experiments with an alternative measurement technique. Using a new filter-based differential hygroscopicity analyzer (Mikhailov et al., 2008), we have carried out cyclic hydration and dehydration experiments with crystalline grains of oxalic acid $(\sim 0.2 \mathrm{~mm}$ diameter). Upon initial hydration, prompt deliquescence was observed at $\sim 97 \%$ $\mathrm{RH}$ in good agreement with bulk measurements and literature data of $\mathrm{RH}_{\mathrm{d}}$ for crystalline OA. Upon dehydration and in further hydration experiments with the same sample, however, we observed essentially the same hygroscopic behavior as in the H-TDMA experiments, i.e., gradual uptake or release of water at $\mathrm{RH}>40 \%$.

\subsubsection{Microstructure and bulk absorption}

The $\sim 7 \%$ mobility diameter decrease observed upon hydration from $\sim 10 \%$ to $\sim 40 \%$ RH can be attributed to the transformation of porous or irregularly shaped solid particles into more compact near-spherical particles (Krämer et al., 2000; Gysel et al., 2004; Brooks et al., 2004; Mikhailov et al., 2004). As for AS, the difference between the mobility diameters of dry OA particles $(\mathrm{RH}<\approx 10 \%)$ observed in the hydration and in the dehydration experiments, respectively, can be explained by differences in the drying process before and after size selection in the H-TDMA system (Mikhailov et al., 2004). Most likely the OA particles generated by nebulization carried excess electric charges and upon rapid diffusion drying they formed highly porous xerogel structures (apparent volume void fraction $\sim 40 \%$, Table 2).

On the other hand, the OA particles formed upon dehydration and efflorescence of size selected particles (mostly carrying only a single elementary charge) appear to have been compact and spherical. The mobility diameter of dry particles in the dehydration experiment $\left(D_{\mathrm{b}, \mathrm{h}, \mathrm{min}}\right)$ was nearly the same as the minimum mobility diameter observed in the hydration\&dehydration $(\mathrm{h} \& \mathrm{~d})$ experiment $\left(D_{\mathrm{b}, \mathrm{h}, \min } \approx\right.$ $D_{\text {b,h\&d,min }}$, Table 2), and Köhler model calculations based on $D_{\mathrm{b}, \mathrm{h} \& \mathrm{~d}, \mathrm{~min}}$ as the mass equivalent dry particle diameter $\left(D_{\mathrm{m}, \mathrm{s}}\right)$ were in fair agreement with the observed hygroscopic growth curve (Sect. B2). As for AS, the higher geometric standard deviation of the particles observed at $\mathrm{RH}<80 \%$ in the dehydration experiment $\left(\sigma_{\mathrm{g}} \approx 1.08-1.12\right)$ compared to the hydration experiment $\left(\sigma_{\mathrm{g}} \approx 1.06-1.08\right.$, Fig. $\left.4 \mathrm{~d}\right)$ can be explained by the size selection of particles with the same mobility but different porosity in the first mobility analyzer of the H-TDMA.

Figure $5 \mathrm{c}$ and $\mathrm{d}$ shows the difference between the mobility diameters observed in hydration experiments and h\&d ex- periments with OA particles and the corresponding monolayer numbers $\left(N_{\mathrm{ML}}\right)$. At $\mathrm{RH}<40 \%$ the differences were apparently dominated by more efficient restructuring in the h\&d mode, as already discussed above for AS particles. At $\mathrm{RH} \approx 40 \%$ the restructuring was essentially completed ( $\left.D_{\mathrm{b}, \mathrm{h} \& \mathrm{~d}} \approx D_{\mathrm{b}, \mathrm{h} \& \mathrm{~d}, \min }\right)$. The value of $N_{\mathrm{ML}} \approx 5$ suggests that bulk absorption of water had already begun at $40 \% \mathrm{RH}$, because stronger surface adsorption than on AS particles appears unlikely ( $N_{\mathrm{ML}} \approx 2-3$ at $40-70 \%$ RH, Fig. $5 \mathrm{~b}$ ).

The pronounced particle swelling observed at $\mathrm{RH} \approx 43 \%$ corresponds to a water uptake of $\sim 15 \mathrm{ML}$ or $\sim 15 \%$ of the particle volume, respectively, and the persistence of $N_{\mathrm{ML}} \approx$ 15 over the range of $\sim 43-55 \%$ RH (plateau in Fig. 5d) supports the idea that a metastable gel was formed (He et al., 2007). At $\mathrm{RH}>55 \%$ the absorption of water vapor continued, but as discussed above, wiggles in the growth curve up to $\sim 80 \%$ RH (Fig. 5c) indicate ongoing transformations of gel-like network structures rather than gradual uptake of water into an homogeneous aqueous solution droplet as observed at $\mathrm{RH}>80 \%$ (for OA as well as for AS).

As indicated above and in earlier studies, the microstructure and morphology of aerosol particles generated by spray drying can be influenced by the rate of drying as well as electric charge effects. Further investigation and elucidation of such effects will require systematic variations of particle generation and conditioning (Mikhailov et al., 2004; Biskos et al., 2006; Dinar et al., 2006, 2007; Rosenoern et al., 2008; Mifflin et al, 2009).

\subsubsection{Related earlier studies}

Three earlier studies have reported hygroscopic growth measurements for oxalic acid aerosol particles: the H-TDMA study by Prenni et al. (2001), an electrodynamic balance (EDB) study by Peng et al. (2001), and an aerosol flow tube Fourier transform infrared spectroscopy (AFT-FTIR) study by Braban et al. (2003).

Prenni et al. (2001) observed similar growth factors as shown in Fig. 5a upon hydration from $\sim 45 \%$ to $\sim 91 \%$ RH (303 K, no dehydration experiments reported). Due to a lack of measurement data at low RH and higher measurement uncertainties $(\sim 4 \%)$ they did not report details about the onset of the deliquescence transition. They assumed that the aerosol particles generated by nebulisation, heating and diffusion drying of aqueous OA (initial diameters: $50-100 \mathrm{~nm}$ ) were not completely dry but rather concentrated solution droplets, and they reported that the measured hygroscopic growth agreed well with Köhler model calculations assuming that the initially generated particles consisted of oxalic acid dihydrate. We suggest that these particles may also have consisted of solid amorphous OA but were less porous due to different drying conditions which involved also a heating step.

Peng et al. (2001) reported hydration and dehydration experiments with of OA particles in the range $10-20 \mu \mathrm{m}$ 
diameter and 5-94\% RH (298 K). Upon hydration they observed no deliquescence but a small increase of particle mass at $\mathrm{RH}>80 \%$, which may be due to uptake of water into cracks on the solid particle surface (adsorption or capillary condensation). Upon dehydration they observed a gradual efflorescence transition that was completed at $52-57 \% \mathrm{RH}$, which is close to the stepwise $\sim 3 \%$ diameter decrease and the concurrent peak of $\sigma_{\mathrm{g}}$ observed at $\sim 50 \% \mathrm{RH}$ in our dehydration experiment (Fig. 5a, b). Peng et al. (2001) suggested that efflorescence transition led to crystallization of anhydrous oxalic acid. If this is the case, gel-like structures and their collapse might also play a role in the crystallization of organic substances from aqueous solution droplets. Alternatively, the effloresced particles might have consisted of amorphous oxalic acid - possibly non-stoichiometric hydrates, because the formation of anhydrous oxalic acid usually requires very low relative humidity (Mod et al., 1973; de Wit et al., 1983; Apelblat, 1986).

Braban et al. (2003) performed hydration and dehydration experiments with polydisperse sub-micrometer OA aerosol particles at $283-293 \mathrm{~K}$ and reported that it was difficult but possible to generate anhydrous particles at $\mathrm{RH}<5 \%$. Upon hydration of anhydrous particles they observed a transition from anhydrous oxalic acid to oxalic acid dihydrate at $\sim 10$ $30 \% \mathrm{RH}$ and a deliquescence transition at $\sim 97-99 \%$. Upon dehydration efflorescence was not observed, and unfortunately experimental data for comparison with the dehydration curves observed in our experiments were not reported. Braban et al. (2003) did not specify how and how often the difficulties in generating anhydrous particles could be overcome, but we hypothesize that the formation of anhydrous crystalline particles occurred preferentially in the larger particles of the investigated polydisperse aerosol and that it was limited by crystal nucleation kinetics and statistics, respectively. The size distribution of the investigated aerosol was not characterized, but a reference to Cziczo et al. (1997) indicates a lognormal distribution with a count median or geometric mean diameter of about $0.45 \mu \mathrm{m}$. The geometric standard deviation was not reported, but most likely micrometersized particles dominated the surface and mass size distributions of the aerosol and thus also the optical properties measured in the AFT-FTIR experiment. The strong particle size dependence of crystallization kinetics and statistics (Onasch et al., 1999; Pruppacher and Klett, 2000; Koop et al., 1997) can explain why the formation of anhydrous crystalline oxalic acid may have been observed by Peng et al. (2001) and Braban et al. (2003) working with micrometer-sized particles but not in the experiments of by Prenni et al. (2001) and in the present study dealing with particles $\leq 100 \mathrm{~nm}$. Moreover, it seems that some of the observations of Peng et al. (2001) and Braban et al. (2003) could also be explained by the formation of (amorphous) oxalic acid hydrate particles instead of (crystalline) anhydrous oxalic acid particles.

Unexpected water uptake has also been reported for other dicarboxylic acids. For malonic acid with crystalline bulk deliquescence at $\sim 72 \% \mathrm{RH}$, Braban et al. (2003) observed deliquescence and efflorescence transitions at $\sim 10 \%$ RH. For maleic acid aerosol particles (crystalline bulk deliquescence at $\sim 89 \% \mathrm{RH}$ ), Brooks et al. (2003) reported substantial water uptake at $\sim 20 \% \mathrm{RH}$ and attributed it to surface adsorption. We suggest that in both cases moisture induced glass transitions and/or gel-like swelling of (semi-)solid amorphous particles may have occurred.

\subsection{Levoglucosan}

\subsubsection{Phase transitions and hygroscopic growth}

Figure 4e shows the mobility equivalent growth factors observed upon hydration and dehydration of levoglucosan (LG) aerosol particles. Upon hydration, we measured a small gradual increase of mobility diameter over the range of $\sim 10-30 \%$ that may be explained by surface adsorption and minor bulk absorption of water vapor into compact spherical particles as discussed below. At $\sim 30 \% \mathrm{RH}$, we observed a steep increase in the slope of the growth curve (Figs. 4e, 5e, 5f) and broadening of the particle size distribution (Fig. 4f) that continued up to $\sim 60 \% \mathrm{RH}$ and indicate a kinetically limited deliquescence transition. Above $\sim 60 \% \mathrm{RH}$, the good agreement of the hydration and dehydration curves for both $g_{\mathrm{b}}$ and $\sigma_{\mathrm{g}}$ indicates that the particles were fully deliquesced. The deliquescence RH range of 30-60\% was much lower than the saturation relative humidity of the crystalline LG bulk sample $\left(\mathrm{RH}_{\mathrm{s}, \mathrm{b}}=81.9 \%\right.$, Table 2$)$, which confirms the amorphous nature of the investigated LG aerosol particles.

As detailed below, the kinetically limited deliquescence transition can be explained by a gradual transformation of the amorphous LG particles from a glassy or semi-solid (rubbery or ultra-viscous) state into a highly viscous or gel-like matrix that absorbs water vapor at rates limited by diffusion or structural rearrangements (swelling). When the water content of the particles exceeded a volume fraction of $\sim 20 \%$ (corresponding to $g_{\mathrm{b}}=1.12$ at $\sim 60 \% \mathrm{RH}$ ), the viscous (or gel-like) organic matrix apparently became so dilute (or fully dissolved), that it ceased to inhibit the reversible hygroscopic growth that is characteristic for liquid aqueous solution droplets.

Upon dehydration, the mobility diameters observed at $\mathrm{RH}<60 \%$ were substantially higher than upon hydration, which can be attributed to the persistence of highly viscous aqueous droplets due to kinetic limitations of evaporation and efflorescence. At $\sim 15 \% \mathrm{RH}$ the particle diameter observed in the dehydration experiment remained $\sim 4 \%$ larger than in the hydration and h\&d experiments. This can be explained by the different drying conditions in the SDD prior to size selection with DMA1 (drying over $\sim 30 \mathrm{~s}$ at $\mathrm{RH}<5 \%$ ) and upon dehydration and sizing in DMA2 (RH conditioning and sizing over $\sim 7 \mathrm{~s}$ ). Apparently, the liquid water content of the aqueous LG droplets did not immediately evaporate upon mixing with the dry sheath flow in DMA2 as it is usually 
observed in experiments with aqueous solution droplets of inorganic salts (see AS particles above and Mikhailov et al., 2004). Instead, the particles retained residual water throughout the drying and sizing process in DMA2 (volume fraction $\sim 12 \%$ at $\sim 15 \% \mathrm{RH}$ ), which is confirmed by the stable value of $\sigma_{\mathrm{g}}$ and by the results of h\&d experiments (Fig. 5e: gradual increase of $D_{\mathrm{b}, \mathrm{h} \& \mathrm{~d}}$ with RH from $D_{\mathrm{b}, \mathrm{h} \& \mathrm{~d}, \min }=D_{\mathrm{b}, \mathrm{h}, \text { min }}$ to $\left.D_{\mathrm{b}, \mathrm{h} \& \mathrm{~d}, \max }=D_{\mathrm{b}, \mathrm{d}, \min }=1.04 D_{\mathrm{b}, \mathrm{h} \& \mathrm{~d}, \min }\right)$.

The inhibition of efflorescence observed upon dehydration of LG particles is consistent with the kinetic limitation of deliquescence observed upon hydration. As detailed below, it can be explained by the formation of a gel or of a semi-solid shell (glassy, rubbery or ultra-viscous) with low molecular diffusivity. Kinetic limitations of water absorption/desorption and inhibition of related phase transitions (moisture-induced glass transition, crystallisation) have also been reported for amorphous lactose particles and other amorphous organic particles generated by spray-drying (Burnett et al., 2004; Wang and Langrish, 2007; Price and Young, 2003).

\subsubsection{Microstructure, surface and bulk uptake, kinetic limitations}

The amorphous LG particles exhibited no shrinking upon hydration, i.e., in none of the H-TDMA modes did the mobility diameter decrease with increasing RH. Apparently, the amorphous LG particles formed upon nebulization and thorough drying were perfectly compact spheres $\left(D_{\mathrm{b} . \mathrm{i}}=\right.$ $D_{\text {b.h.min }}=D_{\text {b.h\&d.min }}$; Table 2). This is unlike the amorphous OA particles investigated in this study but consistent with the behavior of amorphous protein particles reported by Mikhailov et al. (2004).

Figure $5 \mathrm{e}$ and $\mathrm{f}$ shows the difference between the mobility diameters observed in hydration experiments and h\&d experiments with LG particles and the corresponding monolayer numbers $\left(N_{\mathrm{ML}}\right)$. Up to $30 \% \mathrm{RH}, N_{\mathrm{ML}}$ increased gradually to $\sim 3 \mathrm{ML}$, which can be explained by surface adsorption and/or minor bulk absorption onto and/or into compact glassy or semi-solid LG particles. At $\sim 30 \% \mathrm{RH}$, the slope of the growth curve increased by a factor of $\sim 5$ (from $\sim 0.1 \mathrm{ML}$ per $\% \mathrm{RH}$ to $\sim 0.5 \mathrm{ML}$ per $\% \mathrm{RH}$ ), which indicates a gel-like swelling that may have been triggered by a moisture-induced glass transition and accelerated water absorption into the resulting ultra-viscous or rubbery amorphous phase.

According to Zobrist et al. (2008, Fig. A1), moisture induced glass transitions of LG may indeed occur at the temperature level of our experiments ( $298 \mathrm{~K})$. Their best estimate for the glass temperature of pure LG is, however, somewhat lower $(\sim 280 \mathrm{~K})$, and thus the investigated LG particles may have been in a semi-solid rather than glassy amorphous state already before they were humidified.

In any case, the additional steps/wiggles in the growth curve (40-50\% RH, Figs. $4 \mathrm{e}$ and 5f) and the persistent broadening of the particle size distributions (up to $\sim 60 \% \mathrm{RH}$,
Fig. 4f) suggest that the formation and transformation of gel-like structures or non-uniform concentration gradients (e.g., semi-solid shells) played a role in the kinetically limited deliquescence transition. Gelation and/or the formation of a semi-solid shell with low molecular diffusivity can also plausibly explain the inhibition of evaporation and efflorescence, i.e., the retention of absorbed water upon dehydration (Fig. 4e).

As mentioned above, it has long been known in food and materials science that carbohydrates and other organic compounds can form glasses, rubbers, gels and ultra-viscous liquids with low molecular diffusivity (Slade and and Levine, 1991; Keller, 1995; Farhat et al., 1997; Ray et al., 1998; Sangeetha and Maitra, 2005; Sperling, 2006; Laurence, 2006). Good examples for comparison with the sugar anhydride levoglucosan are sugars like glucose, lactose, sucrose and other mono- or disaccharides (Bhandari and Howes, 1999; Burnett et al., 2004; Zobrist et al., 2008).

Further investigations will be required to explore under which conditions glassy, rubbery or gel-like structures may be important for the composition, transformation and environmental effects of atmospheric aerosols. Nevertheless, our results show that they can indeed kinetically limit the uptake as well as the release of water by organic aerosol particles on (multi-)second time scales and may thus influence the hygroscopic growth and possibly also the activation of aerosol particles as cloud condensation nuclei $(\mathrm{CCN})$ or ice nuclei (IN) under lower tropospheric conditions. Another implication is that (semi-)solid phases may inhibit or retard chemical reactions like hydrolysis, oligomerisation or oxidation and thereby increase the chemical lifetime of LG in the atmosphere, which is important for its applicability as a biomass burning tracer (Fraser and Lakshmanan, 2000; Holmes and Petrucci, 2007).

\subsubsection{Related earlier studies}

The hygroscopic properties of levoglucosan particles have been investigated in several earlier studies with H-TDMA (Mochida and Kawamura, 2004; Koehler et al., 2006; Svenningsson et al., 2006) and electrodynamic balance methods (Chan et al., 2005). Mochida and Kawamura (2004) and Chan et al. (2005) performed hydration and dehydration experiments, while Koehler et al. (2006) and Svenningsson et al. (2006) performed only hydration experiments. None of these studies reported phase transitions, and Mochida and Kawamura (2004) and Chan et al. (2005) found no differences between hydration and dehydration. Thus all studies concluded that the investigated particles were not completely dry, which is consistent with our observation that LG particles retain absorbed water upon gentle drying $(\sim 7 \mathrm{~s}$ at $\mathrm{RH} \geq 14 \%)$ and release all water only upon intense drying $(\sim 30 \mathrm{~s}$ at $\mathrm{RH}<5 \%)$. For comparison with literature data we have also calculated growth factors referring to the minimum diameter observed in our dehydration 
experiments $\left(D_{\mathrm{b}, \mathrm{de}, \min }=103.8 \mathrm{~nm}\right.$, Table 2$)$, and these were in good agreement with the results of Mochida and Kawamura (2004) and within the range of experimental uncertainties of the other studies. Thus, it seems that the volume fraction of residual water in the LG particles investigated in earlier studies was similar to the residual volume fraction of water observed in our dehydration experiments $(\sim 10 \%)$. Since our study appears to be the first one in which the mass equivalent diameter of the investigated LG particles is well known, we recommend using these data and the Köhler model parameters presented in Appendix B (Sect. B3) to describe the hygroscopic properties of pure levoglucosan.

\section{Summary and conclusions}

In this study we have presented a conceptual framework and investigated the interaction of amorphous and crystalline aerosol particles with water vapor by H-TDMA experiments and Köhler model calculations.

With regard to the generation of crystalline ammonium sulfate particles by spray-drying, we found that the apparent void volume fractions indicating deviations from compact spherical shape decreased with increasing residual $\mathrm{RH}$ (from $\sim 4 \%$ at $\mathrm{RH}<5 \%$ to $\sim 1 \%$ at $\mathrm{RH} \approx 15 \%$ ). Based on cyclic hydration\&dehydration (h\&d) experiments, we could measure $\sim 2$ monomolecular layers of water adsorbed at the surface of ammonium sulfate crystals in the RH range of 50$70 \%$.

The spray-drying of aqueous oxalic acid yielded amorphous solid particles with a highly porous structure (xerogel with apparent void volume fraction of $\sim 40 \%$ ) composed of oxalic acid dihydrate (or a non-stoichiometric hydrate with about 2 water molecules per oxalic acid molecule). Upon hydration the particles underwent massive restructuring and compaction, and substantial bulk absorption of water began at $\sim 40 \% \mathrm{RH}$, which is well below the threshold of crystalline bulk deliquescence ( $\sim 97 \% \mathrm{RH})$. These observations imply that the particles were neither crystals nor liquid droplets but amorphous solids. In the range of $40-80 \% \mathrm{RH}$ we observed gradual deliquescence and efflorescence transitions. Differences between the growth factors and geometric standard deviations observed upon hydration and dehydration can be plausibly explained by the formation of gel-like structures (supramolecular networks). Especially the stepwise diameter changes and broadenings of the particle size distributions in the range of $40-50 \% \mathrm{RH}$ appear to be indicative of transitions between swollen and collapsed network structures. Fully deliquesced liquid droplets were formed only at $\mathrm{RH}>80 \%$ where the volume fraction of absorbed water exceeded $\sim 50 \%$.

Unlike the electrolytes ammonium sulfate and oxalic acid, the non-electrolyte levoglucosan formed compact spherical particles upon spray-drying. Upon hydration, substantial bulk absorption of water began at $\sim 30 \% \mathrm{RH}$, which is also well below the threshold of crystalline bulk deliquescence $(82 \% \mathrm{RH})$ and proves that the particles were not crystalline. Over the range of 30-60\% RH, stepwise diameter changes and a broadening of the particle size distribution indicated kinetic limitations of the gradual deliquescence transition, which can be plausibly explained by an ultra-viscous or gellike organic matrix with low molecular diffusivity. Fully deliquesced liquid droplets were formed at $\mathrm{RH}>60 \%$ when the volume fraction of absorbed water exceeded $\sim 30 \%$. Upon dehydration, efflorescence appeared to be inhibited by gellike structures or a semi-solid shell (glassy, rubbery or ultraviscous), and at low RH $(<20 \%)$ the particles firmly retained substantial amounts of absorbed water (volume fractions $>10 \%$ ).

Based on these findings and on the results of related studies as referenced and discussed, we come to the following general conclusions and implications:

1. Many organic substances (incl. carboxylic acids, carbohydrates and proteins) tend to form amorphous rather than crystalline phases upon drying of aqueous solution droplets, which can be explained by the low rates of nucleation and crystallization that are characteristic for most organic substances. Compared to pure substances, the multi-component mixtures typically present in atmospheric aerosols are even more likely to form amorphous rather than crystalline phases (Marcolli et al., 2004; Cappa et al., 2008), and besides drying also cooling can lead to the formation of amorphous organic solids in the atmosphere (Murray, 2008; Zobrist et al., 2008). Due to the low degree of structural order, amorphous organic substances appear less likely than their crystalline counterparts to induce ice nucleation, which may be particularly relevant for oxalic acid (Zobrist et al., 2006).

2. Amorphous organic substances tend to absorb water vapor and undergo gradual deliquescence and hygroscopic growth at much lower relative humidity than their crystalline counterparts, which supports earlier suggestions that organic aerosol particles are likely to be in a liquid state under most atmospheric conditions (Bertram et al., 2005; Martin et al., 2004; Marcolli et al. 2004). Again, the multi-component mixtures typically present in atmospheric aerosols are even more likely to remain in aqueous solution than the pure substances investigated in this study (Marcolli et al., 2004).

The results of this and related studies suggest that the deliquescence (liquefaction) of amorphous organic solids at $\sim 298 \mathrm{~K}$ effectively begins when the amount of absorbed water reaches $10-20 \%$ of the solid/dry particle volume ( $g_{\mathrm{b}} \approx 1.03-1.07$, gel-like swelling) and is completed when the amount of absorbed water is in the range of $30-50 \%$ of the of the solid/dry particle volume ( $g_{\mathrm{b}} \approx 1.1-1.2$, complete dissolution). Reversely, 
the efflorescence (solidification) of amorphous organic solids appears to begin when the volume fraction of water decreases into the range of 50-30\% (formation of gel-like structures or semi-solid shells with low molecular diffusivity) and may be completed when the volume fraction of water drops below $\sim 10 \%$ (formation of xerogels, rubbers, or glasses).

For most organics, including carboxylic acids, carbohydrates and protein macromolecules, the RH threshold for the onset of gel-like swelling and deliquescence appears to be in the range of $30-40 \% \mathrm{RH}$. The RH threshold for complete dissolution appears to vary over a broader range of $\sim 60 \%$ for compounds with relatively high solubility and hygroscopicity such as levoglucosan, to $\sim 80 \%$ for compounds with lower solubility and/or stronger hydrogen bonding, and $\sim 90 \%$ for compounds with low hygroscopicity such as protein macromolecules.

3. In the course of hydration and dehydration, certain organic substances can form rubber- or gel-like structures (supramolecular networks) and undergo stepwise transitions between swollen and collapsed network structures. Gel-like structures are most likely to be formed at intermediate relative humidities around $\sim 50 \%$. They may not only influence and introduce steps in the gradual deliquescence and efflorescence of amorphous particles, but they may also play a role in the crystallization of organic substances from aqueous solution droplets (Peng et al., 2001).

4. Organic gels or (semi-)solid amorphous shells with low molecular diffusivity can kinetically limit the uptake and release of water by submicron aerosol particles on (multi-)second time scales, which may influence the hygroscopic growth and activation of aerosol particles as cloud condensation nuclei (CCN) and ice nuclei (IN) in field and laboratory measurements as well as in the atmosphere. Murray (2008) and Zobrist et al. (2008) have already pointed out that glassy solids formed upon cooling of aqueous organic substances may impede water uptake, nucleation and growth of ice as well as heterogeneous chemical reactions in organic-enriched aerosols at upper tropospheric temperatures. We suggest that amorphous organic substances (glasses, rubbers and gels) may influence and kinetically inhibit these and other multiphase processes in aerosol and clouds also at the temperatures and relative humidities of the lower troposphere and atmospheric boundary layer. The influence of mass transport kinetics on CCN activation is presently not well understood (Asa-Awuku and Nenes, 2007; Engelhart et al., 2008; Ruehl et al., 2008; Asa-Awuku et al., 2009; Pöschl et al., 2009). With regard to unraveling the molecular mechanisms and kinetics of water uptake/evaporation and deliquescence/efflorescence of both amorphous and crystalline particles, we suggest that a clear distinction between surface and bulk processes is important and that relevant information can be obtained by highprecision H-TDMA measurements (including h\&d experiments). Besides water uptake, low molecular diffusivity in (semi-)solid amorphous phases may also retard the uptake of gaseous photo-oxidants and the chemical transformation of aerosol particles and components (Smith et al., 2003; Katrib et al., 2005; Pöschl, 2005; Ammann and Pöschl, 2007; Pöschl et al., 2007; McNeill et al., 2008; Griffiths et al., 2009; Hallquist et al., 2009; Pfrang et al., 2009; Shiraiwa et al., 2009).

5. The shape and porosity of amorphous and crystalline particles formed upon dehydration of aqueous solution droplets depend on chemical composition and drying conditions, including the electrolytic properties of the solutes and electric charging of the particles. At least under laboratory conditions, the apparent volume void fractions of spray-dried aerosol particles can reach up to $\sim 50 \%$ (Mikhailov et al., 2004; and this study), which is characteristic for xerogels. With other techniques of aerosol generation, the apparent particle void fractions may reach up to $\sim 90 \%$ (Krämer et al., 2000), which is characteristic for aerogels (Kistler, 1935).

Void fractions as well as residual water in dried aerosol particles that are not water-free (due to kinetic limitations of drying or stable hydrate formation) should be taken into account in Köhler model calculations of hygroscopic growth and $\mathrm{CCN}$ activation. Inaccuracies in the determination of the mass equivalent diameters, residual water and solute amount of substance can easily exceed the uncertainties and deviations caused by solution non-ideality and different modeling approaches (approximations and parameterizations of water activity, etc.; Mikhailov et al., 2004; Rose et al., 2008). For example, the higher effective hygroscopicity parameters and van't Hoff factors of levoglucosan in dilute aqueous solution determined in this study $(\kappa \approx 0.23$, $\left.i_{\mathrm{S}} \approx 1.3\right)$ compared to earlier studies $(\kappa \approx 0.17-0.21$, $i_{\mathrm{s}} \approx 1.0-1.2$ ) are likely due to more complete drying of the investigated aerosol particles. On the other hand, the conversion of effective hygroscopicity parameters into van't Hoff factors can provide information on the most plausible hydration state of spray-dried aerosol particles ("dry" OA particles composed of oxalic acid dihydrate with $\kappa \geq 0.23$ and $i_{\mathrm{s}} \geq 1.0$ ).

6. For efficient description of water uptake and phase transitions of amorphous and crystalline organic and inorganic aerosol particles and particle components, we propose not to limit the terms deliquescence and efflorescence to equilibrium phase transitions of crystalline substances interacting with water vapor. Instead 
we propose the following generalized definitions: Deliquescence is the transformation of a (semi-)solid substance into a liquid aqueous solution, whereby water is absorbed from the gas phase ("liquefaction upon humidification/hydration"). Efflorescence is the transformation of a substance from a liquid aqueous solution into a (semi-)solid phase, whereby water is evaporated ("solidification upon drying/dehydration"). According to these definitions, individual components as well as entire aerosol particles can undergo gradual or prompt, partial or full deliquescence or efflorescence, which is indeed the case not only for amorphous organic substances but also for mixtures of crystalline inorganic substances.

Complementary experiments with internally mixed ASLG-OA particles suggest that the above conclusions and implications are relevant also for aerosols composed of mixed organic, inorganic, amorphous and crystalline substances (Mikhailov et al., 2010).

Other recent studies have suggested that solid amorphous phases (glasses) may be important for aerosol-water interactions at low temperatures in the upper atmosphere. We suggest that (semi-)solid amorphous phases (glasses, rubbers, gels, ultra-viscous liquids) and moisture-induced glass transitions may be important also at ambient temperatures in the lower atmosphere. They might play a role in the kinetics of CCN and IN activation, thus influencing the formation and properties of clouds and precipitation. Moreover, they might influence the uptake of gaseous photo-oxidants and the chemical aging of atmospheric aerosols.

\section{Appendix A}

\section{Köhler theory and models}

\section{A1 Full Köhler model}

According to Köhler theory, the relation between relative humidity and the size and composition of a spherical droplet formed on a soluble particle is given by (Pruppacher and Klett, 2000; Seinfeld and Pandis, 2006):

$s_{\mathrm{w}}=\frac{\mathrm{RH}}{100 \%}=a_{\mathrm{w}} \exp \left(\frac{4 \sigma \bar{V}_{\mathrm{w}}}{R T D_{\mathrm{m}}}\right)$,

where $s_{\mathrm{W}}$ is the water vapor saturation ratio or fractional relative humidity (RH/100\%). In the Kelvin term $\sigma$ is the surface tension of the solution droplet, $\bar{V}_{\mathrm{w}}$ is the partial molar volume of water in solution, $R$ is the ideal gas constant, $T$ is the droplet temperature and $D_{\mathrm{m}}$ is the droplet diameter (geometric diameter $=$ mass equivalent diameter for compact spherical particle).
The partial molar volume of water in the droplet solution can be expressed by (Brechtel and Kreidenweis, 2000)

$\bar{V}_{\mathrm{w}}=\frac{M_{\mathrm{w}}}{\rho}\left(1+\frac{x_{\mathrm{s}}}{\rho} \frac{d \rho}{d x_{\mathrm{s}}}\right)$,

where $\rho$ is the density of the solution, $\rho_{\mathrm{S}}$ is the density of the solute, and $x_{\mathrm{s}}$ is the mass fraction of solute in the droplet. The differential quotient $d \rho / d x_{\mathrm{s}}$ reflects the influence of molecular interactions that change with changing solute mass fraction.

For aqueous solutions of ammonium sulfate and other atmospherically relevant salts, Tang and Munkelwitz (1994) and Tang (1996) have presented parameterizations of $\rho$ as a function of $x_{\mathrm{s}}$, and $d \rho / d x_{\mathrm{s}}$ can be derived accordingly:

$\rho=\rho_{\mathrm{w}}+\left[\sum_{q} A_{q}\left(100 x_{\mathrm{s}}\right)^{q}\right] \cdot 10^{3} \mathrm{kgm}^{-3}$,

$\frac{d \rho}{d x_{\mathrm{s}}}=\left[\sum_{q} A_{q} q\left(100 x_{s}\right)^{q-1}\right] \cdot 10^{3} \mathrm{kgm}^{-3}$,

For ammonium sulfate the polynomial coefficients are (Tang and Munkelwitz, 1994): $A_{1}=5.92 \times 10^{-3}$; $A_{2}=-5.036 \times 10^{-6} ; A_{3}=1.024 \times 10^{-8}$.

The surface tension of the aqueous solution can be calculated based on a relationship proposed by Hänel (1976):

$\sigma=\sigma_{0}+\sigma_{T} \cdot\left(T_{0}-T\right)+\sigma_{\mu} \cdot \mu_{\mathrm{s}}$,

where $\sigma_{0}=0.0756 \mathrm{~N} \mathrm{~m}^{-1}$ is the surface tension of pure water at $T_{0}=273.15 \mathrm{~K}$, the coefficient $\sigma_{T}=1.53 \times 10^{-4} \mathrm{~N} \mathrm{~m}^{-1} \mathrm{~K}^{-1}$ accounts for the influence of temperature, and the coefficient $\sigma_{\mu}=2.17 \times 10^{-3} \mathrm{~N} \mathrm{~m}^{-1} \mathrm{~kg} \mathrm{~mol}^{-1}$ (for ammonium sulfate) accounts for the influence of droplet composition (solute molality, $\mu_{\mathrm{s}}$ ). Solute molality, $\mu_{\mathrm{s}}$, mass fraction, $x_{\mathrm{s}}$, and molar mass, $M_{\mathrm{s}}$ are related by:

$\mu_{\mathrm{s}}=\frac{x_{\mathrm{s}}}{M_{\mathrm{s}}\left(1-x_{\mathrm{s}}\right)}$

The ratio of the aqueous droplet diameter, $D_{\mathrm{m}}$, to the mass equivalent diameter of a particle consisting of the dry solute, $D_{\mathrm{m} . s}$, is defined as the mass equivalent growth factor, $g_{\mathrm{m}}$ :

$g_{\mathrm{m}}=\frac{D_{\mathrm{m}}}{D_{\mathrm{m} . \mathrm{s}}}=\left(\frac{\rho_{\mathrm{s}}}{x_{\mathrm{s}} \rho}\right)^{1 / 3}$

Equations (A1-A7) can be used to model the hygroscopic growth of aerosol particles, i.e., to calculate $g_{\mathrm{m}}$ and $D_{\mathrm{m}}$, respectively, as a function of $D_{\mathrm{m} . \mathrm{s}}$ and RH.

For efficient comparison and clear distinction against other Köhler modeling approaches, we designate the combination of Eq. (A1) with parameterizations of all relevant quantities $\left(a_{\mathrm{w}}, \sigma, \bar{V}_{\mathrm{w}}, \rho\right.$, etc. $)$ as a "full Köhler model". In the present study, we apply a full Köhler model only for ammonium sulfate particles, using the parameterizations given above for $\rho$ and $\sigma$ and water activity from the Aerosol Inorganics Model 
(AIM Clegg et al., 1998a, b), which is a semi-empirical ion interaction model (Pitzer, 1973, 1991; Pitzer and Mayorga, 1973).

In the full Köhler model calculations, $a_{\mathrm{w}}$ was taken as the primary variable and the corresponding solute molality $\mu_{\mathrm{S}}$ was obtained by interpolation of tabulated AIM data (Sect. A3.1). $\sigma$ and $x_{\mathrm{S}}$ were calculated from Eq. (A5) and Eq. (A6), respectively; $\bar{V}_{\mathrm{w}}$ was calculated from Eq. (A2) with $\rho$ from Eq. (A3) and $d \rho / d x_{\mathrm{s}}$ from Eq. (A4). $g_{\mathrm{m}}$ and $D_{\mathrm{m}}$ were calculated with Eq. (A7) assuming $D_{\mathrm{m}}=D_{\text {b.h\&d.min }}=95.7 \mathrm{~nm}$ (Table 2). Finally, $a_{\mathrm{w}}, \sigma, \bar{V}_{\mathrm{w}}$, and $D_{\mathrm{m}}$ were inserted in Eq. (A1) to obtain the RH values corresponding to $D_{\mathrm{m}}$ and $g_{\mathrm{m}}$, respectively.

\section{A2 Volume-additivity Köhler models}

Under the assumption that the volume of the solution droplet is given by the sum of the volumes of the dry solute and of the pure water contained in the droplet ("volume-additivity", VA), the mass equivalent growth factor is given by (Brechtel and Kreidenweis, 2000; Mikhailov et al., 2004):

$g_{\mathrm{m}}=\left(\frac{\rho_{\mathrm{s}}}{\mu_{\mathrm{s}} M_{\mathrm{s}} \rho_{\mathrm{w}}}+1\right)^{1 / 3}$,

where $\rho_{\mathrm{w}}$ is the density of the water.

The VA assumption implies that the density of the droplet is a linear combination of the densities of the dry solute and of pure water, and that the partial molar volumes of water and of the solute in solution are equal to the molar volumes of pure water and pure solute, respectively: $\bar{V}_{\mathrm{w}}=$ $V_{\mathrm{w}}=\rho_{\mathrm{w}} / M_{\mathrm{w}}$ and $\bar{V}_{\mathrm{s}}=V_{\mathrm{s}}=\rho_{\mathrm{s}} / M_{\mathrm{s}}$. Accordingly the full Köhler equation (A1) can be reduced to the following simplified form ("VA Köhler equation"):

$\frac{\mathrm{RH}}{100 \%}=a_{\mathrm{w}} \exp \left(\frac{4 \sigma \rho_{\mathrm{w}}}{M_{\mathrm{w}} R T g_{\mathrm{m}} D_{\mathrm{m} . \mathrm{s}}}\right)$

Moreover, the VA assumption implies that the mole fraction of water in the droplet $\left(X_{\mathrm{w}}\right)$ is given by:

$X_{\mathrm{w}}=\frac{n_{\mathrm{w}}}{n_{\mathrm{w}}+n_{\mathrm{s}}}=\frac{g_{\mathrm{m}}^{3}-1}{\left(g_{\mathrm{m}}^{3}-1\right)+\frac{M_{\mathrm{w}}}{\rho_{\mathrm{w}}} \frac{\rho_{\mathrm{s}}}{M_{\mathrm{s}}}}$,

where $n_{\mathrm{w}}$ and $n_{\mathrm{s}}$ are the mole numbers (amount-ofsubstance) of water and solid in the droplet, respectively.

For the VA Köhler model calculations presented in this study, we assumed that the mass equivalent diameter of the dry solute particle equals minimum mobility equivalent diameter measured in the $\mathrm{h} \& \mathrm{~d}$ experiments $\left(D_{\mathrm{m}, \mathrm{s}}=D_{\mathrm{b}, \mathrm{h} \& \mathrm{~d}, \mathrm{~min}}\right) . \quad g_{\mathrm{m}}$ was taken as the primary variable, different formalisms detailed below were used to calculate the corresponding value of $a_{\mathrm{w}}$, and RH was calculated by inserting $g_{\mathrm{m}}$ and $a_{\mathrm{w}}$ in Eq. (A9). In the VA model calculations we assumed that surface tension of the solution droplet equals the surface tension of pure water $(\sigma=$ $\sigma_{\mathrm{w}}=0.072 \mathrm{~N} \mathrm{~m}^{-1}$ at $298 \mathrm{~K}$ ). According to the available data, this should be a good approximation not only for AS but also for OA and LG as detailed by Koehler et al. (2006).

Depending on the applied models, approximations and parameterizations for $a_{\mathrm{w}}$, we distinguish three types of VA Köhler models that have been used to simulate the hygroscopic growth of the investigated particles and to determine characteristic parameters, respectively. The different approaches of describing water activity are detailed in the following sections: AIM (Sect. A3.1), ideal solution (Sect. A3.2), UNIFAC (Sect. A3.3), and Flory-Huggins (Sect. A3.4).

\section{A3 Water activity representations}

\section{A3.1 Ion interaction model (AIM)}

For aqueous ammonium sulfate particles the relation between $a_{\mathrm{w}}$ and $\mu_{\mathrm{s}}$ was calculated with a semi-empirical ion interaction model (Pitzer, 1973; Pitzer and Mayorga, 1973; Pitzer, 1991). We ran the Aerosol Inorganics Model (AIM; Clegg et al., 1998a, b; http://www.aim.env.uea.ac.uk/aim/ aim.html; Model II) for (NH4) ${ }_{2} \mathrm{SO}_{4}$ at $298.15 \mathrm{~K}$, and we obtained a table of $a_{\mathrm{w}}$ vs. $\mu_{\mathrm{s}}$ covering the range of $a_{\mathrm{w}}=0.3-$ 0.97 and $\mu_{\mathrm{s}}=0.8-40 \mathrm{~mol} \mathrm{~kg}^{-1}$, respectively (23 data points, four significant digits). For model calculations bridging the gap from H-TDMA to CCN measurement data, i.e., at $a_{\mathrm{w}} \geq 0.97$, we used the approach and supplementary data of Rose et al. (2008). Upon plotting and further analysis, the calculated growth curves were interpolated with a polynomial fit (B-spline, Origin 7.5 software). Note that according to Clegg and Wexler (2007) and Rose et al. (2008), the AIM can be regarded as an accurate reference standard for the activity of water in dilute aqueous solutions of ammonium sulfate.

\section{A3.2 Ideal solution model}

In an ideal solution, the activity of water is given by its mole fraction (Raoult's law):

$a_{\mathrm{w}}=X_{\mathrm{w}}$.

In the ideal solution model calculations for aqueous levoglucosan and oxalic acid particles we have thus calculated $a_{\mathrm{w}}$ from Eqs. (A10) and (A11). For oxalic acid, different potential hydration states of the initial "dry" particles have been considered: anhydrous oxalic acid $\left((\mathrm{COOH})_{2}\right.$; $\left.M_{\mathrm{S}}=90.03 \mathrm{~g} \mathrm{~mol}^{-1} ; \quad \rho_{\mathrm{S}}=1.90 \mathrm{~g} \mathrm{~cm}^{-3}\right), \quad$ a monohydrate $\left((\mathrm{COOH})_{2} \cdot \mathrm{H}_{2} \mathrm{O} ; \quad M_{\mathrm{S}}=127.07 \mathrm{~g} \mathrm{~mol}^{-1} ; \quad \rho_{\mathrm{s}}=1.75 \mathrm{~g} \mathrm{~cm}^{-3}\right)$, the dihydrate $\left((\mathrm{COOH})_{2} \cdot 2 \mathrm{H}_{2} \mathrm{O} ; \quad M_{\mathrm{s}}=127.07 \mathrm{~g} \mathrm{~mol}^{-1}\right.$; $\left.\rho_{\mathrm{S}}=1.65 \mathrm{~g} \mathrm{~cm}^{-3}\right), \quad$ and a trihydrate $\left((\mathrm{COOH})_{2} \cdot 3 \mathrm{H}_{2} \mathrm{O}\right.$; $\left.M_{\mathrm{S}}=144.09 \mathrm{~g} \mathrm{~mol}^{-1} ; \rho_{\mathrm{S}}=1.56 \mathrm{~g} \mathrm{~cm}^{-3}\right)$. Note that monoor trihydrates are not known to be stable but were included to test a realistic range of non-stoichiometric compositions around the stable dihydrate. 
The densities of the hypothetical mono- and tri-hydrates were calculated assuming linear additivity of the densities of pure anhydrous oxalic acid and pure water $\left(\rho_{\mathrm{S}}=\right.$ $\left.\rho_{(\mathrm{COOH})_{2}} x_{(\mathrm{COOH})_{2}}+\rho_{\mathrm{H}_{2} \mathrm{O}} x_{\mathrm{H}_{2} \mathrm{O}}\right)$, where $x_{(\mathrm{COOH})_{2}}$ and $x_{\mathrm{H}_{2} \mathrm{O}}$ are the mass fractions of the two components. For oxalic acid dihydrate this approximation yields $1.64 \mathrm{~g} \mathrm{~cm}^{-3}$ which is close to literature value of $1.65 \mathrm{~g} \mathrm{~cm}^{-3}$ and confirms the applicability of the approach.

\section{A3.3 Activity coefficient model (UNIFAC)}

In a real solution, the activity of water can be described by

$a_{\mathrm{w}}=\gamma_{\mathrm{w}} X_{\mathrm{w}}$,

where $\gamma_{\mathrm{w}}$ is the mole fraction-based activity coefficient of water and accounts for non-ideal interactions in the mixture. The universal functional group activity coefficient model (UNIFAC, Fredenslund et al., 1975) was used to calculate $\gamma_{\mathrm{w}}$ as a function of $X_{\mathrm{w}}$ as described in earlier studies (Barton, 1991; Ming and Russell, 2002; Marcolli, 2004). Group interaction parameters for oxalic acid and levoglucosan were taken from Raatikainen and Laaksonen (2005) and Hansen et al. (1991), respectively, and group volume and surface area parameters $\left(R_{k}, Q_{k}\right)$ were based on Bondi (1968). In the model calculations, $g_{\mathrm{m}}$ was taken as the primary variable to calculate $X_{\mathrm{w}}$ from Eq. (A10), the corresponding value of $\gamma_{\mathrm{w}}$ was determined with UNIFAC, and $a_{\mathrm{w}}$ and RH were calculated with Eqs. (A12) and (A9), respectively.

\section{A3.4 Flory-Huggins model}

According to Flory (1953), the activity of water in aqueous solutions of organic substances can be described by

$\ln a_{\mathrm{w}}=\ln \left(1-\phi_{\mathrm{s}}\right)+\left(1-\frac{1}{f}\right) \phi_{\mathrm{s}}+\chi \phi_{\mathrm{s}}^{2}$,

where $\phi_{\mathrm{s}}$ is the volume fraction of the organic solute, $f$ is the ratio of the molecular volumes of solute and solvent, and $\chi$ is the Flory-Huggins (FH) solute-solvent interaction parameter. Earlier studies have shown that the FH approach is suitable to describe the absorption of water by polymerized organic aerosol particles (Petters et al., 2006) and by water-miscible organic solids that are in a rubbery state (Hancock and Zografi, 1993; Zhang and Zografi, 2000, 2001). For FH modeling, we assumed $\phi_{\mathrm{s}}=g_{\mathrm{m}}^{-3}$ and $f=\left(M_{\mathrm{S}} / \rho_{\mathrm{s}}\right) /\left(M_{\mathrm{W}} / \rho_{\mathrm{W}}\right)$ based on volume additivity, and we inserted $a_{\mathrm{w}}$ from Eq. (A13) in Eq. (A9). The resulting equation was fitted to the measured growth curves. We assumed $g_{\mathrm{b}}=g_{\mathrm{m}}\left(D_{\mathrm{m}, \mathrm{s}}=D_{\mathrm{b}, \mathrm{h} \& \mathrm{~d}, \mathrm{~min}}\right)$ and used the data points of coinciding hydration and dehydration curves $(\mathrm{RH} \geq 60 \%$ for $\mathrm{OA}$ and $\mathrm{LG}$ ) to obtain best-fit values of $\chi$ (non-linear least squares fitting, Origin 7.5 software).

\section{A3.5 Three-parameter fit}

As proposed by Kreidenweis et al. (2005), hygroscopic growth curves can be approximately described with a polynomial 3-parameter fit function of the following form:

$g_{\mathrm{m}}=\left(1+\left[k_{1}+k_{2} \cdot a_{\mathrm{w}}+k_{3} \cdot a_{\mathrm{w}}^{2}\right] \times \frac{a_{\mathrm{w}}}{1-a_{\mathrm{w}}}\right)^{1 / 3}$

To convert the measured RH-based growth curves ( $g_{\mathrm{b}}$ vs. $\mathrm{RH})$ into water activity-based growth curves ( $g_{\mathrm{b}}$ vs. $\left.a_{\mathrm{w}}\right)$, we assumed $g_{\mathrm{b}}=g_{\mathrm{m}}$ and divided the RH values through the exponential term (Kelvin term) on the right hand side of Eq. (A9). The activity-based growth curves were then fitted with Eq. (A14) to determine best-fit values of the parameters $k_{1}, k_{2}$ and $k_{3}$ (non-linear least squares fitting, Origin 7.5 software). These best-fit parameters are listed in Table A1 and will be used in a companion paper (Mikhailov et al., 2010) and further follow-up studies describing the hygroscopic growth of aerosol particles consisting of internal mixtures of the investigated compounds. As detailed below, the parameters $k_{1}-k_{3}$ can also be used to describe the dependence of the effective hygroscopicity parameter $\kappa$ on $a_{\mathrm{w}}$, $\mathrm{RH}$ or solute concentration, respectively.

\section{A3.6 Effective hygroscopicity parameter $(\kappa)$ and van't Hoff factor $\left(i_{\mathrm{S}}\right)$}

As proposed by Petters and Kreidenweis (2007), the hygroscopic properties of aerosol particles can be approximately described by a single hygroscopicity parameter $\kappa$ :

$a_{\mathrm{w}}=\frac{D_{\mathrm{m}}^{3}-D_{\mathrm{m} . \mathrm{s}}^{3}}{D_{\mathrm{m}}^{3}-D_{\mathrm{m} . \mathrm{s}}^{3}(1-\kappa)}$.

Under the assumption of volume additivity, Eq. (A15) can be rewritten as:

$\kappa=\frac{\left(g_{\mathrm{m}}^{3}-1\right)\left(1-a_{\mathrm{w}}\right)}{a_{\mathrm{w}}}$.

or

$g_{\mathrm{m}}=\left(\kappa \frac{a_{\mathrm{w}}}{1-a_{\mathrm{w}}}+1\right)^{1 / 3}$

As described above, we have used Eq. (A9) to convert the measurement data points of $g_{\mathrm{b}}$ vs. RH into data pairs of $g_{\mathrm{b}}$ vs. $a_{\mathrm{w}}$, and from each of these data pairs we have calculated a $\kappa$ value using Eq. (A16) under the assumption $g_{\mathrm{b}}=g_{\mathrm{m}}$. According to Eqs. (A14) and (A17), the dependence of $\kappa$ on $a_{\mathrm{w}}$ can be described by:

$\kappa=k_{1}+k_{2} \cdot a_{\mathrm{w}}+k_{3} \cdot a_{\mathrm{w}}^{2}$

To obtain a single best-fit value approximating effective hygroscopicity over the investigated range of $a_{\mathrm{w}}$ and $\mathrm{RH}$, respectively, we have also fitted the activity-based growth 
Table A1. Parameters characterizing the hygroscopic growth of the investigated aerosol particles/substances: best-fit values $( \pm$ standard errors) for the three-parameter fit $\left(k_{1}, k_{2}, k_{3}\right.$; Eq. A14) and for the single-parameter fit ( $\kappa$, Eq. A17) to the water activity-based growth curves ( $g_{\mathrm{b}}$ vs. $a_{\mathrm{W}}$; Fig. A2). $i_{\mathrm{S}}$ is the van't Hoff factor corresponding to the best-fit value of $\kappa . n$ and $R^{2}$ are the number of data points and the correlation coefficients of the fits, respectively.

\begin{tabular}{|c|c|c|c|c|c|c|c|c|}
\hline Substance & $k_{1}$ & $k_{2}$ & $k_{3}$ & $R^{2}$ & $\kappa$ & $i_{\mathrm{S}}$ & $R^{2}$ & $n$ \\
\hline Amm & $1.2384 \pm 0.0971$ & $1.0377 \pm 0.2443$ & $0.2475 \pm 0.1536$ & 0.9987 & $0.510 \pm 0.007$ & 2.11 & 0.9827 & 40 \\
\hline Oxalic acid (OA, dihydrate) & $0.6185 \pm 0.1064$ & $-1.2315 \pm 0.2773$ & $0.9511 \pm 0.1784$ & 0.9952 & $0.233 \pm 0.003$ & 0.98 & 0.9758 & 54 \\
\hline Levoglucosan (LG) & $0.6208 \pm 0.2063$ & $-0.8205 \pm 0.5223$ & $0.4273 \pm 0.3260$ & 0.9943 & $0.231 \pm 0.003$ & 1.29 & 0.9896 & 27 \\
\hline
\end{tabular}

curves with Eq. (A17) (non-linear least squares fitting, Origin 7.5 software). The best-fit values of $\kappa$ as well as the coefficients $k_{1}-k_{3}$ are listed in Table A1 and will be used in a companion paper (Mikhailov et al., 2010) and further followup studies to describe the hygroscopic growth of aerosol particles consisting of internal mixtures of the investigated compounds.

As outlined above, the hygroscopicity of an aerosol particle defined as its ability to absorb water vapor depends on the influence of the particle material (solute) on the activity of water (Raoult effect) and on the partial molar volume of water and the surface tension of the aqueous droplet (Kelvin effect). As discussed by Pöschl et al. (2009), the effective hygroscopicity parameter $\kappa$ as defined and applied in the above Eqs. (A15-A17) describes the overall influence of chemical composition on the hygroscopicity of an aerosol particle: water activity, partial molar volume and surfactant effects, i.e., Raoult effect plus Kelvin effect. Assuming volume additivity and that the surface tension of the aqueous droplet equals the surface tension of pure water, the effective hygroscopicity parameter $\kappa$ can be interpreted as an effective Raoult parameter $\left(\kappa_{\mathrm{R}}\right)$, i.e., as an effective molar density of soluble molecules or ions in the dry particle material normalized by the molar density of water molecules in liquid water $\left(\rho_{\mathrm{W}} / M_{\mathrm{w}} \approx 55 \mathrm{~mol} \mathrm{~L}^{-1}\right.$, Rose et al., 2008; Gunthe et al., 2009; Pöschl et al., 2009):

$\kappa_{\mathrm{R}}=i_{\mathrm{s}} \frac{\rho_{\mathrm{s}} M_{\mathrm{w}}}{\rho_{\mathrm{w}} M_{\mathrm{s}}} \approx v_{\mathrm{s}} \Phi_{\mathrm{s}} \frac{\rho_{\mathrm{s}} M_{\mathrm{w}}}{\rho_{\mathrm{w}} M_{\mathrm{s}}}$

$i_{\mathrm{S}}$ is the van't Hoff factor and $\nu_{\mathrm{S}} \Phi_{\mathrm{S}}$ is the product of the stoichiometric dissociation number and the molal osmotic coefficient of the solute. In dilute solutions $i_{\mathrm{s}}$ equals $\nu_{\mathrm{s}} \Phi_{\mathrm{s}}$, in concentrated solutions $i_{\mathrm{s}}$ and $\nu_{\mathrm{s}} \Phi_{\mathrm{s}}$ can be related through a series expansion as detailed by Kreidenweis et al. (2005). Thus, effective hygroscopicity or Raoult parameters, respectively, can be converted into van't Hoff factors or osmotic coefficients, if the density and molar mass of the solute are known (Rose et al., 2008; Gunthe et al., 2009). For AS we have compared the $\kappa$ values derived from the $\mathrm{H}$ TDMA measurement data (Eq. A16) and the corresponding values of $i_{\mathrm{S}}$ (Eq. A19 with $\kappa=\kappa_{\mathrm{R}}$ ) to the $\kappa$ and $i_{\mathrm{S}}$ values that can be calculated from AIM reference data $\left(a_{\mathrm{w}}\right.$ vs. $\left.\mu_{\mathrm{s}}\right)$ based on the following relation and Eq. (A19) with $\kappa=\kappa_{R}$, respectively (Rose et al., 2008):

$i_{\mathrm{s}}=\left(\frac{1}{a_{\mathrm{w}}}-1\right)\left(\mu_{\mathrm{s}} M_{\mathrm{w}}\right)^{-1}$

\section{Appendix B}

\section{Köhler model results}

\section{B1 Ammonium sulfate}

In Fig. A1a the mobility equivalent growth factors observed for deliquesced ammonium sulfate particles are compared with the mass equivalent growth factors calculated with a full Köhler model (Sect. A1) and with a simplified Köhler model (volume-additivity model with surface tension of pure water; Sect. A2). Both models are based on a water activity parameterization derived from the Aerosol Inorganics Model (AIM, Clegg et al., 1998a, b) and on the minimum mobility equivalent diameter observed in the h\&d experiments (H-TDMA operation mode $3 ; D_{\mathrm{m}, \mathrm{AS}}=D_{\mathrm{b}, \mathrm{h} \& \mathrm{~d}, \min }=95.7 \mathrm{~nm}$.), and both models are in very good agreement with the measurement results and with each other. Averaged over the whole range of $30-95 \% \mathrm{RH}$, the mean relative deviations between measurement and model results as well as between the different models were $<1 \%$.

Since the AIM can be regarded as an accurate reference for the water activity in aqueous ammonium sulfate solutions (Rose et al., 2008, and references therein), the good agreement between model an measurement results confirms that the AS particles with $D_{\mathrm{b}, \mathrm{h}, \min }$ were compact and spherical. Mikhailov et al. (2004) had obtained similar results for $\mathrm{NaCl}$ particles, demonstrating that $\mathrm{h} \& \mathrm{~d}$ experiments $(\mathrm{H}-$ TDMA operation mode) enable efficient and precise experimental determination of particle mass equivalent diameters as required for accurate Köhler model calculations and interpretation of H-TDMA and CCN experiments (Gysel et al., 2002; Biskos et al., 2006; Rose et al., 2008; Duplissy et al., 2009; Kuwata and Kondo, 2009). The agreement between the two models also confirms that the partial molar volume of water and the surface tension of deliquesced AS particles 

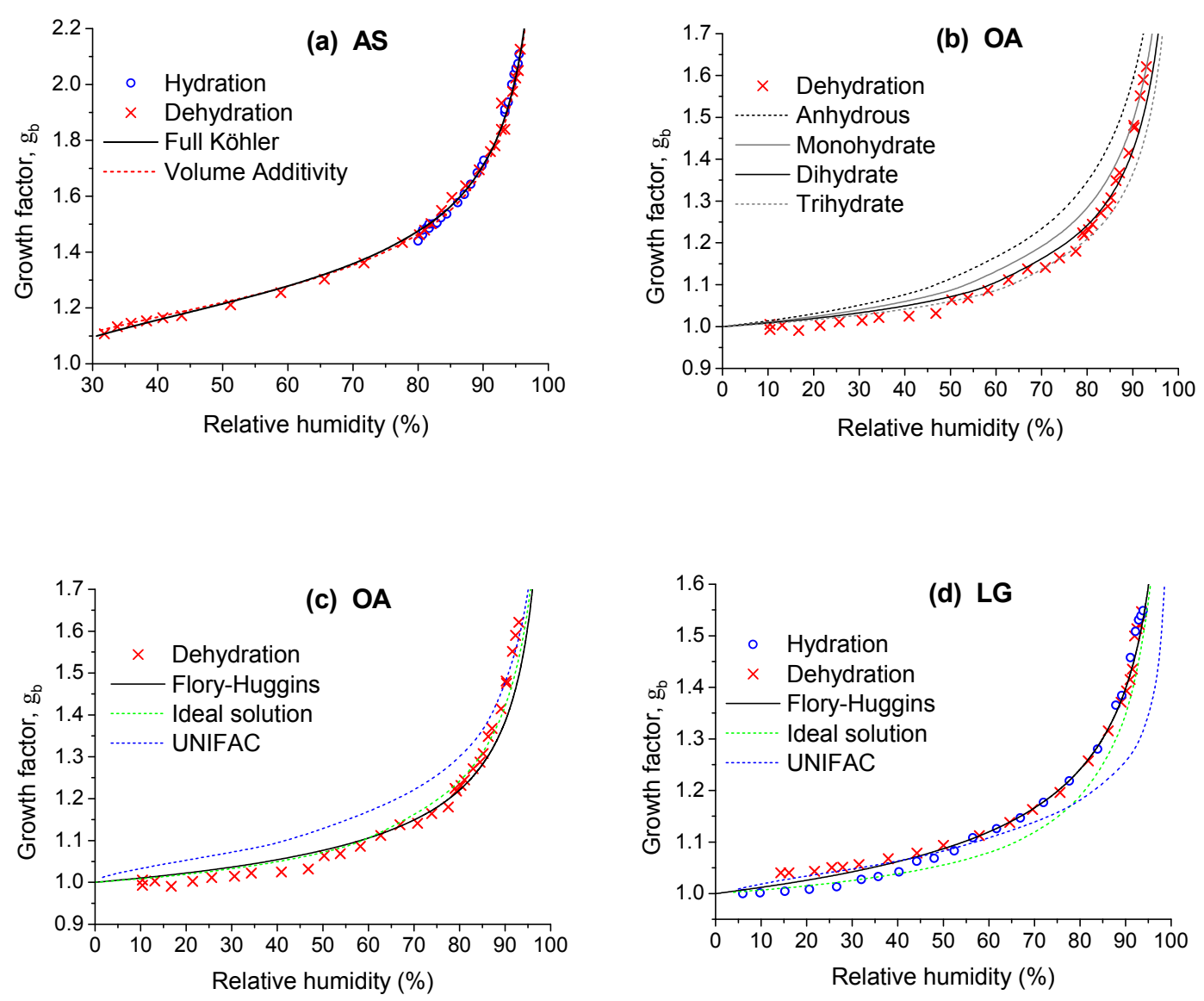

Fig. A1. Mobility equivalent growth factors ( $g_{\mathrm{b}}$, data points) observed for ammonium sulfate (a), oxalic acid (b, c) and levoglucosan (d) particles in comparison to mass equivalent growth factors calculated with different Köhler models ( $g_{\mathrm{m}}$, lines; Appendix A).

can be effectively approximated by the molar volume and surface tension of pure water, even at low relative humidity and high concentration of AS.

Figure A2a shows the water activity-based growth curve $\left(g_{\mathrm{b}}\right.$ vs. $\left.a_{\mathrm{w}}\right)$ obtained by converting measured RH values into corresponding water activity $\left(a_{\mathrm{w}}\right)$ values as described in Sect. A3.5 (correction for Kelvin effect assuming volume additivity and the surface tension of water). The measurement results can be accurately represented by a 3-parameter fit as proposed by Kreidenweis et al. (2005), and the corresponding best-fit parameters are listed in Table A1 $\left(k_{1}-k_{3}\right.$; Eq. A14, Sect. A3.5). A 1-parameter fit based on the $\kappa$ Köhler model approach (best fit value $\kappa=0.51$; Table A1; Eq. A17, Sect. A3.6) yields good agreement at high $a_{\mathrm{w}}$ but deviates significantly at low $a_{\mathrm{w}}$.

As illustrated in Fig. A2b, the deviations of the 1parameter fit are due to a pronounced dependence of the effective hygroscopicity parameter $\kappa$ on $a_{\mathrm{w}}$ and solute concentration in the aqueous particles, respectively. Figure A2b also shows that the concentration dependence of $\kappa$ can be well described with the best-fit parameters of the 3parameter fit from Fig. A2a $\left(k_{1}-k_{3}\right.$, Table A1, Eq. A18,
Sect. A3.6). Moreover, the H-TDMA measurement-based $\kappa$ values are in good agreement with AIM-based model calculations (Sect. A3.6), except for very low $a_{\mathrm{w}}$ in very highly concentrated solution droplets close to efflorescence. Note that the AIM-based $\kappa$ values exhibit a steep increase at high $a_{\mathrm{w}}$, going from $\kappa \approx 0.5$ at $a_{\mathrm{w}} \approx 0.95$ to $\kappa \approx 0.7$ at $a_{\mathrm{w}} \approx 1.0$, which is consistent with measurement and model results for the CCN activation of AS particles (Rose et al., 2008).

As outlined by Pöschl et al. (2009) and detailed in Sect. A3.6, assuming volume additivity and the surface tension of water for Köhler model calculations implies that the effective hygroscopicity parameter $\kappa$ can be regarded as an "effective Raoult parameter" $\left(\kappa_{\mathrm{R}}\right)$ which can be directly converted into a van't Hoff factor $\left(i_{\mathrm{S}}\right)$ or into an osmotic coefficient $\left(\Phi_{\mathrm{S}}\right)$ respectively (Eq. A19; Rose et al., 2008; Gunthe et al., 2009). Accordingly, the secondary y-axis of Fig. A2b translates the $\kappa$ values into van't Hoff factors, which can be intuitively interpreted as effective dissociation numbers of the solute substance explaining the reduction of water activity according to Raoult's law (Pruppacher and Klett, 2000; Seinfeld and Pandis, 2006; Pöschl et al., 2009). This is useful for comparison with related studies applying the parameters 

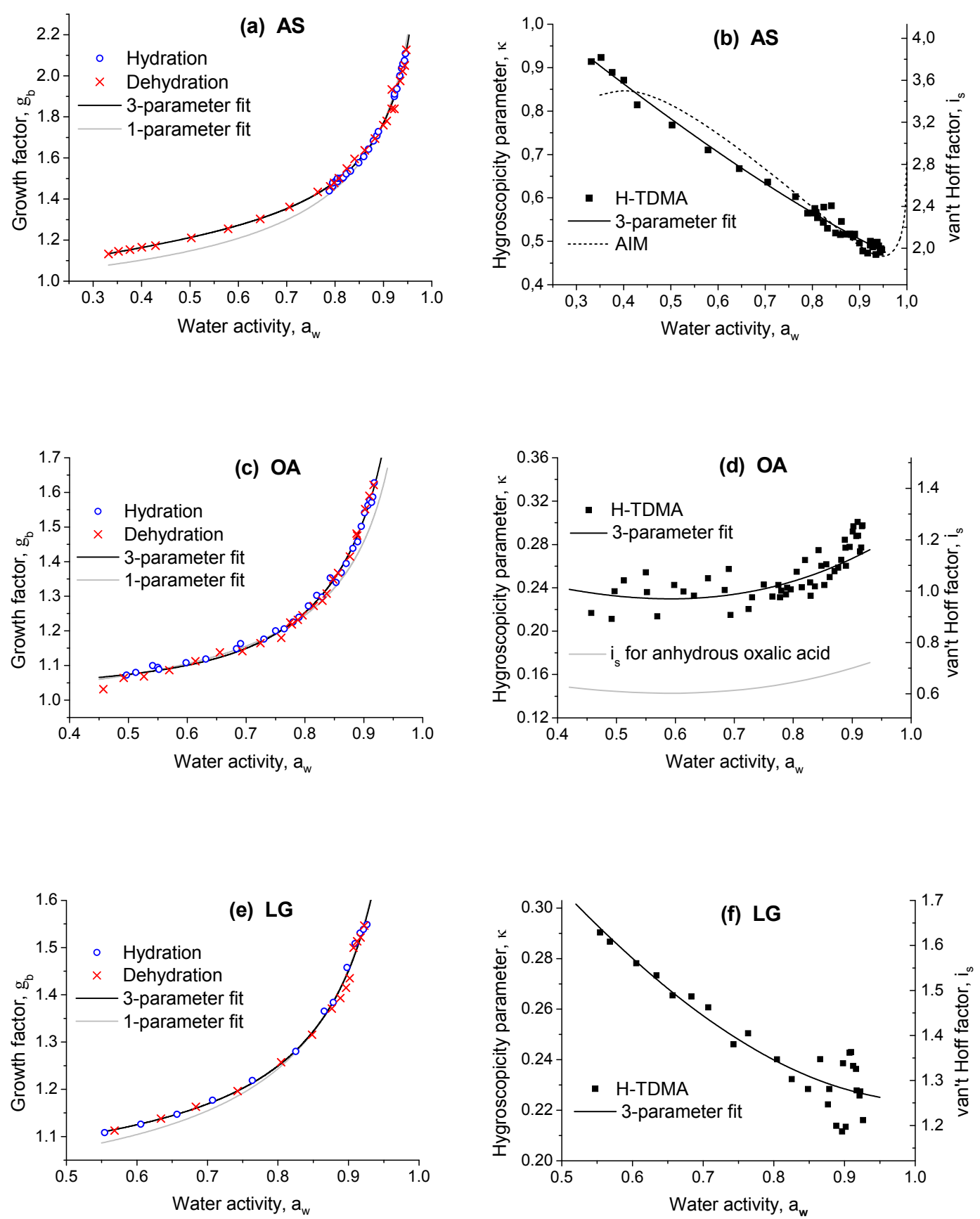

Fig. A2. 3-parameter $\left(k_{1}-k_{3}\right)$ and 1-parameter $(\kappa)$ fits to water activity-based growth curves ( $g_{\mathrm{b}}$ vs. $a_{\mathrm{w}}$; panels a, c, e) and dependence of effective hygroscopicity parameter $\kappa$ and corresponding van't Hoff factor $i_{\mathrm{S}}$ on water activity (panels $\mathbf{b}, \mathbf{d}, \mathbf{f}$ ) for aerosol particles composed of ammonium sulfate (AS), oxalic acid (OA) or levoglucosan (LG). Data points are from H-TDMA experiments (deliquesced particles) with $a_{\mathrm{w}}$ calculated from RH assuming volume additivity and water surface tension. Lines in panels (b), (d), (f) correspond to three-parameter fits in panels (a), (c), (e) (Eq. A18).

$i_{\mathrm{S}}$ or $\Phi_{\mathrm{S}}$ and for the interpretation of the Köhler model results for different types of organic substances as discussed below (Sects. B2 and B3).

Overall, the Köhler model results are in good agreement with earlier H-TDMA and CCN counter experiments charac- terizing the hygroscopic growth and $\mathrm{CCN}$ activation of AS particles (e.g., Gysel et al., 2002; Kreidenweis et al., 2005; Petters and Kreidenweis, 2007; Rose et al., 2008; and references therein). With regard to the high precision of the H-TDMA and CCN experiments with ammonium sulfate as 
well as with sodium chloride $(\mathrm{NaCl})$ aerosol particles presented in this study and related earlier studies (Mikhailov et al., 2004; Rose et al., 2008), we point out that the good agreement between the H-TDMA and CCN measurement results for both $\mathrm{AS}$ and $\mathrm{NaCl}$ with AIM-based Köhler model results re-confirm the validity of the AIM as an accurate reference for water activity in concentrated as well as in dilute aqueous solutions of AS and of $\mathrm{NaCl}$. As illustrated in Fig. A2b, the parameters $\kappa$ and $i_{\mathrm{s}}$ depend in a non-linear way on $a_{\mathrm{w}}$ and solute concentration, respectively. Thus, we would like to renew the recommendation of Rose et al. (2008) to use AIM-based or equivalent Köhler models in experiments and calibrations involving the hygroscopic growth of AS particles.

\section{B2 Oxalic acid}

In Fig. A1b the mobility equivalent growth factors observed for deliquesced OA particles are compared with the mass equivalent growth factors calculated with an ideal solution model (IS, Sect. A3.2) assuming different initial composition of the OA particles, i.e., anhydrous oxalic acid and hydrates containing 1-3 molecules of water per oxalic acid molecule. The agreement between model and measurement results was best under the assumption that the OA particles initially consisted of oxalic acid dihydrate. The agreement was similarly good for $\mathrm{RH}<85 \%$ when assuming a trihydrate and for $\mathrm{RH}>85 \%$ when assuming a monohydrate. When assuming anhydrous oxalic acid, the model results were generally too high.

In Fig. A1c the measured growth factors and the IS model results for oxalic acid dihydrate are compared to the results of volume-additivity (VA) Köhler models based on different water activity formalisms: UNIFAC (Sect. A3.3) and FloryHuggins (FH, Sect. A3.4). The best-fit value of the FH interaction parameter $\chi=0.46$ was close to 0.5 , which indicates near-ideal solution behavior according to Flory-Krigbaum theory (compensation of excess enthalpy and entropy factors; Flory, 1953; Cowie and Arrighi, 2007). Indeed, the FH model results were similar to the IS model results and agreed also fairly well with the measurement data. At $\mathrm{RH}>85 \%$ both the IS and FH model results were too low, which can be explained by an increase of non-ideal behavior of oxalic acid (dissociation) with increasing dilution. In contrast, the UNIFAC model results for oxalic acid dihydrate were in fair agreement with the measurement data at high RH but far too high at low RH, which may be due to inappropriate group interaction parameters (Sect. A3.4). When assuming that the OA particles initially would have consisted of anhydrous oxalic acid, the positive offset of the UNIFAC model was even higher (results not shown).

Figure A2c shows the water activity-based growth curve of the investigated OA particles ( $g_{\mathrm{b}}$ vs. $a_{\mathrm{w}}$; Sect. A3.5). As for AS particles (Fig. 7a), the measurement results are well represented by a 3 -parameter fit, and the corresponding best-fit parameters are listed in Table $\mathrm{A} 1\left(k_{1}-k_{3}\right.$; Eq. A14, Sect. A3.5). A 1-parameter $\kappa$-Köhler model fit yields good agreement at low $a_{\mathrm{w}}$ but deviates significantly at high $a_{\mathrm{w}}$ (best fit value $\kappa=0.23$; Table A1; Eq. A17, Sect. A3.6).

As illustrated in Fig. A2d, the deviations of the 1parameter fit are due to a pronounced increase of $\kappa$ with $a_{\mathrm{w}}$. As for AS particles, the concentration dependence of $\kappa$ can be well described with the best-fit parameters of the 3-parameter fit $\left(k_{1}-k_{3}\right.$, Table A1, Eq. A18, Sect. A3.6) and the $\kappa$ values can be converted into van't Hoff factors $\left(i_{\mathrm{s}}\right)$ as shown by the secondary $\mathrm{x}$-axis of Fig. A2d. The $i_{\mathrm{S}}$ values calculated under the assumption that the OA particles initially consisted of oxalic acid dihydrate confirm the results and interpretation of the IS model calculations, i.e., that oxalic acid behaves like an ideal solute when it is highly concentrated $\left(i_{\mathrm{s}} \approx 1\right.$ at $\left.a_{\mathrm{w}} \leq 0.8\right)$ and exhibits enhanced dissociation with increasing dilution ( $i_{\mathrm{S}}>1$ at $a_{\mathrm{w}}>0.8$ ). Indeed, the observed increase and the value of $i_{\mathrm{s}} \approx 1.1$ at $a_{\mathrm{w}} \approx 0.9$ and $g_{\mathrm{b}} \approx 1.5$, respectively, is fully consistent with the further increase of $i_{\mathrm{S}}$ in more dilute aqueous oxalic acid droplets as reported by Varga et al. (2007) based on measurements of osmolality and surface tension $\left(i_{\mathrm{s}} \approx 1.5\right.$ at $g_{\mathrm{b}}=3$ and $a_{\mathrm{w}} \approx 0.985$ up to $i_{\mathrm{s}} \approx 2$ at $g_{\mathrm{b}} \approx 10$ and $a_{\mathrm{w}} \approx 0.999$ ). Varga et al. (2007) and other studies (Koehler et al., 2006) also show that oxalic acid as well as levoglucosan have very little influence on the surface tension of aqueous solution droplets, which confirms the validity of assuming water surface tension in the presented VA Köhler model calculations (Sect. A2).

When assuming that the OA particles would initially have been anhydrous, the obtained $i_{\mathrm{S}}$ values remain well below one throughout the investigated range of conditions, which is not plausible (dotted line, Fig. A2d). Overall, the Köhler model results confirm that the investigated OA particles did not consist of anhydrous oxalic acid. They suggest that the amorphous OA particles initially consisted of oxalic acid dihydrate or of a non-stoichiometric hydrate containing about 2 water molecules per oxalic acid molecule.

\section{B3 Levoglucosan}

In Fig. A1d the mobility equivalent growth factors observed for LG particles are compared with IS, UNIFAC and FH model results. Neither the IS nor the UNIFAC model were able to reproduce the measurement results. Mochida and Kawamura (2004) had observed similar deviations and attributed these to inappropriate group interaction parameters in the UNIFAC model. In contrast, the FH model with a best-fit value of $\chi=0.26$ was in good agreement with the growth curves observed at $\mathrm{RH}>60 \%$ and right in between the kinetically limited growth factors observed at $\mathrm{RH}<60 \%$. The results demonstrate that volume-based FH models are well-suited to describe not only polymers but also nondissociating organic substances with relatively low molecular mass like LG. 
Figure A2e shows the water activity-based growth curve of the investigated LG particles ( $g_{\mathrm{b}}$ vs. $a_{\mathrm{w}}$; Sect. A3.5). As for AS and OA particles (Fig. 7a, c), the measurement results are well represented by a 3-parameter fit, and the corresponding best-fit parameters are listed in Table A1 $\left(k_{1}-k_{3}\right.$; Eq. A14, Sect. A3.5). A 1-parameter $\kappa$-Köhler model fit yields good agreement at high $a_{\mathrm{w}}$ but deviates significantly at low $a_{\mathrm{w}}$ (best-fit value $\kappa=0.23$; Table A1; Eq. A17, Sect. A3.6).

As illustrated in Fig. A2f, the deviations of the 1parameter fit are due to an apparent decrease of $\kappa$ with $a_{\mathrm{w}}$, which can be described with the best-fit parameters of the 3-parameter fit. As discussed above, the LG particle properties observed at low RH and $a_{\mathrm{w}}$, respectively, can be explained by kinetic limitations and non-ergodic behavior of a semi-solid phase (glassy, rubbery or ultra-viscous). Thus, the $\kappa$ values obtained at $a_{\mathrm{w}} \leq 0.8$ should not be regarded as thermodynamic equilibrium parameters. On the other hand, the $\kappa$ values obtained at high RH and $a_{\mathrm{w}}(\kappa \approx 0.21-0.24$ at $\left.a_{\mathrm{w}}>0.8\right)$ are in good agreement with the best-fit value of $\kappa=0.23$, indicating that the effects of LG on water activity in dilute solutions is not strongly concentration-dependent. These values are also in fair agreement with the hygroscopicity parameter value of $\kappa \approx 0.21$ that Petters and Kreidenweis (2007) calculated for oxalic acid based on the CCN experiments of Svenningson et al. (2006). The lower value of $\kappa \approx 0.17$ calculated on the basis of the H-TDMA results of value Koehler et al. (2006) may be due to an underestimation of growth factors because of incomplete drying of the initially size-selected particles as discussed above (Sect. 4.3.3).

As outlined by Pöschl et al. (2009) and detailed in Sect. A3.6, $\kappa$ can be interpreted as an effective Raoult parameter, i.e., as an effective or equivalent molar density of water-soluble ions or molecules in the aerosol particle or chemical component, respectively, normalized by the molar density of water molecules in liquid water $\left(\sim 55 \mathrm{~mol} \mathrm{~L}^{-1}\right.$; Eq. A19; Rose et al., 2008; Gunthe et al., 2009). With regard to dilute solutions of strong electrolytes with low molar mass, including most atmospherically relevant water-soluble inorganic salts and strong acids, the effective molar density of ions or molecules is usually close to the actual molar density of ions/molecules of the solute, i.e., the van't Hoff factor is close to the stoichiometric dissociation number and the osmotic coefficient is close to unity (e.g., AS: $v_{\mathrm{s}}=3, i_{\mathrm{s}} \approx 2-3$, $\left.\Phi_{\mathrm{s}} \approx 0.7-1\right)$. For weak electrolytes and acids, however, the van't Hoff factor tends to be smaller than the stoichiometric dissociation number, and the osmotic coefficient tends to be less than unity (e.g., OA: $v_{\mathrm{s}}=3, i_{\mathrm{s}} \approx 1-2, \Phi_{\mathrm{s}} \approx 0.3-0.7$ ). On the other hand, organic compounds with high molar mass and volume usually exhibit van't Hoff factors that are larger than their stoichiometric dissociation number and osmotic coefficients that are larger than unity (e.g., LG: $v_{\mathrm{s}}=1$, $i_{\mathrm{S}} \approx \Phi_{\mathrm{s}} \approx 1.4 ; \mathrm{BSA}$ (protein): $v_{\mathrm{s}}=1, i_{\mathrm{s}} \approx \Phi_{\mathrm{s}} \approx 1-100$; Mikhailov et al., 2004).

For LG and similar (non-electrolytic) organic aerosol components it appears thus more suitable to describe and in- terpret the relation between the effective hygroscopicity or Raoult parameter, molar mass and density (Eq. A19) with regard to osmotic effects, rather than describing and interpreting $i_{\mathrm{S}}$ as an effective "ion dissociation number" or referring to an equivalent "ion density" (Rissler et al., 2006; Wex et al., 2007; Gunthe et al., 2009). Osmotic coefficients, van't Hoff factors, or related parameters like osmolality are available for many organic and inorganic substances and can be efficiently measured or approximated with well-established physicochemical techniques and formalisms (e.g., Kiss and Hansson, 2004; Mikhailov et al., 2004; Köhler et al., 2006; McFiggans et al., 2006; Rosenorn et al., 2006; Varga et al., 2007; Clegg et al., 2008; Ekström et al., 2009; and references therein). However, care should be taken to avoid confusion of relevant quantities, units and conversion factors, which seems not always to be the case.

In a companion paper (Mikhailov et al., 2010) and further follow-up studies, the Köhler model results will be further discussed and used to predict the hygroscopic growth of aerosol particles consisting of internal mixtures of the above and other aerosol components.

Acknowledgements. This work has been supported by the Max Planck Society (MPG), the Humboldt Foundation (Research Fellowship S. T. Martin), the German Federal Ministry of Education and Research (BMBF, AFO 2000, CARBAERO), the Russian Foundation for Basic Research (grant 09-05-00883-a), and the European integrated project on aerosol cloud climate and air quality interactions (No. 036833-2, EUCAARI). Thanks to M. O. Andreae and to R. Niessner for support, and to T. Peter, U. Krieger, B. Zobrist, B. P. Luo, and M. Ammann for helpful comments and discussions.

The service charges for this open access publication have been covered by the Max Planck Society.

Edited by: V. F. McNeill

\section{References}

Abdallah, D. J. and Weiss, R. G.: The quest for the simplest possible organogelators and some properties of their organogels, Adv. Materials, 11(3), 209-218, 2000.

Angell, C. A.: Formation of glasses from liquids and biopolymers, Science, 267, 1924-1935, 1995.

Ammann, M. and Pöschl, U.: Kinetic model framework for aerosol and cloud surface chemistry and gas-particle interactions - Part 2: Exemplary practical applications and numerical simulations, Atmos. Chem. Phys., 7, 6025-6045, 2007, http://www.atmos-chem-phys.net/7/6025/2007/.

Andreae M. O. and Rosenfeld, D.: Aerosol-cloud-precipitation interactions. Part 1. The nature and sources of cloud-active aerosols, Earth-Sci. Rev., 89, 13-41, 2008.

Angell, C. A.: Formation of glasses from liquids and biopolymers, Science, 267, 1924-1935, 1995.

Apelblat, A.: Enthalpy of solution of oxalic, succinic, adipic, maleic, malic, tetratic, and citric acids, oxalic acid dihydrate, and 
citric acid monohydrate in water at $298.15 \mathrm{~K}$, J. Chem. Thermod., 18, 351-357, 1986.

Asa-Awuku, A. and Nenes, A.: The Effect of solute dissolution kinetics on cloud droplet formation: Extended Köhler Theory, J. Geophys. Res., 112, D22201, doi:10.1029/2005JD006934, 2007.

Asa-Awuku, A., Engelhart, G. J., Lee, B. H., Pandis, S. N., and Nenes, A.: Relating CCN activity, volatility, and droplet growth kinetics of $\beta$-caryophyllene secondary organic aerosol, Atmos. Chem. Phys., 9, 795-812, 2009,

http://www.atmos-chem-phys.net/9/795/2009/.

Barton, A. F. M.: Handbook of Solubility Parameters and Other Cohesion Parameters, 2nd ed., CRC Press: Boston, 1991.

Bhandari, B. R. and Howes, T.: Implication of glass transition for the drying and stability of dried foods, J. Food Engineering, 40, 71-79, 1999.

Bilde, M., Svenningsson, B., Mønster, J., and Rosenørn, T.: Evenodd alternation of evaporation rates and vapor pressures of C3C9 dicarboxylic acid aerosol, Environ. Sci. Technol., 37, 13711378, 2003.

Biskos, G., Paulsen, D., Russell, L. M., Buseck, P. R., and Martin, S. T.: Prompt deliquescence and efflorescence of aerosol nanoparticles, Atmos. Chem. Phys., 6, 4633-4642, 2006, http://www.atmos-chem-phys.net/6/4633/2006/.

Bondi, A.: Physical properties of molecular crystals, liquids and glasses, Wiley, New York, 1968.

Braban, C. F., Carroll, M. F., Styler, S, A., and Abbatt, J. P. D.: Phase transitions of malonic and oxalic acid aerosols, J. Phys. Chem. A, 107, 6594-6602, 2003.

Brechtel, F. J. and Kreidenweis, S. M.: Predicting particle critical supersaturation from hygroscopic growth measurements in the humidified TDMA. part I: Theory and sensitivity studies, J. Atmos. Sci., 57, 1854-1871, 2000.

Brooks, S. D., Wise, M. E., Cushing, M., and Tolbert, M. A.: Deliquescence behavior of organic/ammonium sulfate aerosol, J. Geophys. Res., 29(19), 1917, doi:10.1029/2002GL014733, 2002.

Brooks, S. D., Garland, R. M., Wise, M. E., Prenni, A. J., Cushing, M., Hewitt, E., and Tolbert, M. A.: Phase changes in internally mixed maleic acid/ammonium sulfate aerosols, J. Geophys. Res., 108(D15), 4487, doi:10.1029/2002JD003204, 2003.

Brooks, S. D., DeMott, P. J., and Kreidenweis, S. M.: Water uptake by particles containing humic materials and mixtures of humic materials with ammonium sulfate, Atmos. Environ., 38, 18591868, 2004.

Brownsey, G. J., Noel, T. R., Parker, R., and Ring, S. G.: The glass transition behavior of the globular protein bovine serum albumin, Biophys. J., 85, 3943-3950, 2003.

Buckton, G. and Darcy, P.: Assessment of disorder in crystalline powders - a review of analytical techniques and their application, Int. J. Pharm, 179, 141-158, 1999.

Burnett, D. J., Thielmann, F., and Booth, J.: Determining the critical relative humidity for moisture-induced phase transitions, Int. J. Pharm., 287, 123-133, 2004.

Cantrell, W., McCrory, C., and Ewing, G. E.: Nucleated deliquescence of salt, J. Chem. Phys., 116, 2116-2120, doi:10.1063/1.1429924, 2002.

Cappa, C. D., Lovejoy, E. R., and Ravishankara, A. R.: Evidence for liquid-like and nonideal behavior of a mixture of organic aerosol components, Proc. Nat. Acad. Sci., 105, 18687-18691, 2008.
Chan, M. N., Choi, M. Y., Ng, N. L., and Chan, C. K.: Hygroscopicity of water-soluble organic compounds in atmospheric aerosols: Amino acid and biomass burning derived organic species, Environ. Sci. Technol., 39, 1555-1562, 2005.

Chitra, R., Das, A., Choudhury, R. R., Ramanadham, M., and Chidambaram, R.: Hydrogen bonding in oxalic acid and its complexes: A database study of neutron structures, Pramana J. Phys., 63(2), 263-269, 2004.

Choi, M. Y. and Chan, C. K.: Contiuous measurements of the water activities of aqueous droplets of water-soluble organic compounds, J. Chem. Phys. A, 106, 4566-4572, 2002a.

Choi, M. Y. and Chan, C. K.: The effects of organic species on hygroscopic behaviors of inorganic aerosols, Environ. Sci. Technol., 36, 2422-2428, 2002 b.

Clegg, S. L., Brimblecombe, P., and Wexler, A. S.: A thermodynamic model of the system $\mathrm{H}^{+}-\mathrm{NH}_{4}^{+}-\mathrm{SO}_{4}^{2}--\mathrm{NO}_{3}--\mathrm{H}_{2} \mathrm{O}$ at tropospheric temperatures, J. Phys. Chem. A, 102, 2137-2154, 1998a.

Clegg, S. L., Brimblecombe, P., and Wexler, A. S.: A thermodynamic model of the system $\mathrm{H}^{+}-\mathrm{NH}_{4}^{+}-\mathrm{Na}^{+}-\mathrm{SO}_{4}^{2-}-\mathrm{NO}_{3}^{-}$ $-\mathrm{Cl}^{-}-\mathrm{H}_{2} \mathrm{O}$ at $298.15 \mathrm{~K}$, J. Phys. Chem. A, 102, 2155-2171, $1998 b$.

Clegg, S. L. and Wexler, A. S.: Interactive Comment on "Calibration and measurement uncertainties of a continuous-flow cloud condensation nuclei counter (DMT-CCNC): $\mathrm{CCN}$ activation of ammonium sulfate and sodium chloride aerosol particles in theory and experiment" by D. Rose et al., Atmos. Chem. Phys. Discuss., 7, S4180-S4183, 2007.

Clegg, S. L., Kleeman, M. J., Griffin, R. J., and Seinfeld, J. H.: Effects of uncertainties in the thermodynamic properties of aerosol components in an air quality model - Part 1: Treatment of inorganic electrolytes and organic compounds in the condensed phase, Atmos. Chem. Phys., 8, 1057-1085, 2008, http://www.atmos-chem-phys.net/8/1057/2008/.

Cohen, M. D., Flagan, R. C., and Seinfeld, J. H.: Studies of concentrated electrolyte solutions using the electrodynamic balance. 1. Water activity for single-electrolyte solutions, J. Phys. Chem., 91, 4563-4574, 1987.

Colberg, C. A., Luo, B. P., Wernli, H., Koop, T., and Peter, Th.: A novel model to predict the physical state of atmospheric $\mathrm{H}_{2} \mathrm{SO}_{4} / \mathrm{NH}_{3} / \mathrm{H}_{2} \mathrm{O}$ aerosol particles, Atmos. Chem. Phys., 3, 909-924, 2003, http://www.atmos-chem-phys.net/3/909/2003/.

Colberg, C. A., Krieger, U. K., and Peter, T.: Morphological investigations of single levitated $\mathrm{H}_{2} \mathrm{SO}_{4} / \mathrm{NH}_{3} / \mathrm{H}_{2} \mathrm{O}$ aerosol particles during deliquescence/efflorescence experiments, J. Phys. Chem. A, 108, 2700-2709, 2004.

Corrigan, O. I., Holohan, E. M., and Sabra, K.: Amorphous forms of thiazide diuretics prepared by spray-drying, Int. J. Pharm., 18, 195-200, 1984.

Cowie, J. M. G. and Arrighi, V.: Polymers: Chemistry and Physics of Modern Materials, CRC Press LLC, 3rd ed., 2007.

Cruz, C. N. and Pandis, S. N.: Deliquescence and hygroscopic growth of mixed inorganic-organic atmosopheric aerosol, Environ. Sci. Technol., 34, 4313-4319, 2000.

Cziczo, D. J., Novak, J. B., Hu, J. H., and Abbatt, J. P. D.: Infrared spectroscopy of model tropospheric aerosols as a function of relative humidity - observation of deliquescence and crystallization, J. Geophys. Res., 101, 18843-18850, 1997. 
Cziczo, D. J. and Abbatt, J. P. D.: Infrared observations of the response of $\mathrm{NaCl}, \mathrm{MgCl}_{2}, \mathrm{NH}_{4} \mathrm{HSO}_{4}$, and $\mathrm{NH}_{4} \mathrm{NO}_{3}$ aerosols to changes in relative humidity from 298 to $238 \mathrm{~K}$, J. Phys. Chem. A, 104, 2038-2047, 2000.

Das, A., Dev, S., Shangpliang, H., Nonglait, K. L., and Ismail, K.: Electrical Conductance and Viscosity of Concentrated H2SO4/H2O Binary Systems at Low Temperatures: Correlation with Phase Transitions, J. Phys. Chem. B, 101, 4166-4170, 1997.

Dawson, K. J., Kearns, K. L., and Ediger, M. D.: Highly stable indomethacin glasses resist uptake of water vapor, J. Phys.Chem. B, 113, 2422-2427, 2009.

Debenedetti, P. G. and Stillinger, F. H.: Supercooled liquids and the glass transition, Nature, 410, 259-267, 2001.

DeCarlo, P. F., Slowik, J. G., Worsnop, D. R., Davidovits, P., and Jimenez, J. L.: Particle morphology and density characterisation by combined mobility and aerodynamic diameter measurements. Part 1: Theory, Aerosol Sci. Technol., 38, 1185-1205, 2004.

De Wit, H. G. M., Bouwstra, J. A., Blok, J. G., and de Kruif, C. G.: Vapor pressures and energies of oxalic acid, mesotartaric acid, phloroglucinol, myoinositol, and their hydrates, J. Chem. Phys., 78(3), 1470-1475, 1983.

Dick, W. D., Saxena, P., and McMurry, P. H.: Estimation of water uptake by organic compounds in submicron aerosols measured during the Southeastern Aerosol and Visibility Study, J. Geophys. Res. 105(D1), 1471-1479, 2000.

Dinar, E., Mentel, T. F., and Rudich, Y.: The density of humic acids and humic like substances (HULIS) from fresh and aged wood burning and pollution aerosol particles, Atmos. Chem. Phys., 6, 5213-5224, 2006,

http://www.atmos-chem-phys.net/6/5213/2006/.

Dinar, E., Taraniuk, I., Graber, E. R., Antilla, T., Mentel, T. F., and Rudich, Y.: Hygroscopic growth of atmospheric and model humic-like substances, J. Geophys. Res., 112, D05211, doi:10.1029/2006JD007442, 2007.

Dougle, P. G., Veefkind, J. P., and ten Brink, H. M.: Crystallization of mixtures of ammonium nitrate, ammonium sulfate and soot, J. Aerosol Sci., 29, 375-386, 1998.

Duplissy, J., Gysel, M., Sjogren, S., Meyer, N., Good, N., Kammermann, L., Michaud, V., Weigel, R., Martins dos Santos, S., Gruening, C., Villani, P., Laj, P., Sellegri, K., Metzger, A., McFiggans, G. B., Wehrle, G., Richter, R., Dommen, J., Ristovski, Z., Baltensperger, U., and Weingartner, E.: Intercomparison study of six HTDMAs: results and recommendations, Atmos. Meas. Tech., 2, 363-378, 2009,

http://www.atmos-meas-tech.net/2/363/2009/.

Dušek, K. and Patterson, D.: Transition in swollen polymer networks induced by intramolecular condensation, J. Polym. Sci., A., 6(7), 1209-1216, 1968.

Ekström, S., Nozière, B., and Hansson, H.-C.: The Cloud Condensation Nuclei $(\mathrm{CCN})$ properties of 2-methyltetrols and C3-C6 polyols from osmolality and surface tension measurements, Atmos. Chem. Phys., 9, 973-980, 2009,

http://www.atmos-chem-phys.net/9/973/2009/.

Endo, Y., Fukushima, N., Tashiro, S., and Kousaka, Y.: Performance of a scanning differential mobility analyzer, Aerosol Sci. Tecnol., 26, 44-49, 1997.

Engelhart, G. J., Asa-Awuku, A., Nenes, A., and Pandis, S. N.: CCN activity and droplet growth kinetics of fresh and aged monoterpene secondary organic aerosol, Atmos. Chem. Phys.,
8, 3937-3949, 2008,

http://www.atmos-chem-phys.net/8/3937/2008/.

Erman, B. and Mark, J. E.: Structure and properties of rubberlike networks, Oxford University Press, New York, 1997.

Estroff, L. A. and Hamilton, A. D.: Water gelation by small organic molecules, Chem. Rev., 104(3), 1201-1216, 2004.

Farahnaky, A., Badii, F., Farhat, I. A., Mitchell, J. R., and Hill, S. E.: Enthalpy relaxation of bovine serum albumin and implications for its storage in the glassy state, Biopolymers, 78, 69-77, 2005.

Farhat, I. A., Loisel, P., Derbyshire, W., and Blanshard, J. M. V.: The effect of sugars on the diffusion of water in starch gels: a pulsed filed gradient NMR study, Int. J. Food Sci., 32, 377-387, 1997.

Flory, P. J.: Principles of polymer chemistry, Cornell University Press, Ithaca, NY, 1953.

Flory, P. J.: Introductory lecture, Faraday Discuss. Chem. Soc., 57, 7-18, 1974.

Fraser, M. P. and Lakshmanan, K.: Using Levoglucosan as a Molecular Marker for the Long-Range Transport of Biomass Combustion Aerosols, Environ. Sci. Technol., 34, 4560-4564, 2000.

Fredenslund, A., Jones, R. L., and Prausnitz, J. M.: Group contribution estimation of activity coefficients in nonideal liquid mixtures, American Institute of Chemical Engineers Journal (AIChE. J.), 21, 1086-1099, 1975.

Fuzzi, S., Decesari, S., Facchini, M. C., Matta, E., Mircea, M., and Tagliavini, E.: A simplified model of the water soluble organic component of atmospheric aerosol, Geophys. Res. Lett., 20, 4079-4082, 2001.

Fuzzi, S., Andreae, M. O., Huebert, B. J., Kulmala, M., Bond, T. C., Boy, M., Doherty, S. J., Guenther, A., Kanakidou, M., Kawamura, K., Kerminen, V.-M., Lohmann, U., Russell, L. M., and Pöschl, U.: Critical assessment of the current state of scientific knowledge, terminology, and research needs concerning the role of organic aerosols in the atmosphere, climate, and global change, Atmos. Chem. Phys., 6, 2017-2038, 2006, http://www.atmos-chem-phys.net/6/2017/2006/.

Greenspan, L.: Humidity fixed points of binary saturated aqueous solutions, J. Res. National Bur. Stand., 81A, 89-96, 1977.

Griffiths, P. T., Badger, C. L., Cox, R. A., Folkers, M., Henk, H. H., Mentel, T. F., J. Phys. Chem. A, 113, 5082-5090, 2009.

Gunthe, S. S., King, S. M., Rose, D., Chen, Q., Roldin, P., Farmer, D. K., Jimenez, J. L., Artaxo, P., Andreae, M. O., Martin, S. T., and Pöschl, U.: Cloud condensation nuclei in pristine tropical rainforest air of Amazonia: size-resolved measurements and modeling of atmospheric aerosol composition and CCN activity, Atmos. Chem. Phys., 9, 7551-7575, 2009, http://www.atmos-chem-phys.net/9/7551/2009/.

Gysel, M., Weingartner, E., and Baltensperger, U.: Hygroscopicity of aerosol particles at low temperatures. 2. Theoretical and experimental hygroscopic properties of laboratory generated aerosol, Environ. Sci. Technol., 36, 63-68, 2002.

Hallquist, M., Wenger, J. C., Baltensperger, U., Rudich, Y., Simpson, D., Claeys, M., Dommen, J., Donahue, N. M., George, C., Goldstein, A. H., Hamilton, J. F., Herrmann, H., Hoffmann, T., Iinuma, Y., Jang, M., Jenkin, M. E., Jimenez, J. L., Kiendler-Scharr, A., Maenhaut, W., McFiggans, G., Mentel, Th. F., Monod, A., Prévôt, A. S. H., Seinfeld, J. H., Surratt, J. D., Szmigielski, R., and Wildt, J.: The formation, properties and impact of secondary organic aerosol: current and emerging issues, 
Atmos. Chem. Phys., 9, 5155-5235, 2009,

http://www.atmos-chem-phys.net/9/5155/2009/.

Hancock, B. C. and Zografi, G.: Charactristics and significance of the amorphous state in pharmaceutical systems, J. Pharm. Sci., 86(1), 1-12, 1997.

Hancock, B. C. and Parks, M.: What is the true solubility advantage for amorphous pharmaceuticals?, Pharm. Res., 17, 397-414, 2000.

Hänel, G.: The properties of atmospheric aerosol particles as functions of the relative humidity at thermodynamic equilibrium with the surrounding moist air, Adv. Geophys., 19, 73-188, 1976.

Hansen, H. K., Rasmussen, P., Fredenslund, A., Schiller, M., and Gmebling, J.: Vapor-liquid equilibria by UNIFAC group contribution. 5. Revision and extension, Ind. Eng. Chem. Res., 30, 2352-2355, 1991.

He, X., Fowler, A., and Toner, M.: Water activity and mobility in solutions of glycerol and small molecular weight sugars: Implication for cryo- and lyopreservation, J. Appl. Phys., 100, 074702, doi:10.1063/1.2336306, 2006.

He, G., Tan, R. B. H., Kenis, P. J. A., and Zukoski, C. F.: Metastable states of small-molecule solutions, J. Phys. Chem. B, 111, 14121-14129, 2007.

Hecksher, T., Nielsen, A. I., Olsen, N. B., and Dyre, J. C.: Little evidence for dynamic divergences in ultraviscous molecular liquids, Nature Phys., 4, 737-741, 2008.

Heintzenberg, J. and Charlson, R. J., Clouds in the Perturbed Climate System - Their Relationship to Energy Balance, Atmospheric Dynamics, and Precipitation, MIT Press, Cambridge, 2009.

Hermida-Ramon, J. M., Cabaleiro-Lago, E. M., and RodriguezOtero, J.: Computational study of the dissociation of oxalic acid in water clusters, Chem. Phys., 302, 53-60, 2004.

Hilfiker, R.: Polymorphism, Wiley-VCH, Weinheim, 2006.

Hoffman, R. C., Laskin, A., and Finlayson-Pitts, B. J.: Sodium nitrate particles: physical and chemical properties during hydration, and implications for aged sea salt aerosols, J. Aerosol Sci., 35, 869-887, 2004.

Holmes, B. J. and Petrucci, G. A.: Oligomerization of levoglucosan by Fenton chemistry in proxies of biomass burning aerosols, J. Atmos. Chem., 58, 151-166, 2007.

Kanakidou, M., Seinfeld, J. H., Pandis, S. N., Barnes, I., Dentener, F. J., Facchini, M. C., Van Dingenen, R., Ervens, B., Nenes, A., Nielsen, C. J., Swietlicki, E., Putaud, J. P., Balkanski, Y., Fuzzi, S., Horth, J., Moortgat, G. K., Winterhalter, R., Myhre, C. E. L., Tsigaridis, K., Vignati, E., Stephanou, E. G., and Wilson, J.: Organic aerosol and global climate modelling: a review, Atmos. Chem. Phys., 5, 1053-1123, 2005,

http://www.atmos-chem-phys.net/5/1053/2005/.

Kanno, H. and Itoi, H.: Glass formation study of sulphuric acid, Ryusan to Kogyo, 37, 181-187, 1984.

Katrib, Y., Biskos. G., Buseck, P. R., Davidovits. P., Jayne, J. T., Mochida, M., Wise, M. E., Worsnop, D. R., and Martin, S. T.: Ozonolysis of mixed oleic-acid/stearic-acid particles: Reaction kinetics and chemical morphology, J. Phys. Chem.. A, 109, 10910-10919, 2005.

Keller, A.: Aspects of polymer gels, Farad. Discuss. Chem. Soc., 101, 1-49, 1995.

Kiss, G. and Hansson, H.-C.: Application of osmolality for the determination of water activity and the modelling of cloud forma- tion, Atmos. Chem. Phys. Discuss., 4, 7667-7689, 2004, http://www.atmos-chem-phys-discuss.net/4/7667/2004/.

Kistler, S. S.: The Relation between Heat Conductivity and Structure in Silica Aerogel, J. Phys. Chem., 39, 79-86, 1935.

Koehler, K. A., Kreidenweis, S. M., DeMott, P. J., Prenni, A. J., Carrico, C. M., Ervens, B., and Feingold, G.: Water activity and activation diameters from hygroscopicity data - Part II: Application to organic species, Atmos. Chem. Phys., 6, 795-809, 2006, http://www.atmos-chem-phys.net/6/795/2006/.

Koop, T., Luo, B., Biermann, U. M., Crutzen, P. J., and Peter, T.: Freezing of $\mathrm{HNO}_{3} / \mathrm{H}_{2} \mathrm{SO}_{4} / \mathrm{H}_{2} \mathrm{O}$ Solutions at Stratospheric Temperatures: Nucleation Statistics and Experiments, J. Phys. Chem. A, 101, 1117-1133, 1997.

Koop, T.: Homogeneous ice nucleation in water and aqueous solutions, Z. Phys. Chem., 218, 1231-1258, 2004.

Krämer, L., Pöschl, U., and Niessner, R.: Microstructural rearrangement of sodium chloride condensation aerosol particles on interaction with water vapor, J. Aerosol Sci., 31, 673-685, 2000.

Kreidenweis, S. M., Koehler, K., DeMott, P. J., Prenni, A. J., Carrico, C., and Ervens, B.: Water activity and activation diameters from hygroscopicity data - Part I: Theory and application to inorganic salts, Atmos. Chem. Phys., 5, 1357-1370, 2005, http://www.atmos-chem-phys.net/5/1357/2005/.

Krueger, B. J., Grassian, V. H., Laskin, A., and Cowin, J. P.: The transformation of solid atmospheric particles into liquid droplets through heterogeneous chemistry: Laboratory insights into the processing of calcium containing mineral dust aerosol in the troposphere, Geophys. Res. Lett., 30, 1148, doi:10.1029./2002GL016563, 2003.

Kuwata, M. and Kondo, Y.: Measurements of particle masses of inorganic salt particles for calibration of cloud condensation nuclei counters, Atmos. Chem. Phys., 9, 5921-5932, 2009, http://www.atmos-chem-phys.net/9/5921/2009/.

Langrish, T. and Wang, E. H.-L.: Crystallization of powders of spray-dried lactose, skim milk, and lactose-salt mixtures, Int. J. Food Engineering., 2, 1-15, http://www.bepress.com/ijfe/vol2/ iss4/art8, 2006.

Laurence, R. L.: Measurement of diffusion in macromolecular systems: solute diffusion in polymers systems, in: Fluid transport in nanoporous material, edited by: Conner W. C. and Fraissard, J., 41-68, Springer, Netherlands, 2006.

Lee, C. T. and Hsu, W. C.: The measurement the liquid water mass associated with collected hygroscopic particles, J. Aerosol Sci., 31, 189-197, 2000.

Liu, Y. J., Zhu, T., Zhao, D. F., and Zhang, Z. F.: Investigation of the hygroscopic properties of $\mathrm{Ca}\left(\mathrm{NO}_{3}\right)_{2}$ and internally mixed $\mathrm{Ca}\left(\mathrm{NO}_{3}\right)_{2} / \mathrm{CaCO}_{3}$ particles by micro-Raman spectrometry, Atmos. Chem. Phys., 8, 7205-7215, 2008, http://www.atmos-chem-phys.net/8/7205/2008/.

Lohmann, U. and Feichter, J.: Global indirect aerosol effects: a review, Atmos. Chem. Phys., 5, 715-737, 2005, http://www.atmos-chem-phys.net/5/715/2005/.

Lourdin, D., Coignard, L., Bizot, H., and Colonna, A.: Influence of equilibrium relative humidity and plasticizer concentration on the water content and glass transition of starch materials, Polymer, 38(21), 5401-5406, 1997.

Lubchenko, V. and Wolynes, P. G.: Theory of structural glasses and supercooled liquids, Annu. Rev. Phys. Chem., 58, 235-266, 2007. 
Mackin, L., Zanon, R., Park, J. M., Foster, K., Opalenik, H., and Demonte, M.: Quantification of low levels $(<10 \%)$ of amorphous content in micronised active batches using dynamic vapour sorption and isothermal microcalorimetry, Int. J. Pharm., 231, 227-236, 2002.

Marcolli, C., Luo, B., and Peter, T.: Mixing of the organic aerosol fractions: Liquids as the thermodynamically stable phases, J. Phys. Chem. A, 108, 2216-2224, 2004.

Martin, S. T.: Phase Transitions of Aqueous Atmospheric Particles, Chem. Rev., 100, 3403-3453, 2000.

Martin, S. T., Schlenker, J. C., Malinowski, A., Hung, H. M., and Rudich, Y.: Crystallization of atmospheric sulfatenitrate-ammonium particles, Geophys. Res. Lett., 30, 2102, doi:10.1029/2003GL017930, 2003.

McDonald, J. E.: Erroneous cloud-physics applications of Raoult Law., J. Meteorol., 10, 68-78, 1953.

McFiggans, G., Artaxo, P., Baltensperger, U., Coe, H., Facchini, M. C., Feingold, G., Fuzzi, S., Gysel, M., Laaksonen, A., Lohmann, U., Mentel, T. F., Murphy, D. M., O’Dowd, C. D., Snider, J. R., and Weingartner, E.: The effect of physical and chemical aerosol properties on warm cloud droplet activation, Atmos. Chem. Phys., 6, 2593-2649, 2006, http://www.atmos-chem-phys.net/6/2593/2006/.

McGraw, R. and Lewis, E. R.: Deliquescence and efflorescence of small particles, J. Chem. Phys., 131, 194705, doi:10.1063/1.3251056, 2009.

McInnes, L. M., Quinn, P. K., Covert, D. S., and Anderson, T. L.: Gravimetric analysis, ionic composition, and associated water mass of the marine aerosol, Atmos. Environ, 30, 869-884, 1996.

McNaught, A. D. and Wilkinson, A.: IUPAC. Compendium of Chemical Terminology, 2nd ed. Blackwell Scientific Publications, Oxford, 1997.

McNeill, V. F., Yatavelli, R. L. N., Thornton, J. A., Stipe, C. B., and Landgrebe, O.: Heterogeneous $\mathrm{OH}$ oxidation of palmitic acid in single component and internally mixed aerosol particles: vaporization and the role of particle phase, Atmos. Chem. Phys., 8, 5465-5476, 2008, http://www.atmos-chem-phys.net/8/5465/2008/.

Mifflin, A. L., Smith, M. L., and Martin, S. T.: Morphology Hypothesized to Influence Aerosol Particle Deliquescence, Phys. Chem. Chem. Phys., 11, 10095-10107, 2009.

Mikhailov, E., Vlasenko, S., Niessner, R., and Pöschl, U.: Interaction of aerosol particles composed of protein and salts with water vapor: hygroscopic growth and microstructural rearrangement, Atmos. Chem. Phys., 4, 323-350, 2004, http://www.atmos-chem-phys.net/4/323/2004/.

Mikhailov, E. F., Vlasenko, S. S., and Pöschl, U.: Filter-based differential hygroscopicity analyzer, Proceedings of the Eurpean Aerosol Conference 2008, T04A068P, Thessaloniki, http://www. eac2008.org/EAC2008-Poster_Session_I.htm\#AI, 24-29 August 2008.

Mikhailov, E., Vlasenko, S., Martin, S. T., and Pöschl, U.: Amorphous and crystalline aerosol particles interacting with water vapor: mixtures of ammonium sulfate, oxalic acid and levoglucosan, Atmos. Chem. Phys. Discuss., to be submitted, 2010.

Ming, Y. and Russell, L. M.: Thermodynamic equilibrium of organic-electrolyte mixtures in aerosol particles, American Institute of Chemical Engineers Journal (AIChE. J.), 48, 1331-1348, 2002.
Mochida, M. and Kawamura, K.: Hygroscopic properties of levoglucosan and related organic compounds characteristic to biomass burning aerosol particles, J. Geophys. Res., 109, D21202, doi:10.1029/2004JD004962, 2004.

Mod, R. R., Magne, F. C., and Skau, E. L.: Preparation and properties of oxalic acid salts of $\mathrm{C}_{18}$ saturated and unsaturated fatty amides, J. Am. Oil Chem. Soc., 50(4), 126-127, 1973

Moore, R. H. and Raymond, T. M.: HTDMA analysis of multicomponent dicarboxylic acid aerosols with comparison to UNIFAC and ZSR, J. Geophys. Res., 113, D04206, doi:10.1029/2007JD008669, 2008.

Murray, B. J.: Inhibition of ice crystallisation in highly viscous aqueous organic acid droplets, Atmos. Chem. Phys., 8, 54235433, 2008,

http://www.atmos-chem-phys.net/8/5423/2008/.

Oksanen, C. A. and Zografi, G.: The relationship between the glass transition temperature and water vapor absorption by poly(vinylpyrrolidine), Pharm. Res., 7(6), 654-657, 1990.

Onasch, T. B., Siefert, R. L., Brooks, S. D., Prenni, A. J., Murray, B., Wilson, M. A., and Tolbert, M. A.: Infrared spectroscopic study of the deliquescence and efflorescence of ammonium sulfate aerosol as a function of temperature, J. Geophys. Res., 104(D17), 21317-21326, 1999.

Onasch, T. B., McGraw, R., and Imre, D.: TemperatureDependent Heterogeneous Efflorescence of Mixed Ammonium Sulfate/Calcium Carbonate Particles, J. Phys. Chem. A, 104, 10797-10806, 2000.

Parker, R. and Ring, S. G.: Diffusion in maltose-water mixtures at temperatures close to the glass transition, Carbohydrate Res., 273, 147-155, 1995.

Parson, M. N.: Phase transitions of pure and mixed organic and inorganic particles, $\mathrm{PhD}$ thesis, The University of British Columbia (http://resolve.library.ubc.ca/cgi-bin/ catsearch?bid=3718908), 2006.

Parsons, T. P., Knopf, D. A., and Bertram, A. K.: Deliquescence and crystallization of ammonium sulfate particles internally mixed with water-soluble organic compounds, J. Phys. Chem. A., 108, 11600-11608, 2004.

Peng, C. and Chan, C. K.: The water cycles of water-soluble organic salts of atmospheric importance, Atmos. Environ., 35, 11831192, 2001.

Peng, C., Chain, M. N., and Chan, C. K.: The hygroscopic properties of dicarboxylic and multifunctional acids: measurements and UNIFAC predictions, Environ. Sci. Technol., 35, 4495-4501, 2001.

Petters, M. D., Kreidenweis, S. M., Snider, J. R., Koehler, K. A., Wang, Q., Prenni, A. J., and Demott, P. J.: Cloud droplet activation of polymerized organic aerosol, Tellus, 58B, 196-205, 2006.

Petters, M. D. and Kreidenweis, S. M.: A single parameter representation of hygroscopic growth and cloud condensation nucleus activity, Atmos. Chem. Phys., 7, 1961-1971, 2007, http://www.atmos-chem-phys.net/7/1961/2007/.

Pfrang, C., Shiraiwa, M., and Pöschl, U.: Coupling aerosol surface and bulk chemistry with a kinetic double layer model (K2-SUB): oxidation of oleic acid by ozone, Atmos. Chem. Phys. Discuss., 9, 26969-27019, 2009,

http://www.atmos-chem-phys-discuss.net/9/26969/2009/.

Pitzer, K. S.: Thermodynamics of electrolytes. I. Theoretical basis 
and general equations. J. Phys. Chem., 77, 268-277, 1973.

Pitzer, K. S. and Mayorga, G.: Thermodynamics of electrolytes. II. Activity and osmotic coefficients for strong electrolytes with one or both ions univalent, J. Phys. Chem., 77, 2300-2308, 1973.

Pitzer, K. S., Activity Coefficients in Electrolyte Solutions, 2nd ed., CRC Press, Boca Raton, 1991.

Pöschl, U.: Atmospheric aerosols: composition, transformation, climate and health effects, Angewandte Chemie International Edition, 44, 7520-7540, 2005.

Pöschl, U., Rudich, Y., and Ammann, M.: Kinetic model framework for aerosol and cloud surface chemistry and gas-particle interactions - Part 1: General equations, parameters, and terminology, Atmos. Chem. Phys., 7, 5989-6023, 2007, http://www.atmos-chem-phys.net/7/5989/2007/.

Pöschl, U., Rose, D., and Andreae, M. O.: Climatologies of CloudRelated Aerosols - Part 2: Particle Hygroscopicity and Cloud Condensation Nucleus Activity, in: Clouds in the Perturbed Climate System - Their Relationship to Energy Balance, Atmospheric Dynamics, and Precipitation, edited by: Heintzenberg, J. and Charlson, R. J., MIT Press, Cambridge, 58-72, 2009.

Pradeep Kumar, P., Broekhuizen, K., and Abbatt, J. P. D.: Organic acids as cloud condensation nuclei: Laboratory studies of highly soluble and insoluble species, Atmos. Chem. Phys., 3, 509-520, 2003,

http://www.atmos-chem-phys.net/3/509/2003/.

Prenni, A. J., DeMott, P. J., Kreindenweis, S. M., Sherman, D. E., Russel, L. M., and Ming, Y.: The effects of low molecular weight dicarboxylic acids on cloud formation, J. Phys. Chem. A, 105, 11240-11248, 2001.

Prenni, A. J., DeMott, P. J., and Kreidenweis, S. M.: Water uptake of internally mixed particles containing ammonium sulfate and dicarbixylic acids, Atmos. Environ., 37, 4243-4251, 2003.

Prise, R. and Young, P. M.: Visualization of the crystallization of lactose from the amorphous state, J. Pharm. Sci., 93, 155-164, 2003.

Pruppacher, H. R. and Klett, J. D.: Microphysics of clouds and precipitation. Dordrecht, Kluwer Academic Publishers, 2000.

Raatikainen, T. and Laaksonen, A.: Application of several activity coefficient models to water-organic-electrolyte aerosols of atmospheric interest, Atmos. Chem. Phys., 5, 2475-2495, 2005, http://www.atmos-chem-phys.net/5/2475/2005/.

Ray, S. S., Rajamohanan, P. R., Badiger, M. V., Devotta, I., Ganapathy, S., and Mashelkar, R. A.: Self-diffusion of water in thermoreversible gels near volume transition: model development and PFG NMR investigation, Chem. Eng. Sci., 53(5), 869-877, 1998.

Rissler, J., Vestin, A., Swietlicki, E., Fisch, G., Zhou, J., Artaxo, P., and Andreae, M. O.: Size distribution and hygroscopic properties of aerosol particles from dry-season biomass burning in Amazonia, Atmos. Chem. Phys., 6, 471-491, 2006, http://www.atmos-chem-phys.net/6/471/2006/.

Ristovski, Z. D., Ross, A., and Modini, R. L.: Nanosize effect of the efflorescence of ammonium sulfate particles, in: Proceedings European Aerosol Conference, Thessaloniki, Greece (http://eprints.qut.edu.au/), 2008.

Roberts, C. J. and Debenedetti, P. G.: Engineering pharmaceutical stability with amorphous solids, American Institute of Chemical Engineers Journal (AIChE. J.), 48, 1140-1144, 2002.

Robinson, R. A. and Stokes, R. H.: Electrolyte solutions, 2nd ed.,
Butterworths, London, 1970.

Romakkaniemi, S., Hämeri, K., Väkevä, M., and Laaksonen, A.: Adsorption of water on 8-15 nm NaCl and (NH4)2SO4 aerosols measured using an ultrafine tandem differential mobility Analyzer, J. Phys. Chem. A., 105, 8183-8188, 2001.

Roos, Y. and Karel, M.: Plasticizing effect of water on thermal behavior and crystallization of amorphous food models, J. Food Sci., 56(1), 38-43, 1991.

Roos, Y. and Karel, M.: Crystallization of Amorphous Lactose, J. Food Sci., 57, 775-777, 1992.

Roos, Y. H., Leslie, R. B., and Lillford, P. J.: Water Management in the Design and Distribution of Quality Foods, CRC Press, 1999.

Rose, D., Gunthe, S. S., Mikhailov, E., Frank, G. P., Dusek, U., Andreae, M. O., and Pöschl, U.: Calibration and measurement uncertainties of a continuous-flow cloud condensation nuclei counter (DMT-CCNC): CCN activation of ammonium sulfate and sodium chloride aerosol particles in theory and experiment, Atmos. Chem. Phys., 8, 1153-1179, 2008, http://www.atmos-chem-phys.net/8/1153/2008/.

Rosenfeld, D., Lohmann, U., Raga, G. B., O’Dowd, C. D., Kulmala, M., Fuzzi, S., Reissell, A., and Andreae, M. O.: Flood or drought: How do aerosols affect precipitation?, Science, 321(5894), 1309-1313, 2008.

Rosenørn, T., Kiss G., and Bilde, M.: Cloud droplet activation of saccharides and levoglucosan particles, Atmos. Environ., 40, 1794-1802, 2006.

Rosenoern, T., Schlenker, J. C., and Martin, S. T.: Hygroscopic Growth of Multicomponent Aerosol Particles Influenced by Several Cycles of relative Humidity, J. Phys. Chem. A, 112, 23782385, 2008.

Ruehl, C. R., Chuang, P. Y., and Nenes, A.: How quickly do cloud droplets form on atmospheric particles?, Atmos. Chem. Phys., 8, 1043-1055, 2008, http://www.atmos-chem-phys.net/8/1043/2008/.

Russell, L. M. and Ming, Y.: Deliquescence of small particles, J. Chem. Phys., 116, 311-321, 2002.

Sangeetha, N. M. and Maitra, U.: Supramolecular gel: functions and uses, Chem. Soc. Rev., 34, 821-836, 2005.

Saxena, P. and Hildemann, L. M.: Water soluble organics in atmospheric particles: A critical review of the literature and application of thermodynamics to identify candidate compounds, J. Atmos. Chem., 24, 57-109, 1996.

Schlenker, J. C., Malinowski, A., Martin, S. T., Hung, H. M., and Rudich, Y.: Crystals Formed at $293 \mathrm{~K}$ by Aqueous SulfateNitrate-Ammonium-Proton Aerosol Particles, J. Phys. Chem. A, 108, 9375-9383, 2004.

Schlenker, J. C. and Martin, S. T.: Crystallization Pathways of Sulfate-Nitrate-Ammonium Aerosol Particles, J. Phys. Chem. A, 109, 9980-9985, 2005.

Seinfeld, J. H. and Pandis, S. N.: Atmospheric chemistry and physics, J. Wiley \& Sons, New York, 2006.

Shiraiwa, M., Pfrang, C., and Pöschl, U.: Kinetic multi-layer model of aerosol surface and bulk chemistry (KM-SUB): the influence of interfacial transport and bulk diffusion on the oxidation of oleic acid by ozone, Atmos. Chem. Phys. Discuss., to be submitted, 2009.

Sjogren, S., Gysel, M., Weingartner, E., Baltensperger, U., Cubison, M. J., Coe, H., Zardini, A. A., Marcolli, C., Krieger, U. R., and Peter, T.: Hygroscopic growth and water uptake kinetics of two- 
phase aerosol particles consisting of ammonium sulphate, adipic and humic acid mixtures, J. Aerosol Sci., 38, 157-171, 2007.

Slade, L. and Levine, H.: A food polymer science approach to structure-property relationships in aqueous food systems: Nonequilibrium behavior of carbohydrate-water systems, in: Water relationships in food, edited by: Levine, H. and Slade, L., Plenum Press, NY, 1991.

Smith, G. D., Woods, E., Baer, T., and Miller, R. E.: Aerosol uptake described by numerical solution of the diffusion - reaction equations in the particle, J. Phys. Chem. A, 107, 9582-9587, 2003.

Sperling, L. H.: Introduction to physical polymer science, Wiley, New York, 2006.

Svenningsson, B., Rissler, J., Swietlicki, E., Mircea, M., Bilde, M., Facchini, M. C., Decesari, S., Fuzzi, S., Zhou, J., Mønster, J., and Rosenørn, T.: Hygroscopic growth and critical supersaturations for mixed aerosol particles of inorganic and organic compounds of atmospheric relevance, Atmos. Chem. Phys., 6, 1937-1952, 2006 , http://www.atmos-chem-phys.net/6/1937/2006/.

Tanaka, T.: Collapse of gels and the critical endpoint, Phys. Rev. Lett.. 40(12), 820-823, 1978.

Tang, I. N. and Willeke, K. (Eds.): In generation of aerosols and facilities for exposure experiments. Ann Arbor: Ann Arbor Science Publishers Inc., 1980.

Tang, I. N. and Munkelwitz, H. R.: Composition and temperature dependence of the deliquescence properties of hygroscopic aerosol, Atmos. Environ., 27, 467-473, 1993.

Tang, I. N. and Munkelwitz, H. R.: Water activities, densities, and refractive indices of aqueous sulfates and sodium nitrate droplets of atmospheric importance, J. Gephys. Res., 99(D9), 1880118808, 1994.

Tang, I. N. and Fung, K. H.: Hydration and Raman scattering studies of levitated microparticles: $\mathrm{Ba}\left(\mathrm{NO}_{3}\right)_{2}, \mathrm{Sr}\left(\mathrm{NO}_{3}\right)_{2}$, and $\mathrm{Ca}\left(\mathrm{NO}_{3}\right)_{2}$, J. Chem. Phys., 106, 1653-1660, 1997.

Tang, I. N., Tridico, A. C., and Fung, K. H.: Thermodynamic and optical properties of sea salt aerosols, J. Geophys. Res., 102, 23269-23275, 1997.

Taraniuk, I., Graber, E. R., Kostinski, A., and Rudich, Y.: Surfactant properties of atmospheric and model humiclike substances (HULIS), Geophys. Res. Lett., 34, L16807, doi:10.1029/2007GLo29576, 2007.

Tomikawa, K. and Kanno, H.: Raman Study of Sulfuric Acid at Low Temperatures, J. Phys. Chem. A, 102, 6082-6088, 1998.

Varga, Z., Kiss, G., and Hansson, H.-C.: Modelling the cloud condensation nucleus activity of organic acids on the basis of surface tension and osmolality measurements, Atmos. Chem. Phys., 7, 4601-4611, 2007,

http://www.atmos-chem-phys.net/7/4601/2007/.

Wang, S. C. and Flagan, R. C.: Scanning electrical mobility spectrometer, Aerosol Sci. Technol., 13, 230-240, 1990.

Wang, S. and Langrish, T.: Measurements of the crystallization rates of amorphous sucrose and lactose powders from spray drying, Int. J. Food Engeneering, 3(4), 1-17, 2007.

Wang, J., Hoffmann, M. A., Park, R., Jacob, D. J., and Martin, S. T.: Global distribution of solid and aqueous sulfate aerosols: effect of the hysteresis of particle phase transitions, J. Geophys. Res., 113, D11207, doi:10.1029/2007JD009367, 2008a.

Wang, J., Jacob, D. J., and Martin, S. T.: Sensitivity of sulfate direct climate forcing to the hysteresis of particle phase transitions,
J. Geophys. Res., 113, D11206, doi:10.1029/2007JD009368, 2008 b.

Weingartner, E., Burtscher, H., and Baltenspenger, U.: Hygroscopic properties of carbon and diesel soot particles, Atmos. Environ., 31, 2311-2327, 1997.

Weingartner, E., Gysel, M., and Baltensperger, U., Hygroscopicity of aerosol particles at low temperatures. 1.New low-temperature H-TDMA instrument: setup and first applications, Environ. Sci. Technol., 6, 55-62, 2002.

Weis, D. D. and Ewing, G. E.: Water content and morpology of sodium chloride aerosol particles, J. Geophys. Res., 104(17), 21275-21285, 1999.

Wenger, M. and Bernstein, G.: Cocrystal design gone awry? A new dimorphic hydrate of oxalic acid, Molec. Pharm., 4(3), 355-359, 2007.

Wex, H., Hennig, T., Salma, I., Ocskay, R., Kiselev, A., Henning, S., Massling, A., Wiedensohler, A., and Stratmann, F.: Hygroscopic growth and measured and modeled critical super-saturations of an atmospheric HULIS sample, Geophys. Res. Lett., 34, L02818, doi:10.1029/2006GL028260, 2007.

Wexler, A. and Brombacher, W. G.: Methods of measuring humidity and testing hygrometers, Nat. Bur. Stand, (US), Circular 512, 1951.

White, G. W. and Cakebread, S. H.: The glassy state in certain sugar containing food products, J. Food Technol., 1(1), 73-82, 1966.

Wise, M. E., Surratt, J. D., Curtis, D. B., Shilling, J. E., and Tolbert, M. A.: Hygroscopic growth of ammonium sulfate/dicarboxylic acids, J. Geophys. Res., 108(D20), 4638, doi:10.1029/2003JD003775, 2003.

Wise, M. E., Biskos, G., Martin S. T., Russell, L. M., and Buseck, P. R.: Phase transitions of single salt particles studied using a transmission electron microscope with environmental cell, Aerosol Sci. Technol., 39, 849-856, 2005.

Zardini, A. A., Sjogren, S., Marcolli, C., Krieger, U. K., Gysel, M., Weingartner, E., Baltensperger, U., and Peter, T.: A combined particle trap/HTDMA hygroscopicity study of mixed inorganic/organic aerosol particles, Atmos. Chem. Phys., 8, 55895601, 2008,

http://www.atmos-chem-phys.net/8/5589/2008/.

Zhang, J. and Zografi, G.: The relation between "BET"- and "Free Volume"-derived parameters for water vapor absorption into amorphous solids, Pharm. Sci., 89(8), 1063-1072, 2000.

Zhang, J. and Zografi, G.: Water vapor absorption into amorphous sucrose-poly(vinyl pyrrolidone) and trehalose- poly(vinyl pyrrolidone) mixtures, Pharm. Sci., 90(9), 1375-1385, 2001.

Zobrist, B., Marcolli, C., Koop, T., Luo, B. P., Murphy, D. M., Lohmann, U., Zardini, A. A., Krieger, U. K., Corti, T., Cziczo, D. J., Fueglistaler, S., Hudson, P. K., Thomson, D. S., and Peter, T.: Oxalic acid as a heterogeneous ice nucleus in the upper troposphere and its indirect aerosol effect, Atmos. Chem. Phys., 6, 3115-3129, 2006, http://www.atmos-chem-phys.net/6/3115/2006/.

Zobrist, B., Marcolli, C., Pedernera, D. A., and Koop, T.: Do atmospheric aerosols form glasses?, Atmos. Chem. Phys., 8, 52215244, 2008,

http://www.atmos-chem-phys.net/8/5221/2008/. 